Cleiton Carvalho Silva ${ }^{1 *}$, Emerson Mendonça Miná ${ }^{1}$, Elineudo P. Moura ${ }^{1}$, Victor Hugo C. de Nickel-based Alloy 625 Weld Metal

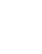

6

7

${ }^{1 *}$ Universidade Federal do Ceará, Departamento de Engenharia Metalúrgica e de Materiais, Albuquerque $^{2}$,

\author{
João Manuel R. S. Tavares ${ }^{3}$
}

(2) Fortaleza, Ceará, Brasil.

Email: cleiton@metalmat.ufc.br

${ }^{2}$ Programa de Pós-Graduação em Informática Aplicada, Universidade de Fortaleza, Fortaleza, 2
${ }^{3}$ Instituto de Ciência e Inovação em Engenharia Mecânica e Engenharia Industrial, Departamento de Engenharia Mecânica, Faculdade de Engenharia, Universidade do Porto, 15

\section{*Corresponding author:}

Prof. Dr. Cleiton Carvalho Silva

Universidade Federal do Ceará

Campus do Pici, s/n

60455-760, Fortaleza, CE, Brazil

email: cleiton@metalmat.ufc.br

Phone: +55 85 33669078, Fax: +55 8533669358 
The aim of this work was to evaluate the different phases formed during solidification and after thermal aging of the as-welded 625 nickel-based alloy, as well as the influence of microstructural changes on the mechanical properties. The experiments addressed aging temperatures of 650 and $950{ }^{\circ} \mathrm{C}$ for 10,100 and $200 \mathrm{~h}$. The samples were analyzed by electron microscopy, microanalysis and X-ray diffraction in order to identify the secondary phases. Mechanical tests such as hardness, microhardness and Charpy-V impact test were performed. Nondestructive ultrasonic inspection was also conducted to correlate the signals with mechanical and microstructural properties. The results show that the alloy 625 when aged at $650{ }^{\circ} \mathrm{C}$ experienced microstructural changes that were responsible by the dissolution of Laves phase formed during the solidification and the appearance of fine carbides along the solidification grain boundaries. When aged at $950^{\circ} \mathrm{C}$, the Laves phase was continuously dissolved and the excess $\mathrm{Nb}$ caused the precipitation of $\delta$-phase $\left(\mathrm{Ni}_{3} \mathrm{Nb}\right)$, which was intensified at 10 hours of aging, with subsequent dissolution for longer periods such as $200 \mathrm{~h}$. Even when subjected to significant microstructural changes, the mechanical properties, especially toughness, were not sensitive to the dissolution and/or precipitation of the secondary phases.

Keywords: Electron microscopy; microanalysis; nickel based superalloys; welding; aging; phase transformation. 
One of the most interesting characteristics of the nickel-based superalloys is its high

corrosion resistance to an aqueous chloride medium. ${ }^{[1]}$ Furthermore, these alloys exhibit extraordinary resistance to a wide range of organic and mineral acids due to their excellent corrosion resistance properties, mainly, at high temperatures, and, therefore, are commonly found in the marine, aerospace, chemical and oil and gas industries. ${ }^{[2-5]}$

The alloy Inconel ${ }^{\circledR} 625$ stands out as one of the leading commercial $\mathrm{Ni}-\mathrm{Cr}-\mathrm{Mo}-\mathrm{Nb}$ alloy grades. ${ }^{[2]}$ The development of this alloy in 1964 was designed to meet the market of alloys for high temperature service. However, with the discovery of its exceptional corrosion resistance, it also came to assume a prominent position in other applications, where corrosion resistance is essential. ${ }^{[1]}$

In addition, the 625 nickel-based superalloy exhibits an outstanding combination of mechanical properties and resistance to pitting, crevice and intergranular corrosion due to the solid-solution strengthening effect of chromium, molybdenum and niobium in its nickel matrix, making precipitation-hardening treatments unnecessary. ${ }^{[1]}$ However, elements such as $\mathrm{Cr}, \mathrm{Ti}, \mathrm{Nb}$ and $\mathrm{Mo}$ are also strong precipitate formers. According to many studies, the presence of these elements influences the formation of the metastable $\gamma$ ', phase $\left(\mathrm{Ni}_{3} \mathrm{Nb}\right)$, primary $\mathrm{MC}$ carbides where $\mathrm{M}$ denotes $\mathrm{Nb}$ and $\mathrm{Ti}$. There are other types of carbides such as $\mathrm{M}_{6} \mathrm{C}$, where $\mathrm{M}$ denotes $\mathrm{Si}, \mathrm{Ni}$ and $\mathrm{Cr}$, and also $\mathrm{M}_{23} \mathrm{C}_{6}$ where $\mathrm{M}$ denotes mainly $\mathrm{Cr}$ and/or Mo. ${ }^{[6-9]}$

Nevertheless, the high cost of nickel based superalloys makes them unviable for massive applications in some situations. In order to overcome this obstacle and make the use of Ni-based alloys attractive to equipment manufacturers, providing high service performance 
using this particular class of material, overlays with Ni-based alloys on $\mathrm{C}-\mathrm{Mn}$ low alloy and stainless steels have become an option in recent years. ${ }^{[10-12]}$

During welding with the Inconel 625 alloy as filler metal, there is an intense microsegregation of elements, such as niobium and molybdenum, within the interdendritic regions causing the supersaturation of the liquid metal in its final stage of solidification. ${ }^{[10]}$ This important phenomenon results in the precipitation of Nb-rich Laves phase and $\mathrm{MC}$ primary carbides of type $\mathrm{NbC} .^{[13,14]}$ The segregation and precipitation of secondary phases like Nb-rich Laves phase, which has a low melting point, can cause an increase in the temperature solidification range, making the alloy susceptible to solidification cracking. ${ }^{[15]}$ However, an adequate selection of the welding conditions can minimize the formation of the $\mathrm{Nb}$-rich Laves phases, thus reducing susceptible to solidification cracking.

Although several studies have reported the presence of Laves phase in alloys containing $\mathrm{Nb}$ and Mo, such as 625 and 718, there are few studies that address the effect of the presence of this phase on the mechanical properties, especially impact resistance. ${ }^{[16,17]}$ However, there are several studies on the effect of high temperature exposure on secondary phase precipitation and the effect of such precipitations on the mechanical properties has been investigated. ${ }^{[18-21]}$ Nonetheless, on many occasions, these alloys are evaluated from wrought or annealing bars, which are very different when compared with the as-welded condition.

As a general rule, the microstructural changes in these alloys, and consequently any changes to their mechanical properties are extensively investigated using metallographic evaluations supported by microscopic techniques. These investigations can be difficult, especially in field applications where access to the affected areas may be restricted. ${ }^{[22]}$ Recently, the potential of nondestructive testing methods, based on ultrasonic signals, to evaluate microstructural characterization and mechanical properties in ferrous alloys has been systematically evaluated. These authors analyzed ultrasonic results of velocity and attenuation 
and compared them against the ones obtained by destructive testing such as the Charpy impact, X-ray diffraction and hardness tests. ${ }^{[23-25]}$ The findings showed that ultrasonic testing is a promising technique to follow-up material phase transformations. This approach was used with the 625 alloy to detect microstructural changes based on ultrasonic attenuation and velocity measurements by Albuquerque et al., ${ }^{[26]}$ confirming again its main advantages.

Besides such approaches, further research work has been developed to obtain faster and more accurate methods for microstructural characterization. One such example is the ultrasonic signal classification method using the recent and powerful Optimum Path Forest classifier $^{[27]}$ and the traditional Support Vector Machines, with Bayesian and Artificial Neural Network algorithms ${ }^{[28]}$. Results with more than $90 \%$ of accuracy were achieved in $1.40 \pm 0.57$ milliseconds with material samples aged at $650^{\circ} \mathrm{C}$ and aging times of $0,10,100,200$ hours. However, the performance of these techniques is lower for the samples aged at temperatures of $950^{\circ} \mathrm{C}$ for the same period of times, with an accuracy of approximately $73 \%$ in $0.77 \pm 0.02$ milliseconds.

Recently Silva et al. ${ }^{[29]}$ evaluated the performance of magnetic permeability as a nondestructive low-cost and alternative tool for the microstructural characterization of a duplex stainless steel, and was able to confirm that the magnetic permeability can be used to successfully track the formation of the alpha line phase from the alpha phase on a duplex stainless steel.

Thus, the aim of this study was to evaluate the microstructural evolution during aging heat treatments performed on welds of 625 nickel-based alloys. Extensive microstructural characterization was carried out by scanning electron microscopy and energy dispersive spectroscopy, as well as by non-destructive testing. In addition, the influence of the 
microstructural changes on the mechanical properties such as impact strength and hardness were also evaluated.

\section{$2 \quad$ Experimental procedures}

Inconel 625 alloy coatings deposited on an ASTM A36 steel base were used in the experiments. The chemical compositions of these materials are shown in Table 1. A $4.0 \mathrm{~mm}$ diameter tungsten electrode doped with thorium was used, and pure argon (99.99\%) was chosen as the shielding gas.

An electronic multi-process power source connected to the data acquisition system was used during the welding to monitor the current and tension applied. The manipulation of the torch was carried out using an industrial robot system, Figure 1a. An automatic cold wire feed system for the gas tungsten arc welding (GTAW) was used to supply the filler metal. A positioning unit was used to guide the wire into the arc so that adjustments to the configuration parameters and geometry of the wire feed could be made, Figure 1b.
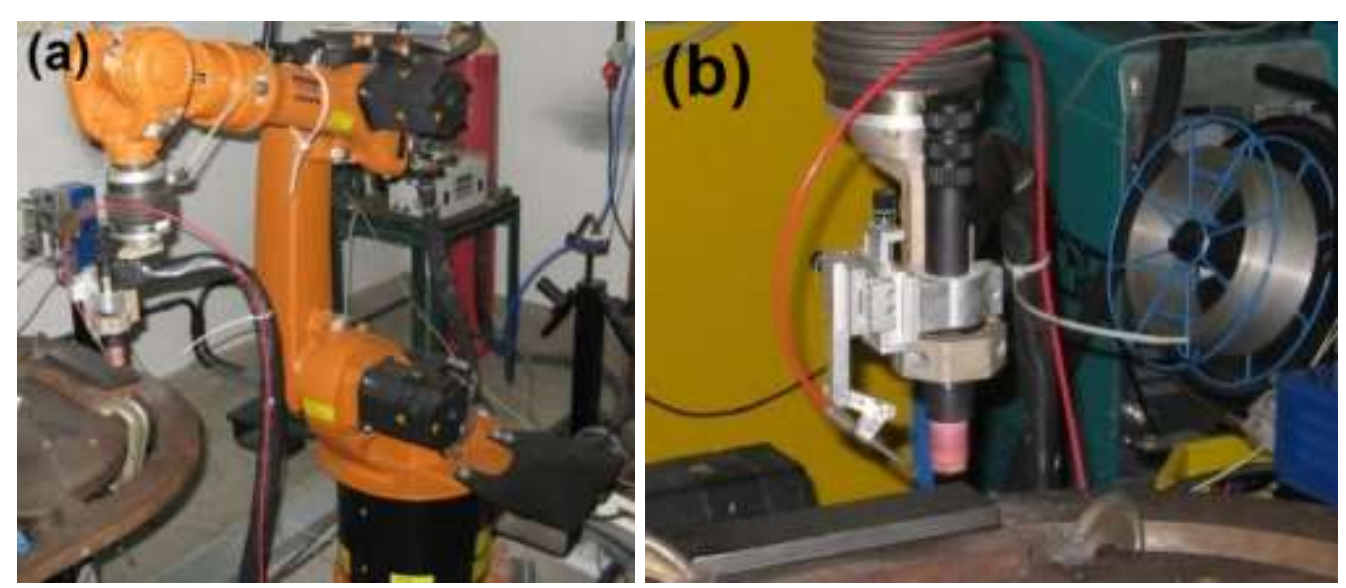

Figure 1. Experimental setup used in the welding process: (a) robotic system, (b) GTAW guide wire feed and torch. 
The coating was welded onto an ASTM A36 steel base plate, resulting in a coating of 350x60x14 $\mathrm{mm}^{3}$. The other welding parameters were: $285 \mathrm{~A}$ of welding current (DCEN), arc voltage of $20 \mathrm{~V}$, travel speed equal to $21 \mathrm{~cm} / \mathrm{min}$, welding heat input of $16 \mathrm{~kJ} / \mathrm{cm}$, wire feed speed equal to $6.0 \mathrm{~m} / \mathrm{min}$, arc length of $10 \mathrm{~mm}, 15 \mathrm{l} / \mathrm{min}$ of gas flow and arc oscillation describing a double- 8 trajectory. Other minor settings included the wire feed direction ahead of the arc weld, wire tip to pool surface kept at a distance of $3 \mathrm{~mm}$, wire feeding angle maintained constant and equal to $50^{\circ}$, and electrode tip angle fixed at $50^{\circ}$.

To guarantee a good overlaying due to multiple pass deposited side by side, a distance equal to $2 / 3$ of the initial weld bead width was established as an ideal step. Other arc oscillating parameters adopted were: oscillation amplitude of $8 \mathrm{~mm}$ and wave length equal to $1.2 \mathrm{~mm}$. To produce a $10 \mathrm{~mm}$ thick coating on the substrate, seven layers with eight passes were deposited under identical welding conditions.

After the welding, the coating was detached from the substrate by conventional machining, as the material of interest was only the Inconel 625 alloy. Then, the coating was divided into seven plates, three plates were submitted to aging heat treatments at $650{ }^{\circ} \mathrm{C}$ for times of 10,100 and $200 \mathrm{~h}$, another three plates were submitted to aging heat treatments at $950{ }^{\circ} \mathrm{C}$ for times of 10,100 and $200 \mathrm{~h}$, and the remaining plate was kept in the as-welded state $(0 \mathrm{~h})$. The aged plates were water cooled with moderate agitation at room temperature.

Afterwards, the seven samples were cut and subjected to metallographic preparation that included grinding using silicon paper with several granulometries, followed by mechanical polishing using diamond paste with $3 \mu \mathrm{m}$ and $1 \mu \mathrm{m}$. Electrolytic etching using aqueous solution with $10 \%$ chromic acid and a tension of $2 \mathrm{~V}$ for 15 seconds was used to reveal the nickel-alloy microstructure. Microstructural analysis of all samples was performed by a scanning electron microscope (SEM) Philips XL30 (Oxford Instruments, England), and a 
171 study of the chemical composition of the secondary phases was carried out through energy

172 dispersive spectroscopy of X-rays (EDS).

$\mathrm{X}$-ray diffraction analysis (XRD) was also used to characterize the secondary phases

174 precipitated during solidification and due to solid state transformation during aging treatment. Since the quantities and dimension of the particles are quite small, an alternative evaluation was carried out according the ASTM 936 standard, which covers the procedures for the isolation of TCP (topologically close-packed) in nickel-based alloys. The Panalytical XPert Pro MPD X-ray spectrometer was used in the present investigation. For post-processing and peak matching the X'Pert HighScore software and its database were used. The scan details applied in these analyses were: 2 Theta range from 10 to $120^{\circ}$ with a step size of approximately $0.02^{\circ}$ and counting at each step for 4 seconds; $\mathrm{Cu}$ Ka radiation was used and the X-ray generator power was set at $40 \mathrm{kV}$ and $40 \mathrm{~mA}$.

To evaluate the influence of TCP precipitation on mechanical performance of weld metals, the impact Charpy test was performed according to ASTM E23 using specimens with dimensions of $55 \times 10 \times 10 \mathrm{~mm} 3$ with a $45^{\circ} \mathrm{V}$-notch, a notch radius of $0.25 \mathrm{~mm}$ and a notch depth of $2 \mathrm{~mm}$, Figure 2. The impact tests for all conditions were performed at room temperature. The micro-hardness test was performed on as-welded and aged samples using a Vickers hardness tester Shimadzu (HVMG) using a $200 \mathrm{~g}$ load and a dwell time of 15 second. 


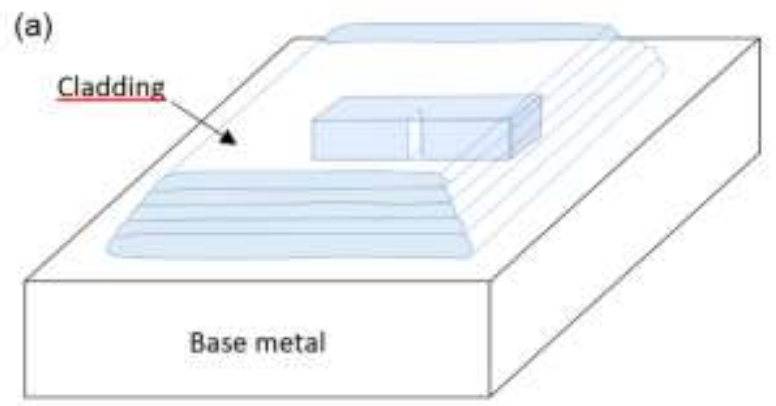

(b)
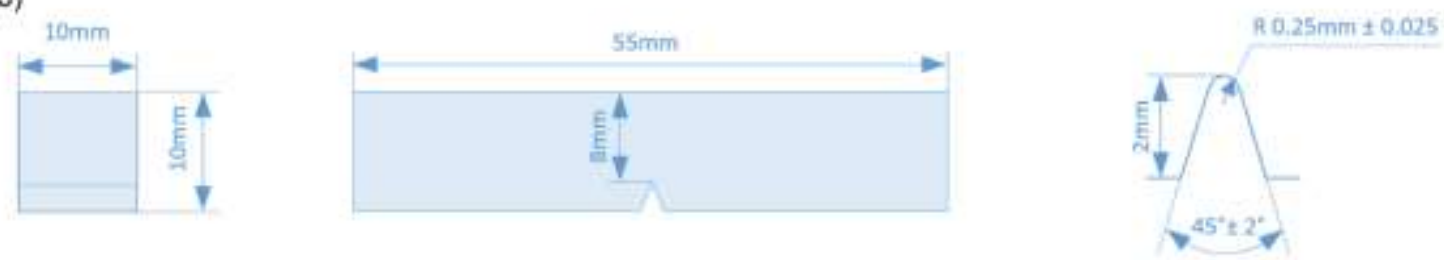

190

191 Figure 2. Schematic diagram showing: (a) the location and orientation of the Charpy-V specimens taken from the weld cladding; (b) dimensions of the Charpy impact specimens.

For the physical property assessment via ultrasonic nondestructive testing (aka ultrasonic NDT), the pulse echo technique was used to obtain average ultrasonic velocity and attenuation measurements considering twenty signals acquired with 10,000 points, sampling rate of $1 \mathrm{Gs} / \mathrm{s}$, and ultrasonic transducers of 4 and $5 \mathrm{MHz}$.

For each sample, twenty signals with two adjacent echoes per signal were acquired for the velocity measurements. Next, the time between the first two echoes was measured through an echo overlapping algorithm. ${ }^{[30]}$ With the wave propagation time and the thicknesses of the samples, obtained by using a micrometer at the same signal acquisition points, it was possible to determine the average velocity of wave propagation through the equation: ${ }^{[31]}$

$v=\frac{2 X}{\tau_{0}}$,

in which $X$ is the thickness of the sample [m] and $\tau_{0}$ is the time of the wave course [s] until the two adjacent echoes $\left(B_{1}\right.$ and $\left.B_{2}\right)$ overlap each other, and its value is determined using: ${ }^{[31]}$ $\left|\int_{-\infty}^{\infty} B_{1}(t) \cdot B_{2}(t-\tau) d t\right|$. 
Although, the time measurement can be obtained directly from the oscilloscope, as previously mentioned, the echo overlapping method was used for it provides greater sensitivity and maximum accuracy. ${ }^{[30]}$

The ultrasonic attenuation coefficient, $\alpha,[\mathrm{dB} / \mathrm{mm}]$, was calculated using: ${ }^{[31]}$ $\alpha=\frac{20}{2 x} \log \frac{A_{0}}{A_{1}}$,

in which $x$ is the thickness of the sample [mm], $A_{0}$ is the amplitude of the first echo [dB], and $A_{1}$ is the amplitude of the second echo [dB]; more details can be found in Normando et al. $^{[30]}$

\section{$3 \quad$ Results}

\subsection{Microstructural characterization}

The microstructures of the coatings deposited with Inconel 625 alloy by the GTAW cold wire feed process were analyzed by SEM, and the results revealed a Ni-fcc matrix that solidified in a cellular/dendritic mode. During the solidification process, an intense Mo and $\mathrm{Nb}$ microsegregation occurred. Due to this particular phenomenon, extensive amounts of secondary phases were formed at the intercellular or interdendritic regions. An example of the representative microstructure of the as-welded alloy condition $(0 \mathrm{~h})$ can be seen in Figure 3a, which also shows in detail the secondary phase formed in the interdendritic region, confirming the large amount of these secondary phases. Figure $3 \mathrm{~b}$ shows that there are two different types of particles. The first is a bright phase with a shapeless or eutectic morphology, which is due to this phase taking on the shape of the remaining liquid volume during solidification. The second is a faceted or cubic morphology, which is indicated in the Figure. 

enrichment of Mo and $\mathrm{Nb}$, as well as the presence of $\mathrm{Si}$ at higher concentrations (Figure 3c).

With reference to the other elements, such as $\mathrm{Ni}, \mathrm{Fe}$ and $\mathrm{Cr}$, a lower concentration in the

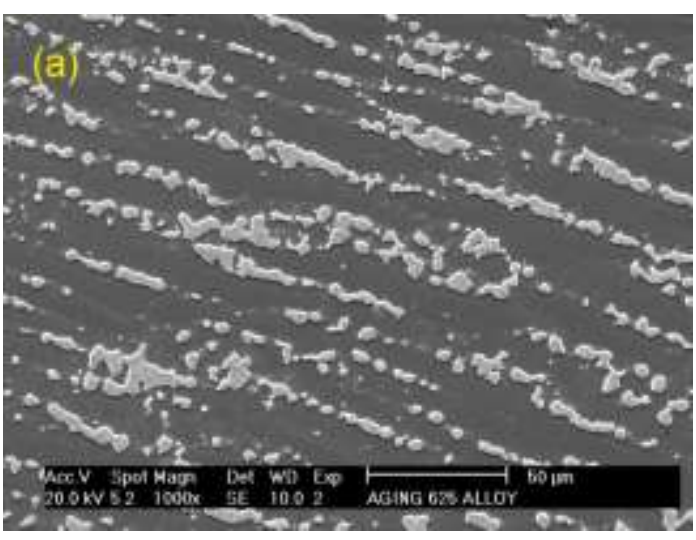

(c)

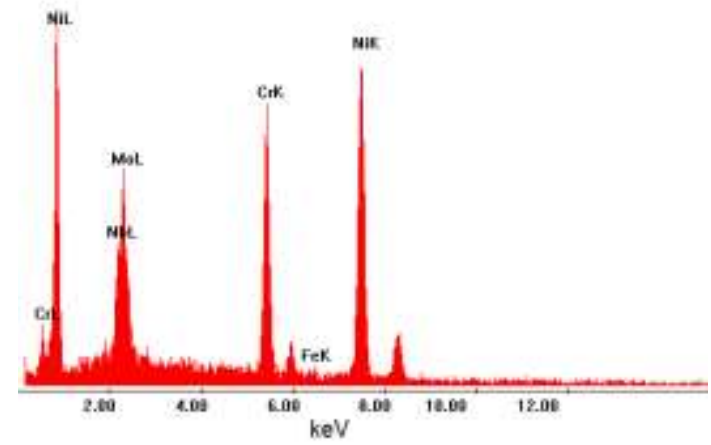

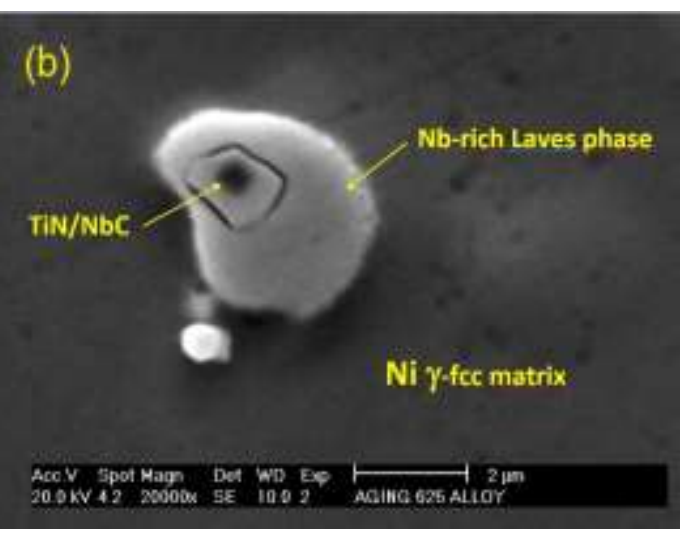

(d)

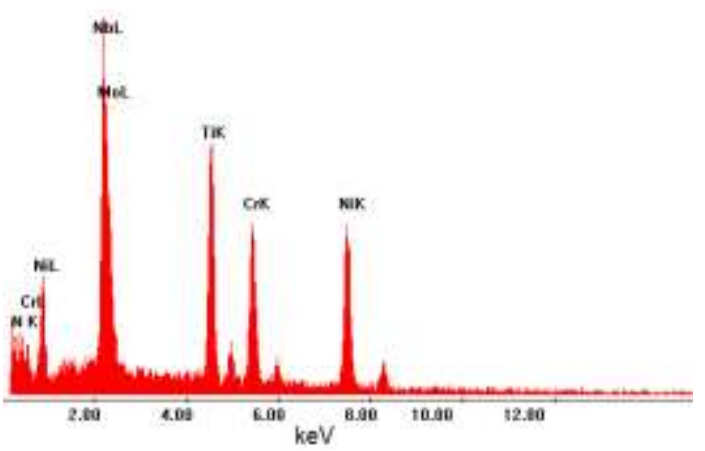

235

Figure 3. (a) SEM micrographs using secondary electrons showing the Ni-fcc matrix and the secondary phases of the sample as-welded, (b) In detail, an agglomerate formed by a cuboidal precipitate of $\mathrm{NbC/TiN}$ wrapped by Nb-rich Laves phase, (c) EDS spectrum of Laves phase, (d) EDS spectrum of $\mathrm{NbC} / \mathrm{TiN}$ cuboidal precipitate.

SEM/EDS analysis performed on the cubic precipitate showed higher concentrations of $\mathrm{Nb}$ and $\mathrm{Ti}$ and lower concentrations of $\mathrm{Cr}$, $\mathrm{Ni}$ and $\mathrm{Mo}$ (Figure 3d). It is important to point that the MoL $\alpha$ peak overlaps with $\mathrm{Nb}$ L $\alpha$. In addition, a NK $\alpha$ peak was found. The concentration of the main elements is shown in Table 2. 
$200 \mathrm{~h}$, respectively, and the microstructural modifications can be seen. These micrographs

247 show that the microstructural evolution is mainly due to dissolution of the Nb-rich Laves

248 phase, and the cubic particles of $\mathrm{Nb}$ and $\mathrm{Ti}$ complex carbides/nitrides remain in the 249 microstructure.

250

251
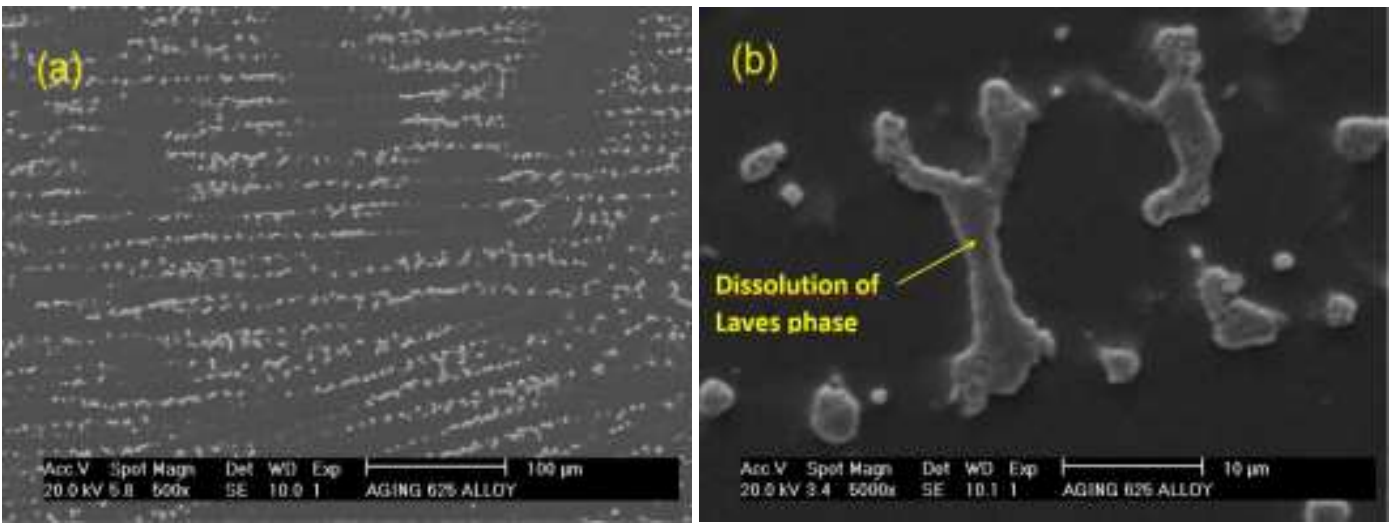

Figure 4. (a) Representative microstructure of the sample aged at $650^{\circ} \mathrm{C}$ for 10 hours; (b) Detail of the Eutectic-like Laves phase and some cuboidal precipitates of NbTi carbides/nitrides
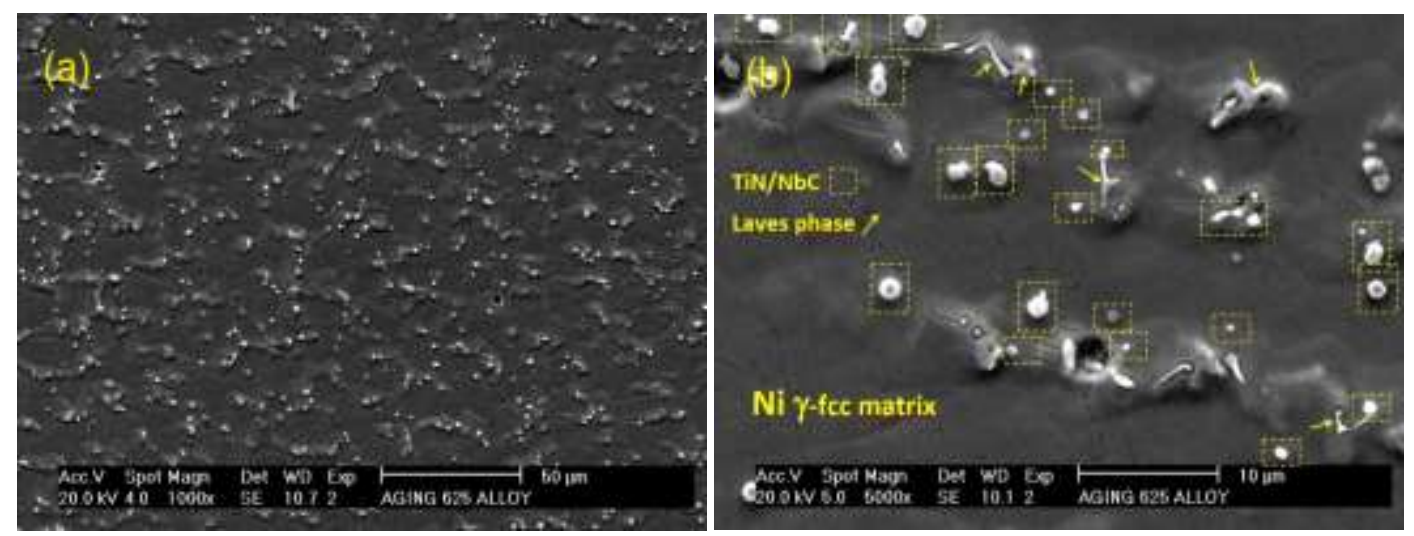

Figure 5. (a) Representative microstructure of the sample aged at $650^{\circ} \mathrm{C}$ for 100 hours; (b)

Detail decomposition of the Laves phase with significantly reduced dimensions, and where some cuboidal precipitates of carbides/nitrides can also be seen. 

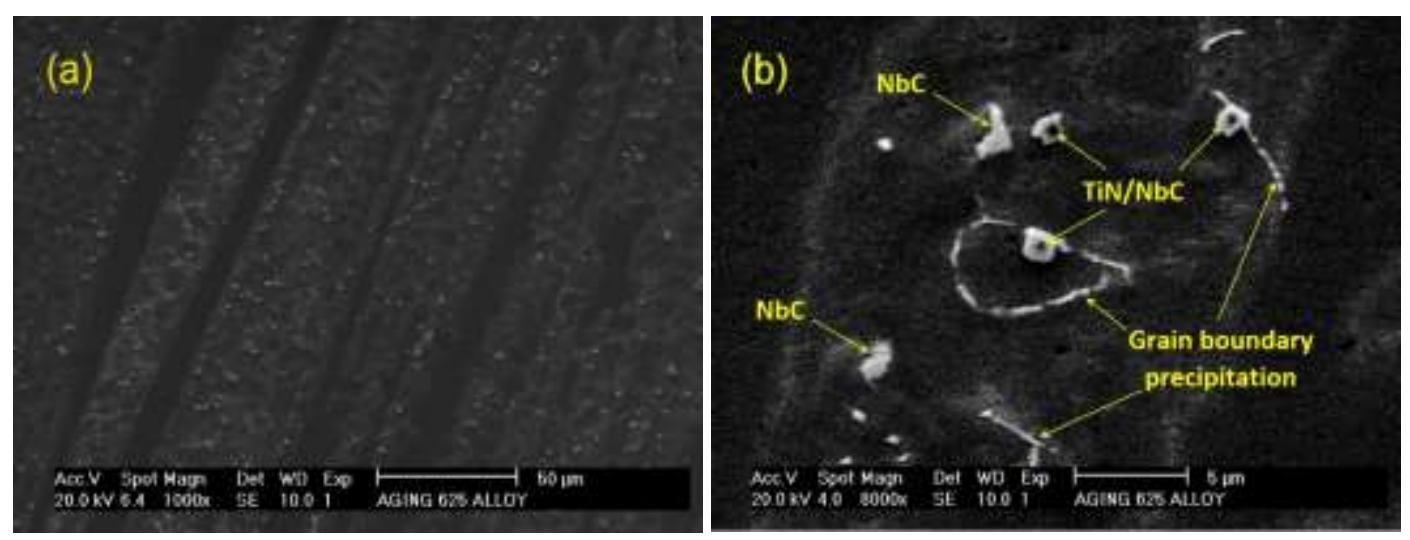

Figure 6. (a) Representative microstructure of the sample aged at $650{ }^{\circ} \mathrm{C}$ for 200 hours showing practically only NbTi carbides/nitrides; (b) Detail showing a small particle of Laves phase reminiscent of the incomplete decomposition.

A representative microstructure of the sample aged at $650^{\circ} \mathrm{C}$ for 10 hours is shown in

Figure 4. There was a very low tendency for the dissolution of Laves phase particles. For the sample aged at $650^{\circ} \mathrm{C}$ for $100 \mathrm{~h}$, an intense dissolution of Laves phase is evident. The volume

271 fraction of the phase reduced greatly compared to the initial conditions (Figure 5). The microstructure for the aged condition of 200 hours at a temperature of $650^{\circ} \mathrm{C}$, there was almost a total dissolution of the Laves phase; only remnants were perceived in the microstructure, as shown in Figure 6. In this case, the microstructure consisted almost entirely 275 of the $\gamma$-fcc matrix and the particles of cubic NbTi complex carbides/nitrides.

277 precipitation after $100 \mathrm{~h}$ and $200 \mathrm{~h}$, especially along solidification grain boundaries and sub278 grain boundaries. Figure 7a clearly shows the behavior of the precipitation for the $100 \mathrm{~h}$ aging 279 condition, in which a discontinuous precipitation of very thin precipitates can be seen along 
the grain boundaries. For the $200 \mathrm{~h}$ aging, a continuous thin film precipitate can be seen along the grain boundaries in Figure $7 \mathrm{~b}$.
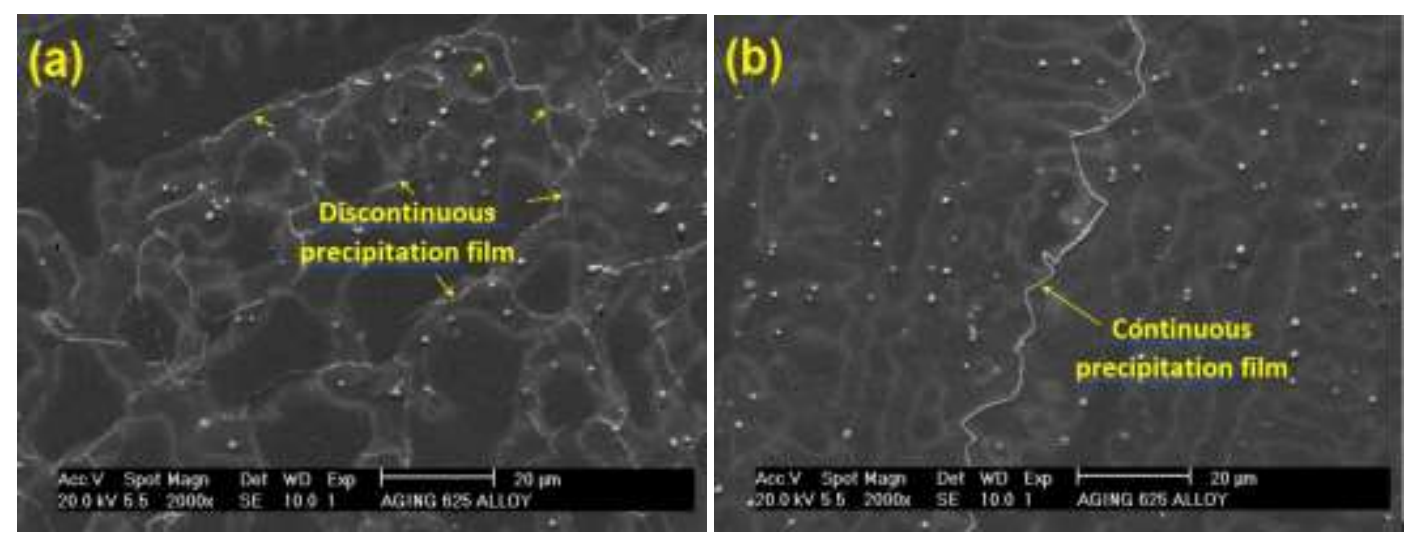

Figure 7. (a) Grain boundary precipitation in an early stage observed in the sample aged at $650{ }^{\circ} \mathrm{C}$ for 100 hours; (b) Grain boundary precipitation like continuous film observed in the sample aged at $650{ }^{\circ} \mathrm{C}$ for 200 hours.

\section{particles precipitated at the grain boundary were performed (Figure 8a). Unfortunately, due to} the size of those particles precipitated along the grain boundary, the results of the EDS analysis were not conclusive. However, there was a slight increase in $\mathrm{Cr}$ in these particles and an intense peak of carbon and silicon in many cases (Figure 8b). This may indicate the formation of carbides such as $\left(\mathrm{Cr}_{6} \mathrm{C}\right)$ and/or $(\mathrm{CrMo})_{23} \mathrm{C}_{6}$. Also, there was a higher concentration of $\mathrm{Nb}$ in the matrix than in the interdendritic region, indicating an enrichment caused by Laves phase dissolution (Figure 8c). 

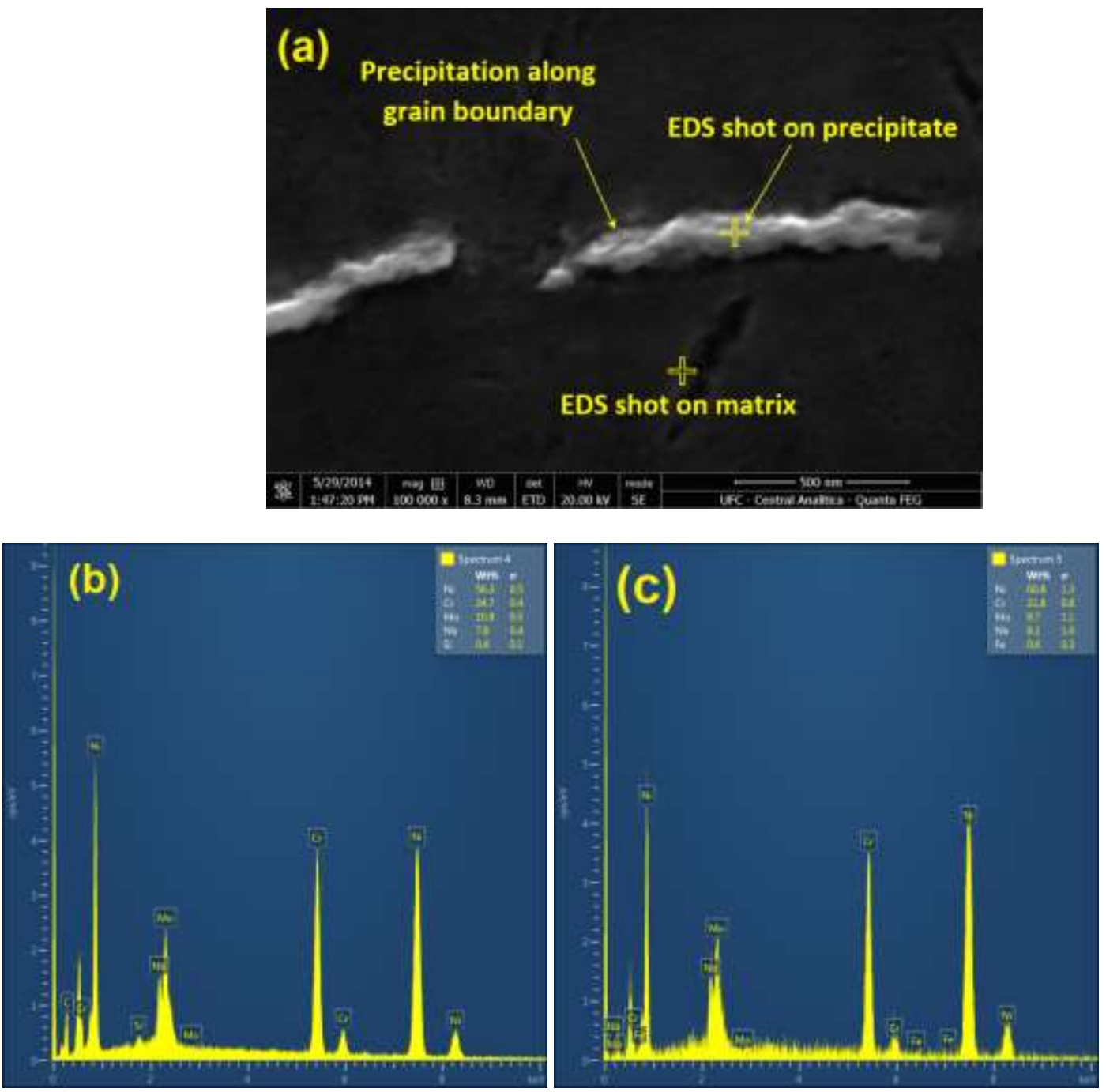

Figure 8. (a) Microchemical analysis of nano-sized precipitates along the grain boundary performed by EDS; (b) EDS spectrum of the particle; and (c) Spectrum of the matrix adjacent to the precipitate.

According to the Thermo-Calc analysis for the chemical composition of the weld

306 metal evaluated by optical emission spectroscopy (Table 3), $\mathrm{M}_{23} \mathrm{C}_{6}$ is able to precipitate at all 307 temperatures evaluated in this study (Figure 9). Therefore, $\mathrm{M}_{23} \mathrm{C}_{6}$ is considered a strong candidate to precipitate in grain boundaries as was found at $650{ }^{\circ} \mathrm{C}$ after $200 \mathrm{~h}$. 
310 frequently found in alloys containing chromium, molybdenum and niobium. ${ }^{[32]}$ In addition, is 311 reported that $\mathrm{M}_{6} \mathrm{C}$ exhibit excellent temperature stability, however may undergo a 312 transformation to $\mathrm{M}_{23} \mathrm{C}_{6}$ for long exposure time at high temperature $\left(816^{\circ} \mathrm{C}-927^{\circ} \mathrm{C}\right) .{ }^{[32]} \mathrm{In}$ 313 addition, Figure 10 shows the presence of a very thin precipitation along the interdendritic 314 region, together with grain boundary precipitation.

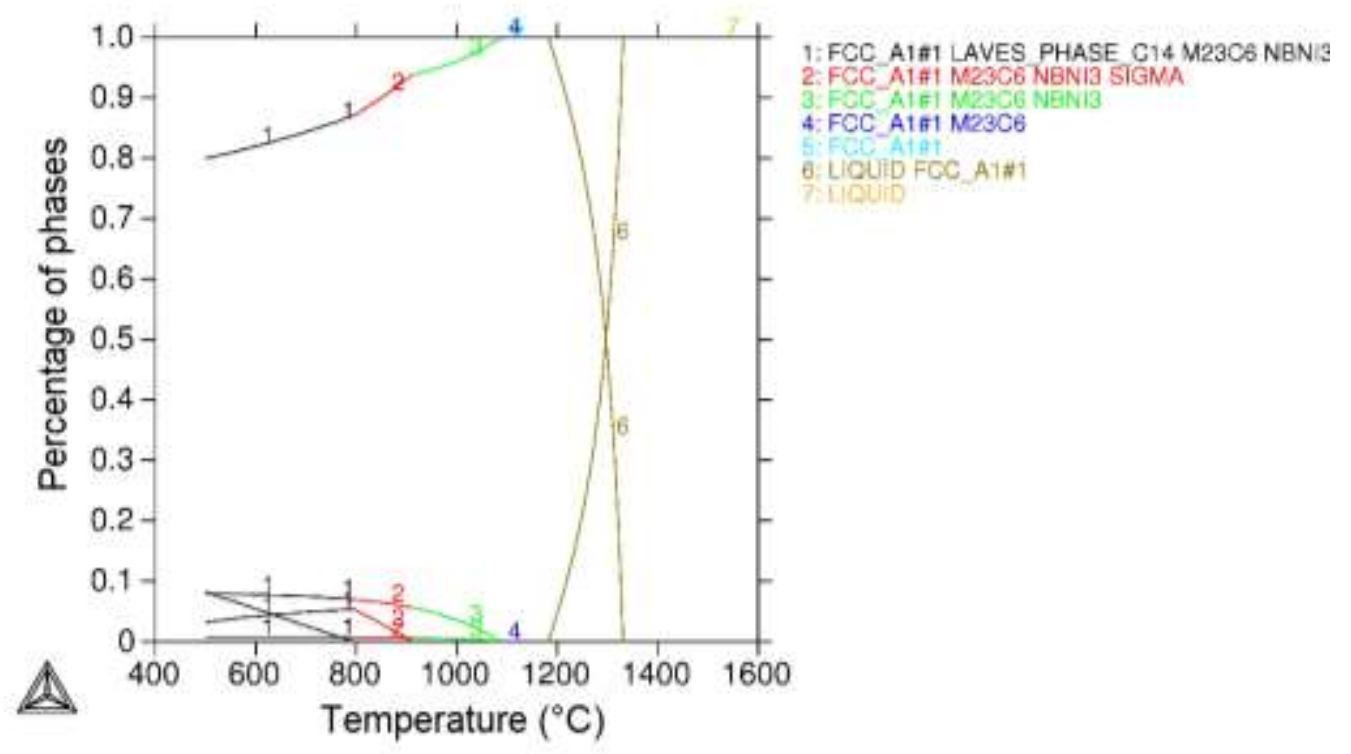

316 Figure 9. Phase diagram calculated by Thermo-Calc ${ }^{\odot}$ based on the weld metal chemical 317 composition.
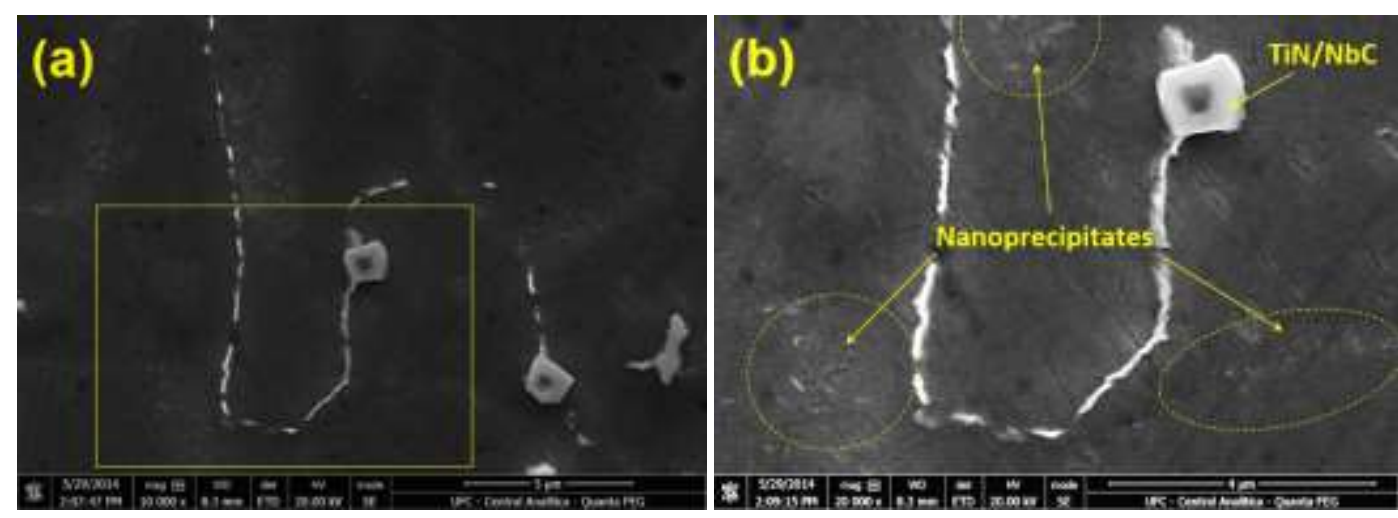
Figure 10. Precipitation along the grain boundary and a very thin precipitation dispersed into

321 the interdendritic region which may be an indicative of the $\gamma^{\prime \prime}\left(\mathrm{Ni}_{3} \mathrm{Nb}\right)$ phase.

On increasing the aging temperature from 650 to $950{ }^{\circ} \mathrm{C}$, several microstructural

changes were found. Figure 11 shows representative microstructures of the Inconel 625 alloy the interdendritic region. Another observation is that Laves phase apparently dissolved to give needle phase.
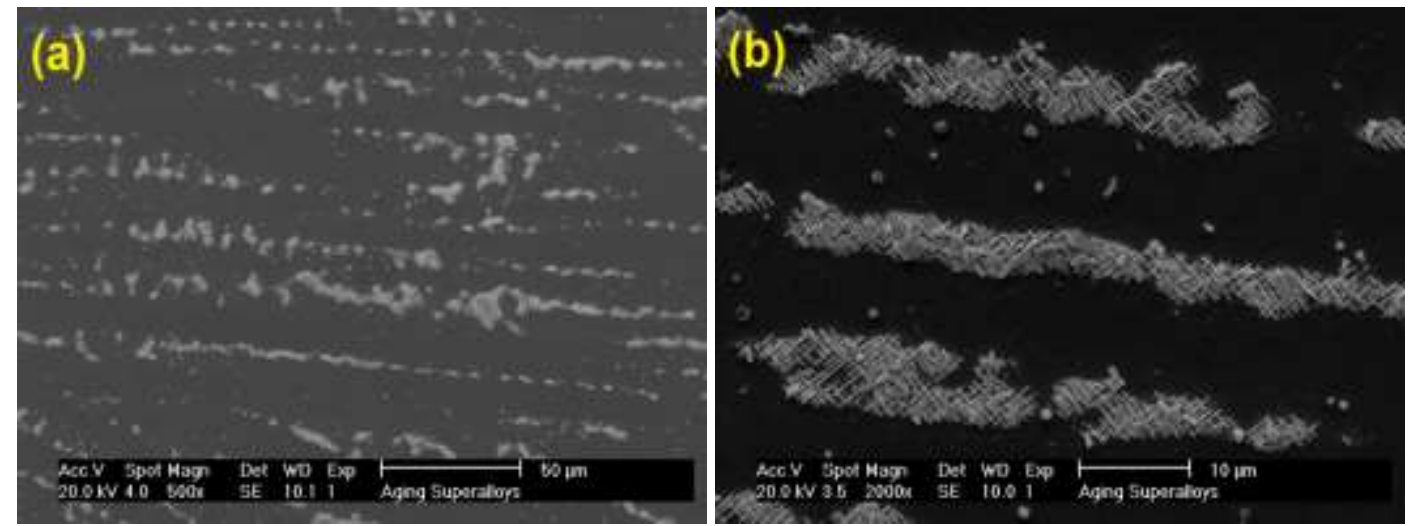

330
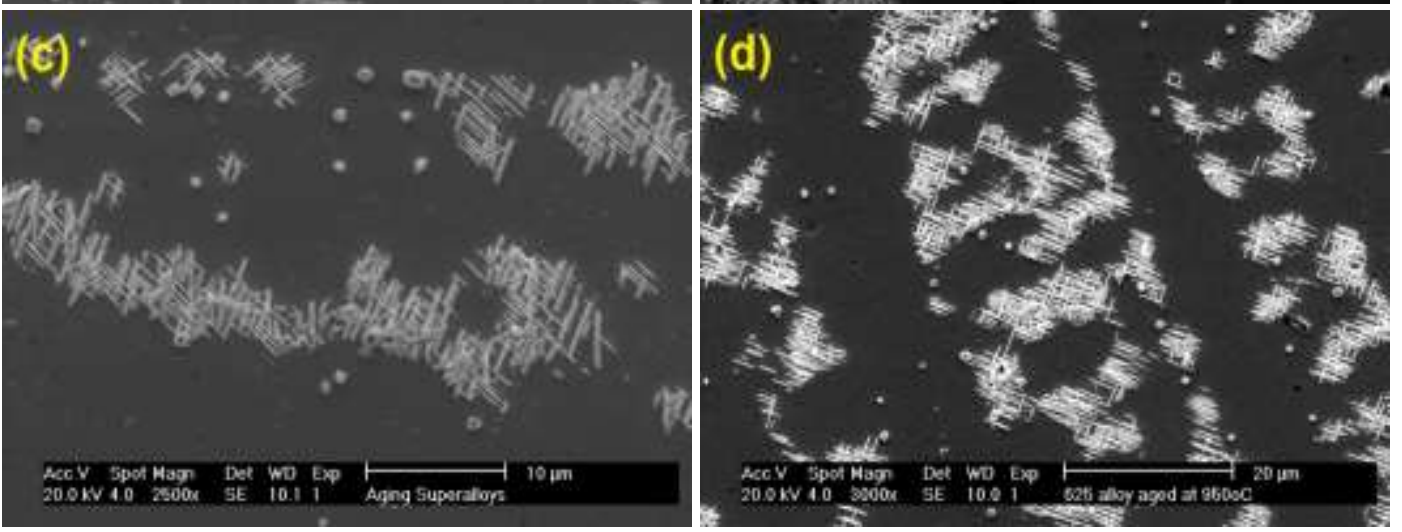

Figure 11. Examples of SEM micrographs using secondary electrons showing the aged microstructure at $950{ }^{\circ} \mathrm{C}$ for 10 hours taken from different positions. 

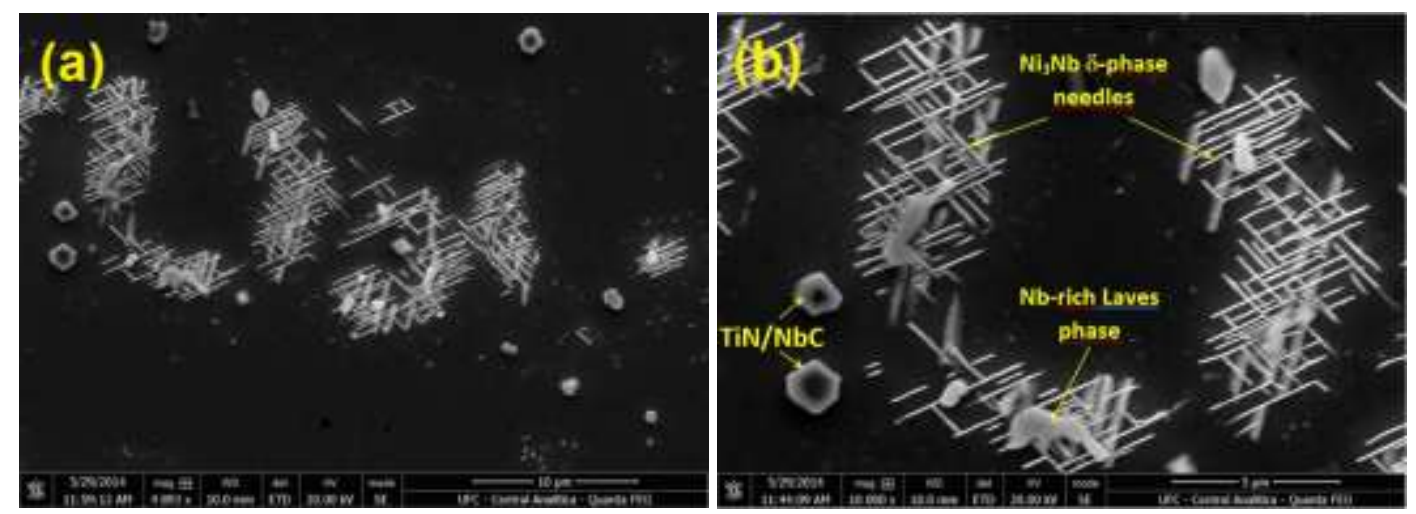

Figure 12. Details of TCP phases in the microstructure showing $\mathrm{Ni}_{3} \mathrm{Nb} \delta$-phase needles

together with $\mathrm{Nb}$-rich Laves phases into the interdendritic region. Also a large cubic precipitate of NbTi complex carbide/nitrite was observed.

A chemical mapping acquired by EDS analysis for the main alloying elements is

341 shown in Figure 13. The results indicated that the region where needles are precipitated is rich

342 in $\mathrm{Nb}$. This shows that the precipitation occurred preferably in the interdendritic region, since

343 due to microsegregation, this zone is enriched in $\mathrm{Nb}$. This region also has a high volume

344 fraction of Laves phase rich in $\mathrm{Nb}$, which is indicated in the Figure 13 by a dotted ellipse, and

345 whose dissolution serves as a continuous supply of $\mathrm{Nb}$ to form the needle particles. No

346 alterations were seen in the NbTi complex carbide/nitrides, or in the microstructure (indicated

347 in the chemical maps by a dotted square). 

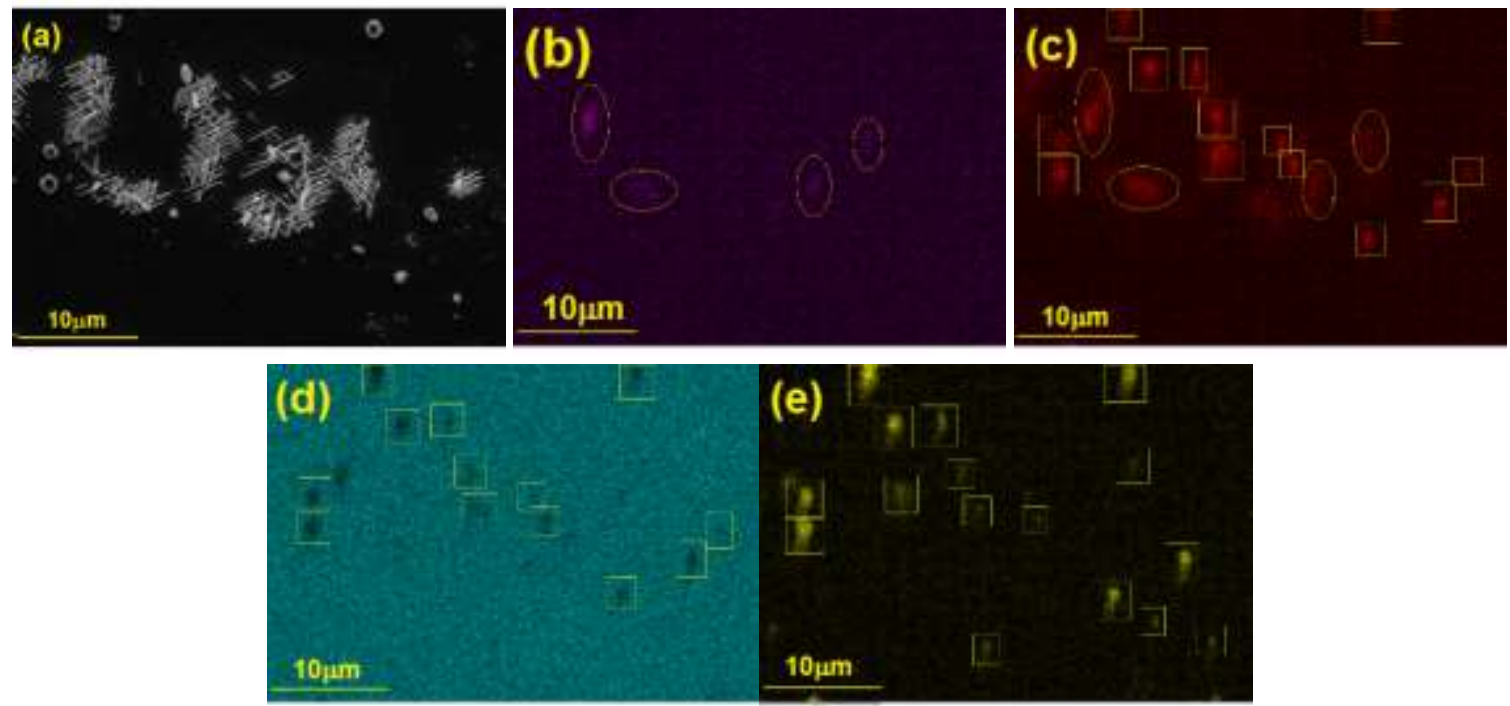

Figure 13. Chemical mapping obtained by EDS for the alloying elements: (a) SEM image, (b)

$\mathrm{Mo}$, (c) $\mathrm{Nb}$, (d) Ni, and (e) Ti.

352

The 625 alloy weld metal showed a partial dissolution of the $\delta$-phase up to $100 \mathrm{~h}$ aged

at $950{ }^{\circ} \mathrm{C}$, as can be seen in Figure $14 \mathrm{a}$. In addition, several particles of the cubic complex carbides/nitrides and large blocks of $\mathrm{NbC}$ carbides that grow from preexisting carbides/nitrides can be seen. Also, but with a lower frequency, small particles of Laves phase were found, which were almost completely solubilized during the aging.

Figure $14 \mathrm{~b}$ shows an early stage of nucleation of thin particles maidenly precipitated along grain boundaries and sub-grain boundaries. Figure $15 \mathrm{a}$ and $15 \mathrm{~b}$ details the microstructure of the sample aged at $950{ }^{\circ} \mathrm{C}$ for $100 \mathrm{~h}$ showing the apparent dissolution of the

$\mathrm{Ni}_{3} \mathrm{Nb} \delta$-phase needles and the presence of residual $\mathrm{Nb}$-rich Laves phases in the interdendritic 

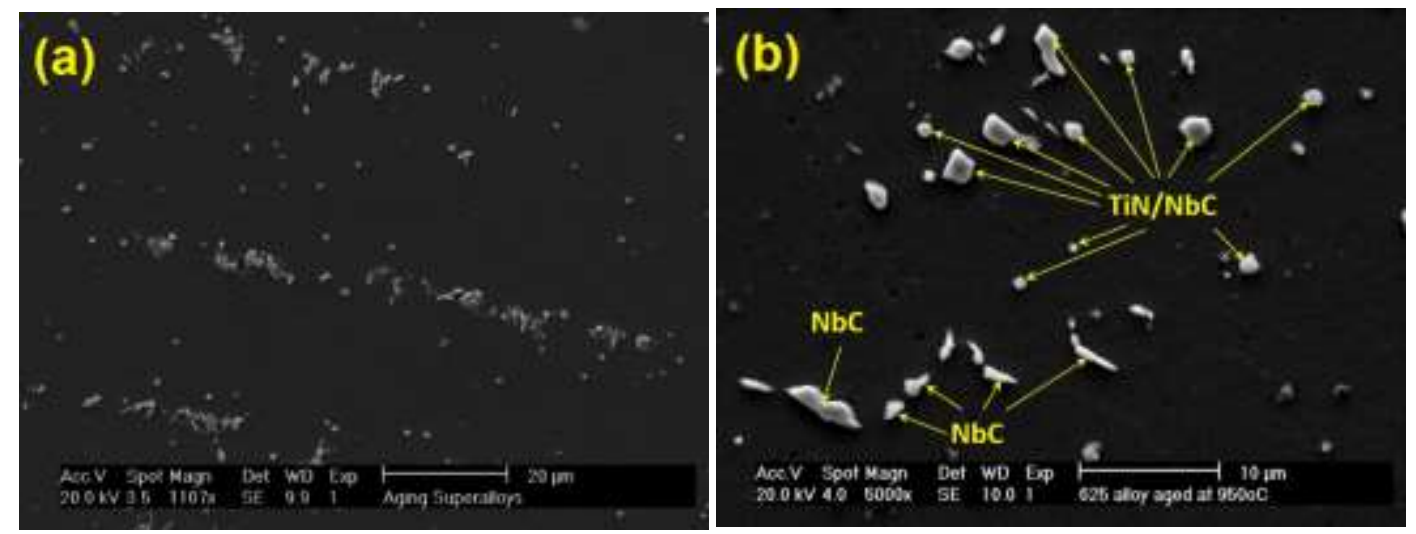

Figure 14. Examples of SEM micrographs using secondary electrons showing the aged microstructure at $950{ }^{\circ} \mathrm{C}$ for 100 hours taken from different positions.
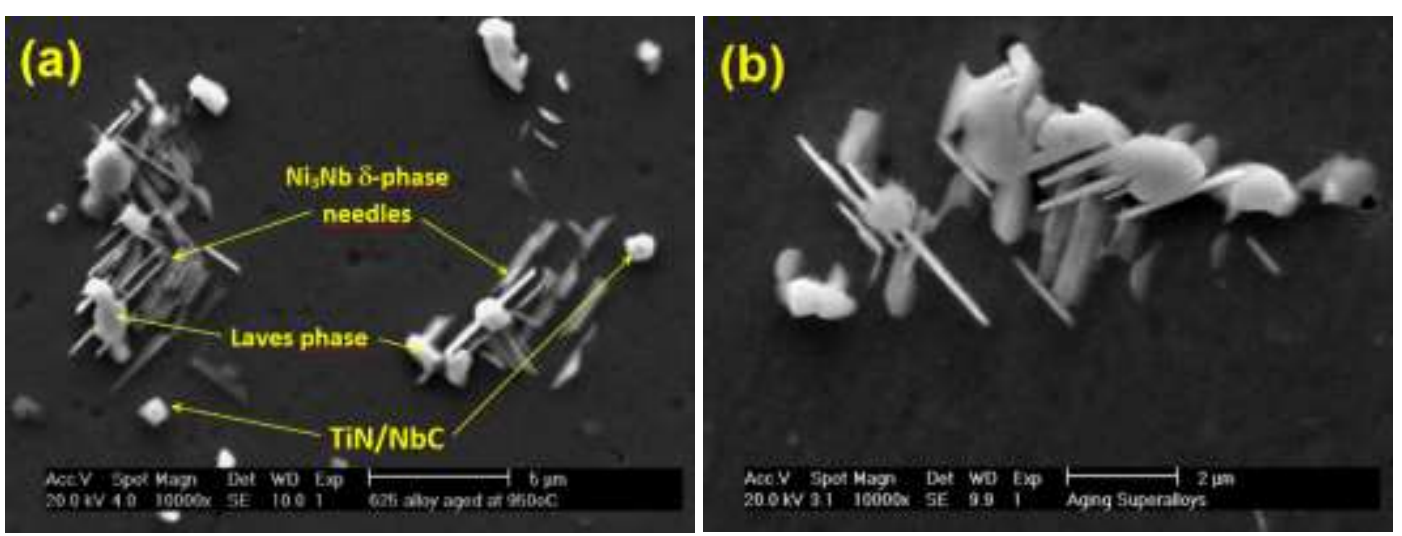

Figure 15. In detail, some secondary phases formed by Laves phase unsolved, $\delta$-phase $\mathrm{Ni}_{3} \mathrm{Nb}$ needle-like and some NbTi carbide/nitride cuboidal particles. Sample aged at $950{ }^{\circ} \mathrm{C}$ for 100h.

Figure 16a and Figure16b show representative micrographs of the treated material 373 held at high temperatures for periods of up to $200 \mathrm{~h}$. Here these Figures show an almost complete dissolution of the precipitates previously present in the microstructure. No precipitates with needled morphology can be seen, indicating that for this condition of aging, there was a complete dissolution of the $\delta$-phase. Furthermore, Laves phase particles were not

377 clearly observed, indicating also the complete dissolution of this phase. Therefore, for this condition of treatment, all TCP phases were dissolved and only cubic NbTi carbides/nitrides and large $\mathrm{NbC}$ carbides were present in the microstructure. In some regions, where there were 
no large blocks of primary carbides $(\mathrm{NbC})$, a fine precipitation along the grain boundaries and sub-grain boundaries together with the cubic NbTi carbides/nitrides can be seen, as shown in

382
Figure 16c and Figure16d.

In order to increase the volume fraction of the analyzed material, increasing the peak intensities and to improve the identification of the phases formed in the weld metal, X-ray diffraction analyzes were performed on powder precipitates produced by the extraction technique in accordance with ASTM A923. XRD results showed the whole X-ray diffractogram recorded for the $10 \mathrm{~h}$ aged sample for the two temperatures, 650 and $950{ }^{\circ} \mathrm{C}$ (Figure 17). All the peaks were identified and indexed according to the standards, depending on the phases formed. For the sample aged at $650{ }^{\circ} \mathrm{C}$ for $10 \mathrm{~h}$ (Figure17a), the peaks corresponded to Laves phase, ( $\mathrm{Nb}, \mathrm{Ti}) \mathrm{C}$ carbide and $\square$-fcc matrix, which confirm the microstructural observations made by SEM. Some minor peaks were not associated to the phases and were indexed, for example, as iron oxide.
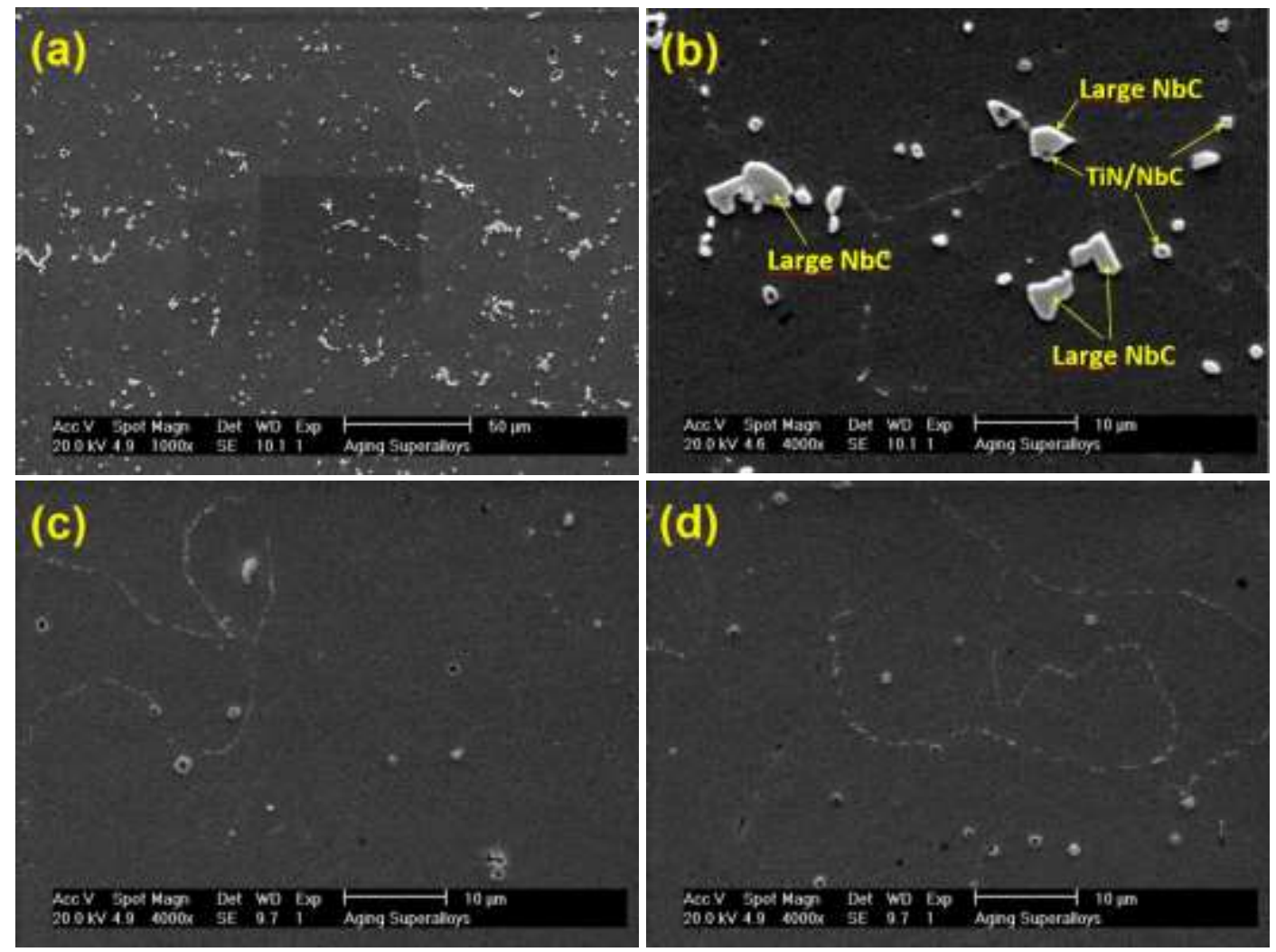
Figure 16. Examples of SEM micrographs using secondary electrons showing the aged microstructure at $950{ }^{\circ} \mathrm{C}$ for 200 hours taken from different positions. (a) and (b) Regions showing cubic NbTi carbides/nitrides and large NbC carbides; (c) and (d) Small cubic NbTi carbides/nitrides and a fine precipitation at the grain boundaries can be seen.

Figure $17 \mathrm{~b}$ shows the diffractogram for the sample aged at $950{ }^{\circ} \mathrm{C}$ for $10 \mathrm{~h}$. The peaks were identified and indexed as $\delta$-phase, $(\mathrm{Nb}, \mathrm{Ti}) \mathrm{C}$ carbide and $\gamma$-fcc matrix, according to the ASTM A936 standard which covers the procedure for the isolation of TCP in nickel-based alloys. This result confirm that supposed $\mathrm{Nb}$-rich needle-like phase is in fact $\delta$-phase $\left(\mathrm{Ni}_{3} \mathrm{Nb}\right)$.
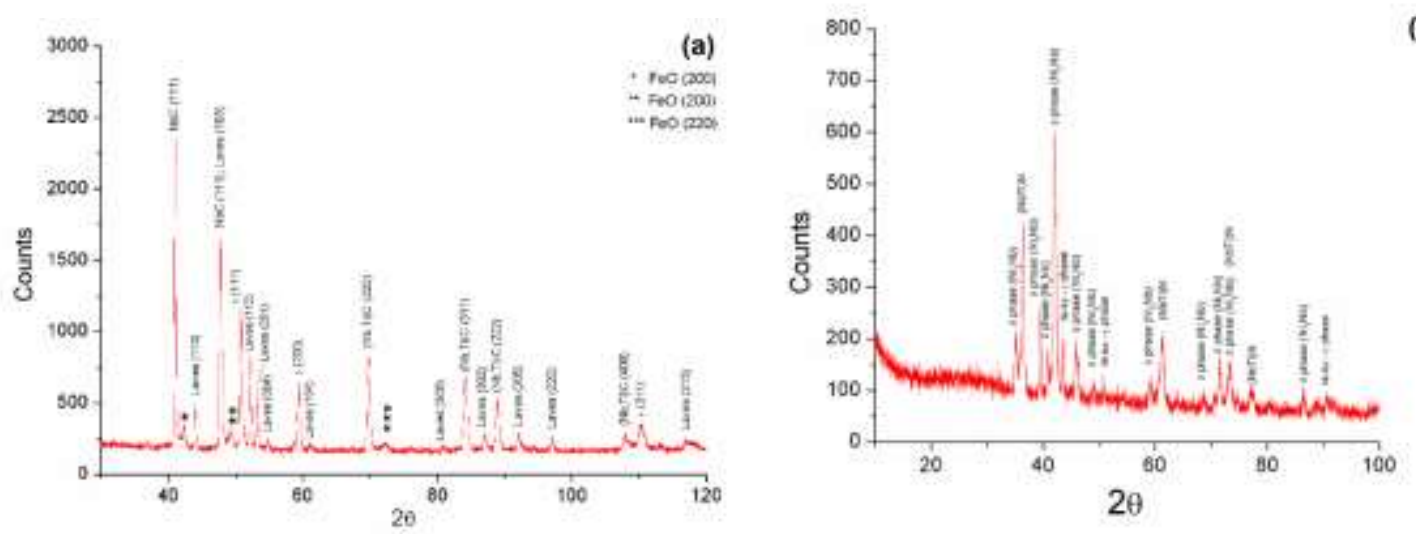

(b)

Figure 17. X-ray diffractograms from powder extraction concentrated in the secondary phases: (a) Sample aged at $650{ }^{\circ} \mathrm{C}$ for $10 \mathrm{~h}$; and (b) Sample aged at $950{ }^{\circ} \mathrm{C}$ for $10 \mathrm{~h}$.

\subsection{Mechanical properties evaluation}

Figure 18 presents the results of the Charpy-V impact test. The analysis of variance (ANOVA) indicated that the absorbed energy in joules for both aging temperatures evaluated was significant, and varied as a function of aged time; the significance factor was below 

welded non-aged condition (0h), which was higher than $140 \mathrm{~J}$. For the sample aged at $650{ }^{\circ} \mathrm{C}$,

417 there was a slight increase in toughness, from 142 to $151 \mathrm{~J}$. On prolonging the aging time, 418 there was a noticeable drop in the absorbed energy values for the times of 100 and $200 \mathrm{~h}$. 419 However, it is important to note that even after 200 hours of aging, the absorbed energy 420 values were greater than $98 \mathrm{~J}$. For the sample aged at $950{ }^{\circ} \mathrm{C}$ for $10 \mathrm{~h}$ aging time, there was a 421 slight decrease in toughness, with a mean value of $121 \mathrm{~J}$, while the energy absorbed for prolonged aging time $(100 \mathrm{~h}$ and $200 \mathrm{~h})$ increases again.

423

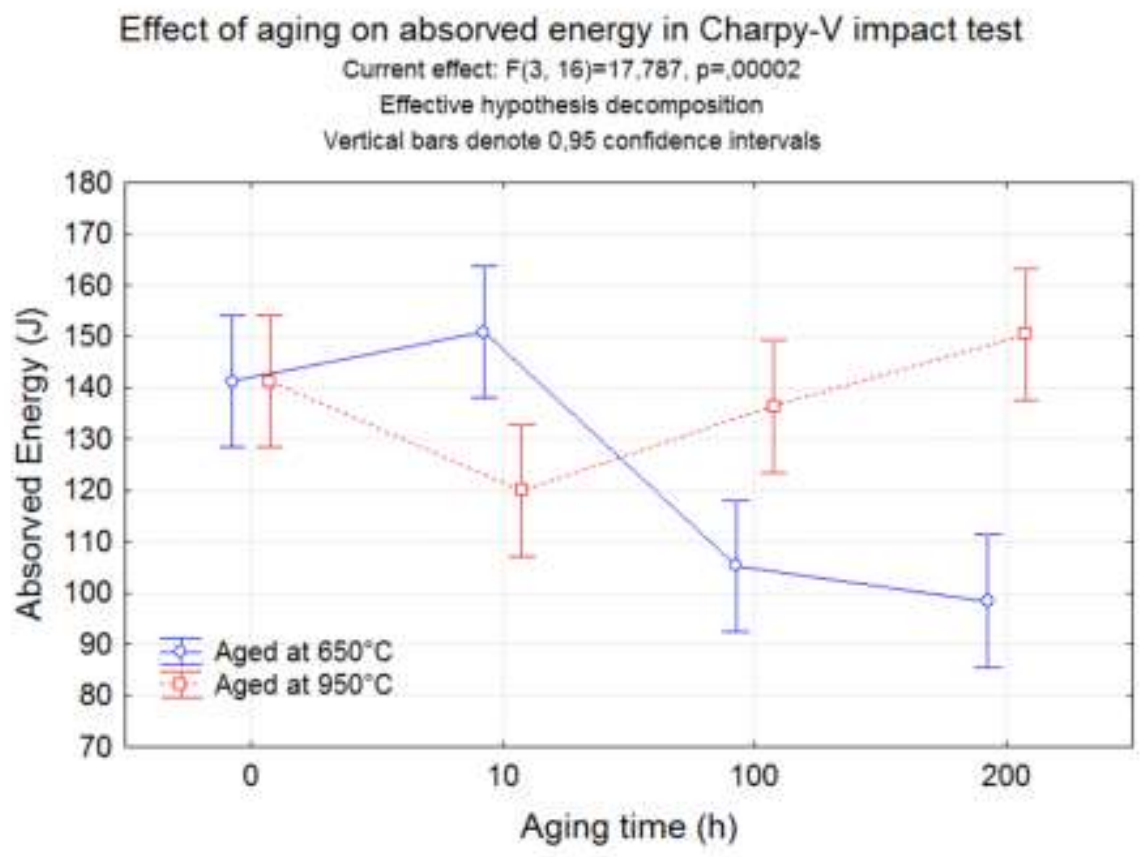

424

425 Figure 18. Results of the effect of aging temperature and time on the absorbed energy in the 426 Charpy-V impact test, evaluated by analysis of variance.

Fractography analysis were performed on the surface of the Charpy-V impact test samples, in order to understand the details about the cracking behavior. The images were acquired using SEM operating in SE mode. Figure 19a and Figure 19b shows the 
fractography images for the samples aged at $650^{\circ} \mathrm{C}$ for $10 \mathrm{~h}$ and $200 \mathrm{~h}$, respectively. In both

432 cases, ductile fracture characteristic was observed, with dimples structures.

Figure 20a and Figure 20b shows the fractography surface of the samples aged at $950^{\circ} \mathrm{C}$ for $10 \mathrm{~h}$ and $200 \mathrm{~h}$, respectively. As observed in the fractography images of conditions 435 aged at $650^{\circ} \mathrm{C}$, the conditions aged at $950^{\circ} \mathrm{C}$ show the same ductile fracture characteristic. An EDS mapping was obtained from the sample aged at $950^{\circ} \mathrm{C}$ for $200 \mathrm{~h}$, in order to 437 detect the position of the secondary phases in relation with the fracture morphologies. The 438 Figure 21 show the EDS mapping, which highlighted a high concentration of $\mathrm{Nb}$ and $\mathrm{Ti}$ into 439 the dimples core, indicating thus the presence of precipitates in that region.
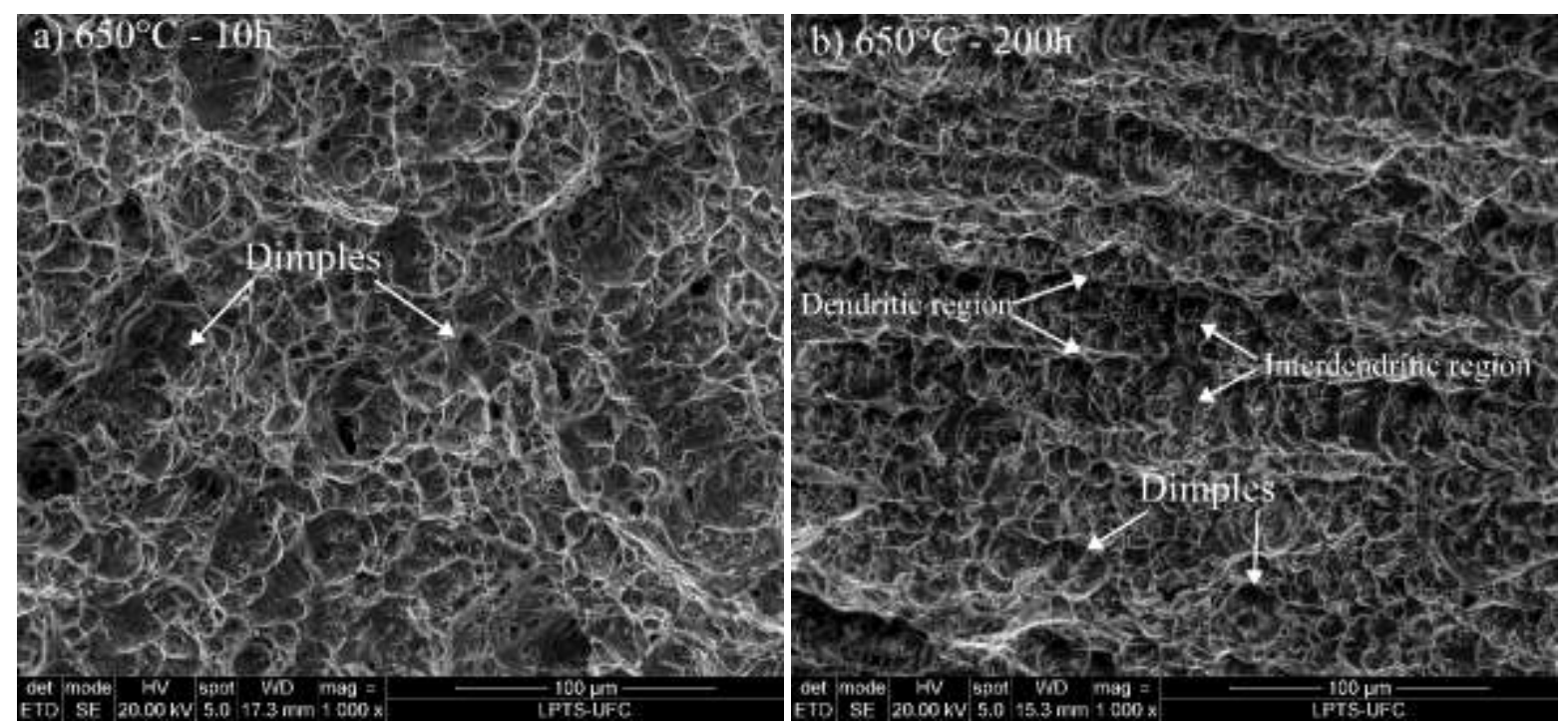

Figure 19. Fractography images of the conditions at $650^{\circ} \mathrm{C}$ for (a) $10 \mathrm{~h}$ and (b) $200 \mathrm{~h}$. 

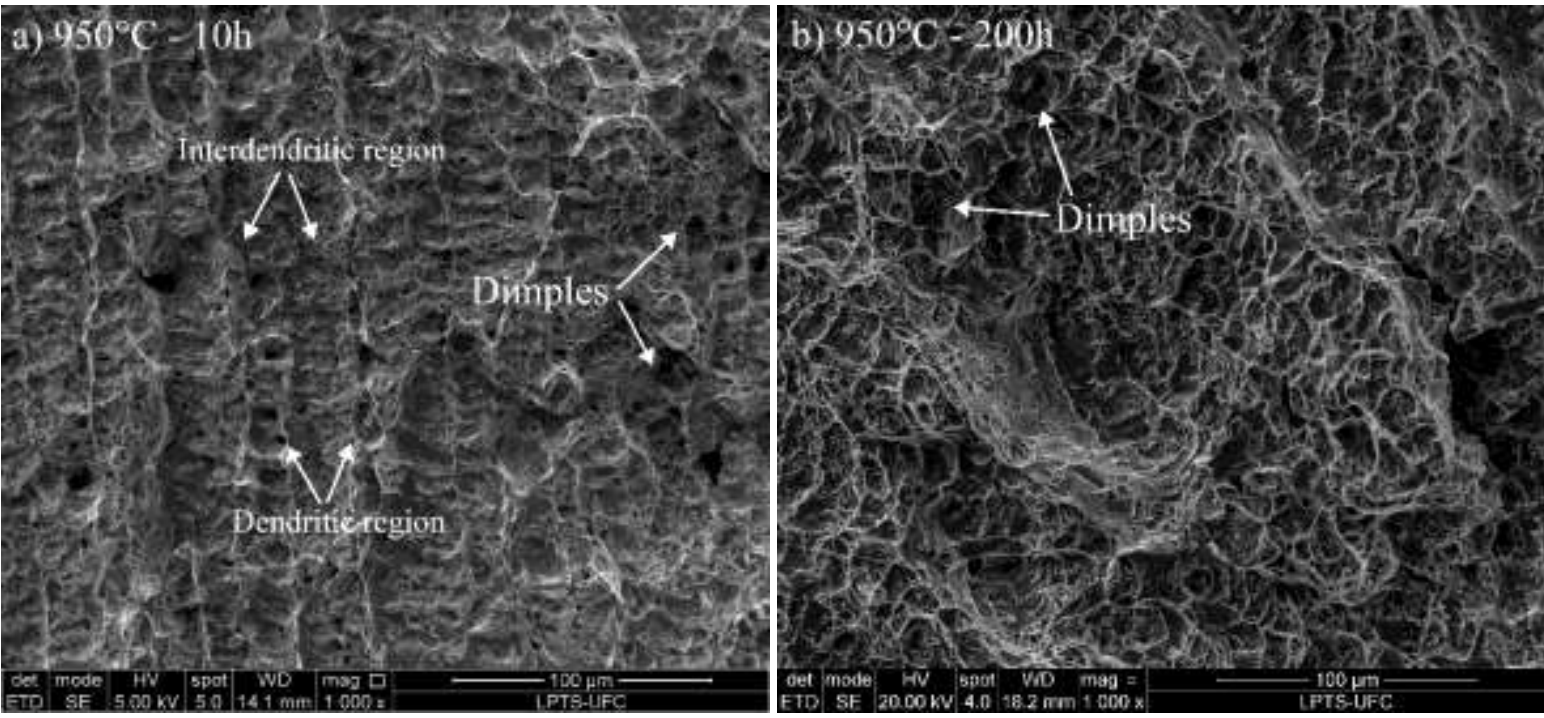

444 Figure 20. Fractography images of the conditions at $950^{\circ} \mathrm{C}$ for (a) $10 \mathrm{~h}$ and (b) $200 \mathrm{~h}$.
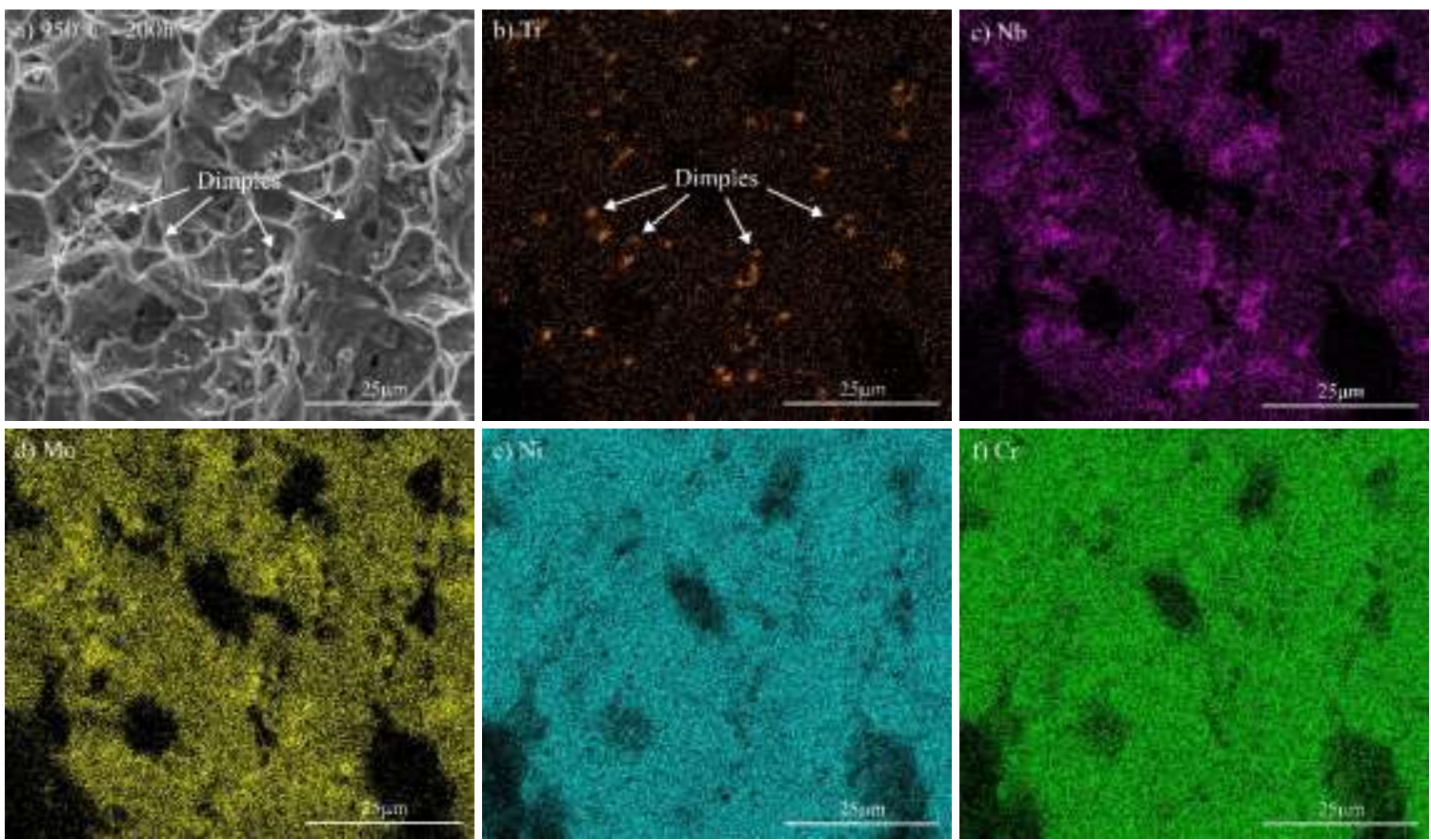

Figure 21. EDS mapping of the condition aged at $950^{\circ} \mathrm{C}$ for $200 \mathrm{~h}$. (a) Fracture surface image

449 and yours respective chemical mapping of the elements (b) $\mathrm{Ti}$, (c) $\mathrm{Nb}$, (d) Mo, (e) $\mathrm{Ni}$ and (f) Cr. 
varied with $95 \%$ confidence as a function of aged time, which is indicated by the significance factor below 0.00002 . On evaluating the hardness curve for samples aged at $650{ }^{\circ} \mathrm{C}$ for a short period of time, no significant changes were found for the hardness, which remained at approximately $300 \mathrm{HV}$. However, increasing the exposure at high temperatures for long times such as $100 \mathrm{~h}$ and $200 \mathrm{~h}$, the hardness values rises to $437 \mathrm{HV}$ and $443 \mathrm{HV}$, respectively. However, no difference in terms of hardness was found when the time of exposure was changed from $100 \mathrm{~h}$ to $200 \mathrm{~h}$. In addition to the statistical analysis, the variation in hardness was very significant in practice, since the difference from lower to higher values was almost $150 \mathrm{HV}$.

Effect of Aging on Microhardness Behavior

Wilks lambda $=, 01355, F(6,30)=37,954, p=, 00000$

Effective hypothesis decomposition

Vertical bars denote 0,95 confidence intervais

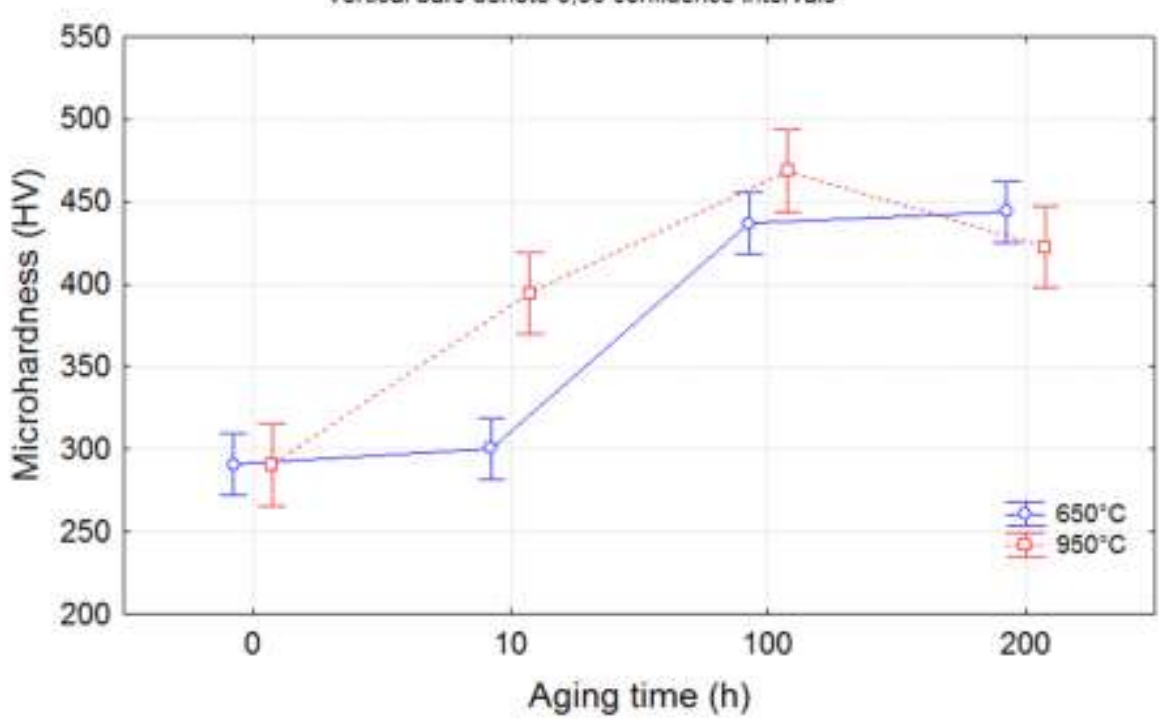

Figure 22. Results of the effect of aging temperature and time on the microhardness Vickers test evaluated by analysis of variance.

These results of hardness are in agreement with toughness behavior evaluated by the Charpy test. As shown in Figure 18, the samples aged at $650{ }^{\circ} \mathrm{C}$ during short times $(0$ and 10 h) had an impact energy between 140 to $150 \mathrm{~J}$, whereas samples aged for 100 and $200 \mathrm{~h}$ 
experienced a drop in this property. Since the hardness remained low for short aging times and underwent an increase for long times of exposure, the behavior of both properties are fully consistent, having a direct correlation, and indicate that a hardening mechanism took place during aging at $650{ }^{\circ} \mathrm{C}$.

\subsection{Physical properties evaluation}

Albuquerque et al., ${ }^{[25]}$ presented the ultrasound velocities obtained using the transducers with frequencies of 4 and $5 \mathrm{MHz}$ from the as-welded and aged at temperatures of $650{ }^{\circ} \mathrm{C}$ for 10,100 and $200 \mathrm{~h}$ samples, showing that ultrasound velocity decreased with the time of the aging heat treatment between $0 \mathrm{~h}$ (as-welded) and $100 \mathrm{~h}$, and increased from 100 to $200 \mathrm{~h}$. This behavior is more similar to results obtained by Charpy impact testing (Figure 18) and inversely proportional to hardness test (Figure 22).

However, Albuquerque et al. ${ }^{[25]}$ did not consider inspection by ultrasound at temperatures of $950{ }^{\circ} \mathrm{C}$. Considering this to be important, Figures $23 \mathrm{a}$ and $23 \mathrm{~b}$ present the results of ultrasonic velocity and attenuation, respectively. Based on these results, none significant modification of the ultrasonic measurements can be seen between the times of $0 \mathrm{~h}$ to $200 \mathrm{~h}$. This behavior was completely different of the observed for microstructure, Charpy impact energy, see Table 4, as well as for hardness testing, Figure 22. We used the same conditions here as Albuquerque et al. ${ }^{[25]}$

According to measurements for $650^{\circ} \mathrm{C}$ aged conditions, non-destructive ultrasonic testing may be a promising tool for monitoring phase changes in the Inconel 625 . Notwithstanding, based on $950^{\circ} \mathrm{C}$ aged condition it is demonstrated that this technique was sensitive to the microstructure. Therefore, it is clearly demonstrated that further studies on the application of non-destructive techniques for detection of microstructural changes in nickel- 
499

500

501

502

503

504

505

506

507

508

509

510

511

512

513

based alloys by ultrasound should be developed to identify the technical capabilities and limitations.

(a)

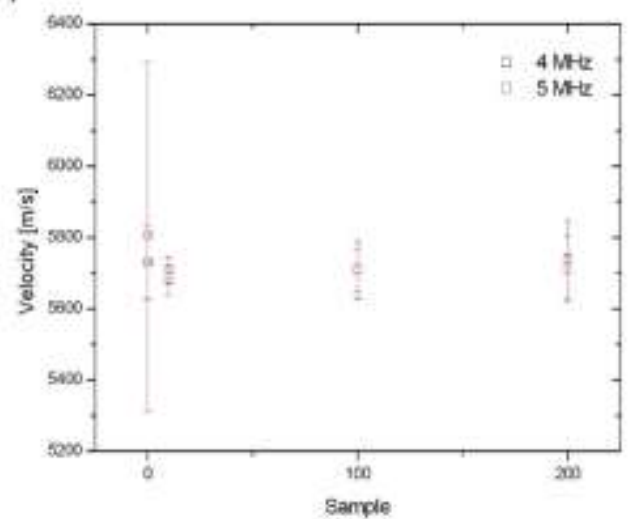

(b)

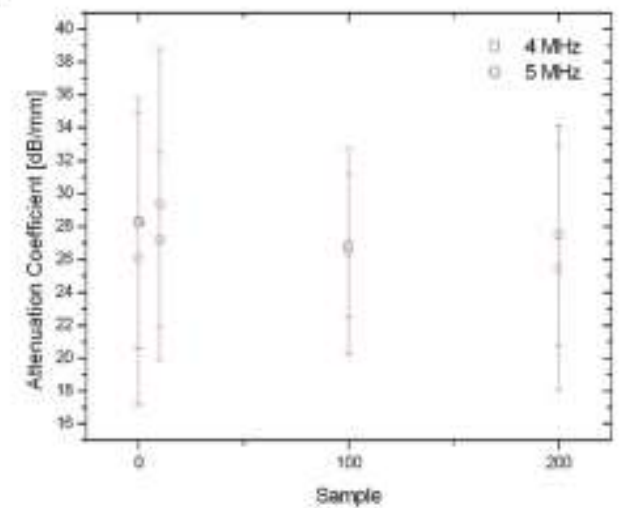

Figure 23. Ultrasonic a) velocity and b) attenuation measurements.

\section{Discussion}

Based on morphology and chemical composition performed by SEM-EDS analysis, the shapeless or eutectic particles were characterized as a TCP phase named Laves phase rich in $\mathrm{Nb}$. These results are consistent with those reported by other authors evaluating the microstructure of the 625 alloy. ${ }^{[13,14,33]}$

In addition, the presence of cubic precipitates has been reported for the 625 alloy in the literature ${ }^{[33,34]}$. In another study, Silva et al. ${ }^{[33]}$ confirmed by TEM analysis that these cubic precipitates observed in the microstructure, are a complex precipitate, consisting of a core with titanium nitride (TiN) surrounded by a niobium titanium carbide $(\mathrm{NbTi}) \mathrm{C}$.

Due to the high melting point of the NbTiN complex of carbides/nitrides $(2,927$ $\left.{ }^{\circ} \mathrm{C}\right),{ }^{[35]}$ which is approximately twice the liquidus temperature of the 625 alloy, it is quite likely that they remain in the solid state within the volume of the liquid pool, differently of Laves phases which have a low melting point and are formed during the solidification reaction. 

clearly shows the formation of a discontinuous precipitation of very thin precipitates along the grain boundaries for the sample aged at $650{ }^{\circ} \mathrm{C}$ for $100 \mathrm{~h}$, whereas for the $200 \mathrm{~h}$ aging, a continuous thin film precipitate along the grain boundaries has been observed. Chakravartty et al. ${ }^{[16]}$ evaluated a tube exposed to high temperatures ranging from 650 to $680{ }^{\circ} \mathrm{C}$ after $100,000 \mathrm{~h}$ in service, and reported the formation of a thin layer of discrete carbide particles at the grain boundaries, which were identified by TEM as $\mathrm{M}_{23} \mathrm{C}_{6}$ carbide. In addition, they found large chunky $\mathrm{M}_{23} \mathrm{C}_{6}$ carbide particles at the grain boundaries.

Evans et al. ${ }^{[36]}$ performed a series of creep testing of foils in air at $750{ }^{\circ} \mathrm{C}$, and among several significant changes in microstructure, they reported that the grain boundaries became heavily decorated with precipitates, the majority of which were rhombohedral $\mu$ phase. Additionally, a significant fraction of the grain boundary precipitates were found to be a Sirich variant of $\mathrm{M}_{6} \mathrm{C}$.

For the samples thermal aged at $950{ }^{\circ} \mathrm{C}$ the microstructural analysis shows the presence of a new type of precipitation. The evaluation of the characteristics of this new phase of needle particles, and their comparison with information reported in literature, showed that these needles are most probable an ordered phase, whose stoichiometric composition is $\mathrm{Ni}_{3} \mathrm{Nb}$ and whose crystallographic structure is orthorhombic. ${ }^{[37,38]}$ This phase is commonly observed in Ni-based alloys containing $\mathrm{Nb}$, such as 625 and 718 alloys, and can precipitate in a wide range of temperatures and with various morphologies. ${ }^{[39]}$

As mentioned before, the interdendritic region is enriched in $\mathrm{Nb}$ due to microsegregation during solidification, which makes the precipitation of phases rich in this element possible. In fact, based on the results presented before, the $\delta$-phase needles are formed due to the favorable microchemistry in the dendritic region, having a high 
different from what has been observed for $\mathrm{Ni}$-based superalloys with the addition of $\mathrm{Nb}$ in annealing conditions, when the $\delta$-phase forms due to the decomposition of $\gamma$ " phase, since

543 both phases have the same stoichiometry but different crystal structures.

In this study, it was proven that Laves phase formed due to microsegregation during solidification which acts as a niobium reserve for the formation of the delta phase, and its dissolution over time, which acts as a necessary supply of the said element to the system, in order to have a continuous formation of the $\delta$-phase.

According to Delueme et al., ${ }^{[38-40]}$ there are two kinds of $\delta$-phases depending on the precipitation temperature. Phases formed in the temperature range $\left(900{ }^{\circ} \mathrm{C}-1000{ }^{\circ} \mathrm{C}\right)$ are named $\delta_{\mathrm{HT}}$ and are characterized by coarse spheroidized or platelet formation. When the $\delta$ phase is precipitated at lower temperatures (around $750{ }^{\circ} \mathrm{C}$ ) during the ageing heat treatment, the phase is named $\delta_{\mathrm{LT}}$, precipitating in the form of a film or continuous strings along the grain boundaries.

Mittra et al. ${ }^{[18]}$ suggested that lath-shaped $\delta$-phases form in Alloy 625 when the alloy is held isothermally at $850^{\circ} \mathrm{C}$. Since, this temperature is the nose temperature of the "C" curve corresponding to the $\delta$-phase of Alloy 625; the presence of this ordered phase is expected in all the samples.

The literature reports that the formation of the $\delta$-phase in significant quantities can be harmful to the mechanical properties for precipitation hardening Ni-based alloys. ${ }^{[39-41]}$ In the case of the 625 alloy, which is a solid-solution strengthened alloy, the precipitation of the $\delta$ phase is produced after long time exposure at high temperatures from the solid solution supersaturated. Precipitation of the $\delta$-phase leads to reduced ductility. ${ }^{[40-42]}$

Another study showed that both hardness and tensile strength decreased with an increase in ageing temperature due to the precipitation and coarsening of the delta-phase. ${ }^{[41-43]}$ 
Therefore, the precipitation of the $\delta$-phase in weld metal of the 625 alloy aged at $950{ }^{\circ} \mathrm{C}$ found in this study may have a harmful effect on the mechanical properties.

According the detailed microscopic analysis performed for samples thermal aged at $950{ }^{\circ} \mathrm{C}$, was found that many particles remain in microstructure even for longest time of exposure. This behavior indicates that the aging conditions (time and temperature) were not favorable to dissolve completely the TCP phases. Cai et al., ${ }^{[42-44]}$ studied the dissolution kinetics of the $\delta$-phase in the 718 alloy, which has additional $\mathrm{Nb}$, and mentions that the $\delta$ phase can be fully dissolved into the matrix after a heat treatment at $1020{ }^{\circ} \mathrm{C}$ for more than 2h. However, when held at 980 and $1000{ }^{\circ} \mathrm{C}$, a certain amount of $\delta$-phase was still found in the alloy, even after more than $6 \mathrm{~h}$. In this case, the chemical inhomogeneity due to microsegregation and the formation of $\mathrm{Nb}$-rich phases during solidification makes the precipitation and dissolution kinetics of the $\delta$-phase different in the 625 nickel-based weld metals.

Xing et al. ${ }^{[43-45]}$ evaluated the effect of post-weld heat treatment temperature on the microstructure of Inconel 625 and found that at $950{ }^{\circ} \mathrm{C}$, the $\gamma$ " phase and the $\delta$ phase disappeared, similar to the behavior observed in this study. In addition, the authors reported that small amounts of blocky secondary phases appeared at the grain boundaries, which were identified by TEM analysis as $\mathrm{M}_{6} \mathrm{C}$-type carbide, with a face-centered cubic (fcc) structure and lattice parameter of $1.12 \mathrm{~nm}$. Thomas \& Tait ${ }^{[19]}$ also reported some precipitates at grain boundaries. The EDS analysis of those particles indicated that they were rich in molybdenum and niobium, which has led the authors to conclude that they were carbides of the $\mathrm{M}_{6} \mathrm{C}$ type. Similar results were found by Ferrer et al. ${ }^{[44-46]}$ and Burke \& Miller. ${ }^{[45-47]}$ This reinforces the suspicions that the thin precipitation along the grain boundaries are particles of $\mathrm{M}_{6} \mathrm{C}$ carbides. 
In addition, the results obtained by XRD analysis were consistent with the ones

reported in literature. ${ }^{[46-48]}$ This result confirms that most probably the whole volume of Laves phase were consumed during the aging treatment, providing the niobium necessary for the formation the of $\delta$-phase. This behavior is in agreement with the microstructural observations performed by SEM.

Evaluating the results obtained in Charpy-V impact test for $650{ }^{\circ} \mathrm{C}$ aged condition was found that energy absorbed varied as a function of aged time. As reported by Thomas \& Tait, ${ }^{[19]}$ the heat treatment at comparatively modest temperatures ranging from 650 to $700^{\circ} \mathrm{C}$ and for reasonable times of 6-12 h proved beneficial in regenerating the toughness of some alloys.

Notwithstanding, the behavior exhibited by the post aging material was consistent with the microstructural changes previously reported. From the as-welded sample to $10 \mathrm{~h}$ aged sample, a small dissolution of Laves phase was observed, this implicated in an increase in toughness. For longer times of exposures $(100-200$ h), the main microstructural changes were the dissolution of the Laves phase and precipitation of nanometric particles at grain boundaries. If on one hand the decrease in the volume fraction of Laves phase has proved interesting to improve the impact resistance, on the other hand the precipitation of finely dispersed nanosized particles at grain boundaries and sub-grain boundaries was found to be harmful to toughness (impact test).

Also for 100 and $200 \mathrm{~h}$ of exposure at $650{ }^{\circ} \mathrm{C}$ the presence of large blocks of $\mathrm{NbC}$ carbides and cubic NbTi complex were found, which remained from solidification. However, these particles probably have low or no effect on toughness, since in another study, carried out by Silva et al. ${ }^{[48-49]}$ evaluating the effect of the interpass temperature on mechanical properties in weld metal of 625 alloy, these particles were found. The results of the Charpy-V impact test at cryogenic temperature $\left(-196^{\circ} \mathrm{C}\right)$ showed no significant differences among the 
weld conditions and the level of energy absorbed was higher than $100 \mathrm{~J}$. Therefore, it is believed that the harmful effect on impact strength was due to the precipitation along the grain boundaries.

For the conditions aged at $950{ }^{\circ} \mathrm{C}$, a different behavior was observed. There was a significant drop in fracture toughness for the sample with $10 \mathrm{~h}$ treatment. Then, it was perceived an increasing toughness, returning at about the same level as-welded condition. This drop in the impact strength for the sample of $950{ }^{\circ} \mathrm{C}$ and $10 \mathrm{~h}$ may be attributed to precipitation of the delta phase needles precipitated in interdendritic regions. This indicates a detrimental effect of precipitation. For $100 \mathrm{~h}$ treatment at $950{ }^{\circ} \mathrm{C}$, there was a significant reduction in the amount of the delta phase, which resulted in a recovery of the impact resistance. For $200 \mathrm{~h}$ treatment, as reported above, a microstructure consisting of only large blocks of $\mathrm{Nb}$ carbides and cubic precipitates of $\mathrm{NbTi}$ carbides/nitrides was found. Although nanometric precipitation along the grain boundaries has been reported, this was less intense compared to those observed for aging at $650{ }^{\circ} \mathrm{C}$. Therefore, the results of impact resistance indicate that this microstructural condition was not detrimental to the weld properties.

According Mittra et al., ${ }^{[18]}$ the ductility of which alloy after $1200 \mathrm{~h}$ of aging at $540^{\circ} \mathrm{C}$ $(813 \mathrm{~K})$ is seen to be much higher than that of all samples aged at $700^{\circ} \mathrm{C}(973 \mathrm{~K})$ and $850^{\circ} \mathrm{C}$ $(1123 \mathrm{~K})$. The formation of large plate-shaped $\delta$ phases at $850^{\circ} \mathrm{C}(1123 \mathrm{~K})$ results in lower strength and ductility compared to that of $700^{\circ} \mathrm{C}(973 \mathrm{~K})$. A considerable amount of $\delta$ formation after $1200 \mathrm{~h}$ of isothermal holding is also seen to produce $\{111\}$ plane facets. However, fine micro-dimples of uniform size are seen along the facets of the fractograph. Since the ductility and toughness of the Ni-fcc matrix is very high, the reduction in impact strength was lower than expected for aged conditions, but its influence was enough to observe the behavior that was directly linked with the microstructural changes. 

$650-700{ }^{\circ} \mathrm{C}$ was most successful for the recovery of some toughness as observed in the asreceived material. However, the toughness still remained low compared to new material. It is

640

possible that this was due to the formation of the orthorhombic $\delta$ phase. Another works ${ }^{[49-50]}$ has found that a reduction in Charpy impact energy to around 180 to $\mathrm{J} / \mathrm{cm}^{2}$ occurred as a result of intermediate temperature ageing, which was attributed primarily to the formation of the orthorhombic $\delta$ phase.

About fractography images of the conditions aged at $650^{\circ} \mathrm{C}$, it was observed that the changes in toughness do not reflected in the fractography behavior. The ductile characteristic observed in the recovered condition aged for $10 \mathrm{~h}$ was the same noted for the worst toughness condition, which was aged for a long period of exposure (200h). For all conditions aged at $950^{\circ} \mathrm{C}$ were observed a ductile fracture, even for $10 \mathrm{~h}$ of treatment that show the lowest impact toughness. According to Mittra et al., ${ }^{[18]}$ the most cases of heat treatment performed on Inconel 625 , the nickel matrix hold the ductile fracture characteristic even for significant changes in the microstructure, since the nickel matrix holding the resistant to impact test.

As shown previously, the fractographies indicates the presence of some small particles into the cavities of the dimples. In addition, the fracture features reveled some similarity with microstructure, in which the crack propagation pattern and dimples were aligned along a specific direction (Figures $19 \mathrm{~b}$ and 20a), similar to dendrite growth orientation assumed during solidification.

The presence of precipitates located into the dimples cores suggest that the interdendritic regions observed in microstructure were the prefer region to open cavities under deformation. In this case, the precipitates acted as pinning points, blocking the movement of dislocations and preventing the plastic deformation of the Ni matrix, which is in accordance 
661

662

663

664

665

666

667

668

669

670

671

672

673

674

675

676

677

678

679

680

681

682

683

684

with reported by Sheng et al. ${ }^{[51]}$ On the other hand, the dendrite core regions are precipitate free and show an impoverishment of solid solution elements such as $\mathrm{Mo}, \mathrm{Nb}$ and $\mathrm{Ti}$, when compared with the interdendritic regions, due to the microsegregation phenomena, ${ }^{[33]}$ which probably reduced the mechanical strengthening and improve the ductility of the dendrites formed by $\gamma$-fcc matrix.

The EDS mapping in the sample aged at $950^{\circ} \mathrm{C}$ for $200 \mathrm{~h}$, highlighted the presence of $\mathrm{Nb}$-rich carbides and cubic precipitates of $\mathrm{NbTi}$ carbides/nitrides located mainly in the dimples cores, giving thus the support to the hypothesis that the precipitates act as barrier to movement of dislocations.

Thus, is possible to correlate the fracture surface with microstructure, assuming that the dimples arise from small precipitates into interdendritic regions, and the dendrite core which is precipitate free, is necked and sheared during further yielding.

Concerning to the micro hardness test, the results were also evaluated and its behavior was statistically significant, which varied as a function of aged time. Thomas \& Tait ${ }^{[19]}$ evaluated the hardness of an aged 625 alloy and found $230 \mathrm{HV}_{30}$ to annealed material conditions, while for samples aged at $650{ }^{\circ} \mathrm{C}$ after 3, 6 and 12 hours resulted in hardness values ranging from 303 to $317 \mathrm{HV}_{30}$. In fact, the $10 \mathrm{~h}$ aged sample achieved hardness similar to that found by Thomas \& Tait ${ }^{[19]}$ for aged materials $(300 \mathrm{HV})$. Nonetheless, the materials studied were not weld metals, therefore the initial precipitation of Laves phase due to solidification would probably make the hardness higher if compared to annealing conditions. In addition, the authors reported that the results of hardness for a pipe that had been in service for approximately $50,000 \mathrm{~h}$ at $500{ }^{\circ} \mathrm{C}$, a value of $444 \mathrm{HV}_{30}$ was found. Kirman and Warrington ${ }^{[50,52]}$ also reported that the aged material at $650{ }^{\circ} \mathrm{C}$ achieved a peak hardness of $400 \mathrm{HV}$ after about $500 \mathrm{~h}$. Therefore, the hardness values measured for samples aged at 650 
685

686

687

688

689

690

691

692

693

694

695

696

697

698

699

700

701

702

703

704

705

706

${ }^{\circ} \mathrm{C}$ for higher time of exposure evaluated in this study (100 and $\left.200 \mathrm{~h}\right)$ are in agreement with those in the literature.

Considering the samples aged at $950{ }^{\circ} \mathrm{C}$, the hardness measures increased continuously from 0 until $100 \mathrm{~h}$, going up from $291 \mathrm{HV}(0 \mathrm{~h})$ to $395 \mathrm{HV}$ (10 h) and $469 \mathrm{HV}$ for aging times of $100 \mathrm{~h}$. However, on increasing the aging time to $200 \mathrm{~h}$, the hardness decreased to $422 \mathrm{HV}$. This behavior shows that intense $\delta-\mathrm{Ni}_{3} \mathrm{Nb}$ phase precipitation after $10 \mathrm{~h}$ exposure, produces an increment of $100 \mathrm{HV}$ approximately, compared to the as-welded condition (0h).

Nevertheless, the maximum value of hardness was achieved when the 625 alloy weld metal was exposed to $950{ }^{\circ} \mathrm{C}$ for $100 \mathrm{~h}$. For this particular condition, the microstructure shows a significant reduction in the amount of $\delta$-phase precipitated. Also for $200 \mathrm{~h}$ of exposure, the hardness value does not drop significantly, even experiencing an expressive microstructural variation, denoted by a complete delta-phase dissolution and a very low amount of particles precipitated, according to SEM analysis.

Comparing the hardness values with the toughness results obtained in the Charpy-V impact test, it was possible to observe that the $\delta$-phase, whose precipitation was quite intense and highlighted an embrittlement effect denoted by a drop in impact resistance, did not cause any significant effect on hardness. On the other hand, for the condition of maximum hardness in the treatment of $950{ }^{\circ} \mathrm{C}(100 \mathrm{~h})$, the microstructure had a very smaller amount of delta phase and experienced a higher impact resistance when compared to the $10 \mathrm{~h}$ aged condition. Thereby, it was not possible to establish a direct correlation between hardness and impact resistance for the 625 alloy aged at $950{ }^{\circ} \mathrm{C}$. 

were not observed by microscopic techniques used in this study. The main microstructural change from 0 and $10 \mathrm{~h}$ to 100 and $200 \mathrm{~h}$ at $650{ }^{\circ} \mathrm{C}$ was the Laves phase dissolution and $\delta$ $\mathrm{Ni}_{3} \mathrm{Nb}$ precipitation followed by dissolution together Laves phase at $950^{\circ} \mathrm{C}$, which may supply for example the $\mathrm{Nb}$ necessary to precipitation of another phase such as $\gamma "\left(\mathrm{Ni}_{3} \mathrm{Nb}\right)$.

As the analytical techniques used are not able to confidently identify other precipitates one should not assume the probable formation of $\gamma^{\prime}, \gamma^{\prime \prime}$ or $\mathrm{Ni}_{2}(\mathrm{Cr}, \mathrm{Mo})$ dispersion strengthening phases. Based on Kumar et al. ${ }^{[37-53]}$, who studied a service tube of Inconel 625 alloy exposed to $\sim 600{ }^{\circ} \mathrm{C}$ for $\sim 60,000 \mathrm{~h}$, a short duration aging at $650{ }^{\circ} \mathrm{C}$ up to $10 \mathrm{~h}$ caused a dissolution of the $\mathrm{Ni}_{2}(\mathrm{Cr}, \mathrm{Mo})$ phase. When the alloy was aged at $850{ }^{\circ} \mathrm{C}$ for $1 \mathrm{~h}$, there was a complete dissolution of both $\gamma^{\prime \prime}$ and $\mathrm{Ni}_{2}(\mathrm{Cr}, \mathrm{Mo})$ precipitates. $\gamma^{\prime}$ or $\gamma^{\prime \prime}$. However, phases such as $\gamma^{\prime}$ and $\gamma^{\prime \prime}$ cannot be identified by XRD due to their small size. Therefore, the possibility that there was formation of these phases cannot be discarded, since, as is well established by numerous studies, that these phases are formed together with Laves and delta phases in aged conditions ranging from $600{ }^{\circ} \mathrm{C}$ to $900{ }^{\circ} \mathrm{C}^{[43-47]}$. Therefore, as previously mentioned, it is believed that some $\gamma$ " may have precipitated, which would justify the increase in hardness.

\section{Conclusions}

Based on the results obtained experimentally in this study about the effect of aging temperature and exposure time on the microstructure and mechanical properties of 625 alloy weld metal, the following conclusions can be pointed out: 
(1) The microstructural evolution at $650{ }^{\circ} \mathrm{C}$ revealed that the Laves phase rich in $\mathrm{Nb}$ produced

732

733 by microsegregation during solidification was continuously dissolved with the increase of exposure time and an intense precipitation of nanosized particles along the grain boundaries was observed. For the TiNb complex carbides/nitrides found in the as-welded condition, no change was observed.

(2) For the aging temperature of $950{ }^{\circ} \mathrm{C}$ for a short exposure time, there was an intense precipitation of $\mathrm{Ni}_{3} \mathrm{Nb} \delta$-phases along the interdendritic region, and the Laves phase was partially dissolved and replaced by $\delta$-phases. For the longest exposure times, the $\delta$-phases were completely dissolved, and only the TiNb complex carbides/nitrides remained together with a very fine precipitation along $\gamma$-fcc matrix grain boundaries.

(3) In terms of the Charpy-V impact test results, the energy absorbed for 0 and $10 \mathrm{~h}$ samples aged at $650{ }^{\circ} \mathrm{C}$ was kept almost the same; however there was a decrease for the longer exposure times such as 100 and $200 \mathrm{~h}$. When the aging temperature was increased to $950{ }^{\circ} \mathrm{C}$, the impact energy absorbed fell at $10 \mathrm{~h}$ exposure but increased for longer exposure times. The impact energy values achieved were regarded as very good, and in general were higher than $100 \mathrm{~J}$.

(4) The aging effect at $650^{\circ} \mathrm{C}$ on the hardness behavior showed a good correlation with the response of impact resistance, since when there was an increment in hardness there was a drop in the impact energy absorbed. The same behavior was not found for the treatment at $950{ }^{\circ} \mathrm{C}$, in which the lower impact energy did not correspond to the maximum hardness condition.

(5) The non-destructive techniques for detection of microstructural changes in nickel-based alloys based on ultrasound signals was not able to identify the microstructural changes for the temperature of $950{ }^{\circ} \mathrm{C}$, but demonstrated to be a very promising technique for monitoring 
755 phase changes in the nickel-based alloys for temperature of $650{ }^{\circ} \mathrm{C}$. Thus, requires further studies to identify the technical capabilities and limitations for temperatures above $650{ }^{\circ} \mathrm{C}$.

\section{Acknowledgments}

All authors are also grateful for the support given by the following laboratories of the Federal University of Ceará: Welding Research \& Technology Laboratory (LPTS-UFC), Materials Characterization Laboratory (LACAM), Center of Non-Destructive Testing (CENDE), X-ray Difraction Laboratory (LRX-UFC), Analytical Central - UFC/CTINFRA/MCTI-SISNANO/Pró-Equipamentos CAPES. The authors would also like to thank the financial support given by the National Council for Research and Development (CNPq), Research and Projects Financing (FINEP), Coordination for the Improvement of People with Higher Education (CAPES) and finally to Petróleo Brasileiro S/A (Petrobras) in Brazil. Victor Hugo C. de Albuquerque received support from the CNPq via grants \#470501/2013-8 and \#301928/2014-2.

\section{References}

[1] F.G. Hodge: JOM, 2006, vol. 58, pp. 28-31.

[2] C.T. Sims, N.S. Stoloff, W.C. Hagel. Superalloys II. John Wiley \& Sons, New York, USA, 1987.

[3] J. N. Dupont, S. Babu, S. Liu: Metall. Mater. Trans. A, 2016, vol. 44, pp 3385-3410.

[4] P.M. Mignanelli, N.G. Jones, K.M. Perkins, M.C. Hardy, H.J. Stone: Mater. Sci. Eng. A, 2015, vol 621, pp. 265-271. 
[5] E. M. Miná, Y. C. da Silva, J. Dille, C. C. Silva: Metall. Mater. Trans. A, 2016, vol. 47A, pp 6138-6147.

[6] M. Sundararaman, L.Kumar,G. Eswara Prasad, P. Mukhopadhyay, S. Banerjee: Metall. Mat. Trans. A, 1999, vol. 30A, pp. 41-52.

[7] S.S. Hosseono, S. Nategh, A.A. Ekrami: J. Alloys Compd., 2012, vol. 512, pp. 340-350.

[8] L. M. Suave, J. Cormier, P. Villechaise, A. Soula, Z. Hervier, D. Bertheau, J. Laigo: Metall. Mater. Trans. A, 2014, Vol. 45A, pp 2963-2982.

[9] Y.J. Zhang, Y.J. Huang, L. Yang, J.G. Li: J. Alloys Compd., 2013, vol. 570, pp. 70-75.

[10] C.C. Silva, C.R.M. Afonso, A.J. Ramirez, M.F. Motta, H.C. Miranda, J.P. Farias: J. Alloys Compd., 2016, vol. 684, pp. 628-642.

[11] D. Verdi, , M.A. Garrido, C.J. Múnez, P. Poza: Mater. Des., 2015, vol. 67, pp. 20-27.

[12] T.E. Abioye, D.G. McCartney, A.T. Clare, Laser cladding of Inconel 625 wire for corrosion protection, J. Mater. Process. Technol. 217 (2015) 232-240.

[13] J.N. Dupont, Solidification of an Alloy 625 Weld Overlay, Metall. Mater. Trans. A. 27A (1996) 3612-3620.

[14] M. J. Cieslak, T. J. Headley, T. Kollie, A. D. Romig: Metall Trans A, 1988, vol. 19A, pp. 2319-2331.

[15] J. N. DuPont, C. V. Robino, J. R. Michael, M. R. Notis, A. R. Marder: Metall Mater Trans A, 29A (1998), pp. 2785-2796. 
[16] J. K. Chakravartty, J. B. Singh, M. Sundararaman: Mater. Sci. Technol. 2012, vol. 28, pp. 702-710.

[17] P. Liu, J.O. Nilsson: Mater. Sci. Technol. 1990, vol. 6, pp. 764-771.

[18] J. Mittra, S. Banerjee, R. Tewari, G.K. Dey: Mater. Sci. Eng. A., 2013, vol. 574, pp. 8693.

[19] C. Thomas, P. Tait: Int. J. Press. Vessels Pip.: 1994, vol. 59, pp. 41-49.

[20] S. Floreen, G.E. Fuch, W.J. Yang. In: E.A. Loria (Ed.), Superalloys 718, 625, 706 and Various Derivatives, TMS, Warrendale, PA (1994), pp. 13-37.

[21] J. J. Schirra, R. H. Caless, R. W. Hatala. In: E. A. Loria (Ed.), Superalloys 718, 625, 706 and Various Derivatives, TMS, Warrendale, PA (1991), pp. 375-388.

[22] V.H.C. Albuquerque, C.C. Silva, T.I.S. Menezes, J.P. Farias, J.M.R.S. Tavares: Microsc. Res. Tech., 2011, vol. 74, pp. 36-46.

[23] V. L. A. Freitas, V. H. C. Albuquerque, E. M. Silva, A. A. Silva, J. M. R. S. Tavares: Mater. Sci. Eng. A: 2010, vol. 527, pp. 4431-4437.

[24] E.M. Silva, V.H.C. Albuquerque, J.P. Leite, A.C.G. Varela, E.P. Moura, J.M.R.S. Tavares: Mater. Sci. Eng. A., 2009, vol. 516, pp. 126-130.

[25] V. H. C. Albuquerque, C. C. Silva, P. G. Normando, E. P. Moura, J. M. R. S. Tavares: Mater. Des., 2012, vol. 36, pp. 37-47.

[26] T. M. Nunes, V. H. C. Albuquerque, J. P. Papa, C. C. Silva, P. G. Normando, E. P. Moura, J. M. R. S. Tavares: Expert Syst. Appl., 2013, vol. 40, pp. 3096-3105. 
[27] V.H.C. Albuquerque, C.V. Barbosa, C. C. Silva, E.P. Moura, P.P. Rebouças Filho, J.P.

[28] F.E. Silva, F.N.C. Freitas, H.F.G. Abreu, L.L. Gonçalves, E.P. Moura, M.R. Silva: J. Mater. Sci., 2011, vol. 46, pp. 3282-3290.

819

820

821

822

823

824

825

826

827

828

829

830

831

832

833

[29] E. M. Silva, J. P. Leite, F. A. França Neto, W. M. L. Fialho, V. H. C. Albuquerque, J. M.

R. S. Tavares: J. Test. Eval., 2016, vol. 44, pp. 2003-2013.

[30] P. G. Normando, E. P. Moura, J. A. Souza, S. S. M. Tavares, L. R. Padovese: Mat. Sci. Eng. A, 2010, vol. 527, pp. 2886-2891.

[31] ASNT 147/147WCD, Nondestructive Testing Handbook, 3rd ed., vol. 7, Ultrasonic Testing, American Society for Nondestructive Testing, 2007.

[32] C.T. Sims, N.S. Stoloff, W.C. Hagel (Eds.) Superalloys II. Wiley, New York (1987).

[33] C. C. Silva, H. C. Miranda, M. F. Motta, J. P. Farias, C. R. M. Afonso, A. J. Ramirez: J. Mater. Res. Tech., 2013, vol. 2, pp. 228-237.

[34] C. C. Silva, C. R. M. Afonso, A. J. Ramirez, M. F. Motta, H. C. Miranda, J. P. Farias: Sold. Insp., 2012, vol. 17, pp. 251-263.

[35] W. Lengauer. Transition metal carbides, nitrides and carbonitrides. R. Riedel (Ed.), Handbook of ceramic hard materials, vol. 1Wiley-VCH, Weinheim (2000), pp. 202-252.

[36] N.D. Evans, P.J. Mazias, J.P. Shingledecker, Y. Yamamoto: Mater. Sci. Eng. A, 2008, vol. 498, pp. 412-420. 
834 [37] M. Sundararaman, P. Mukhopadhyay, S. Banerjee: Metall. Trans. A, 1988, vol. 19A, pp. $835 \quad 453-465$

836

[38] S.H. Zhang, H.-Y. Zhang, M. Cheng: Mater. Sci. Eng. A: 2011, vol. 528, pp. 6253-6258.

837 [39] N. Kashaev, M. Horstmann, V. Ventzke, S. Riekehr, N. Huber: J. Mater. Res. Tech., 838 2013, vol. 2, pp. 43-47.

839

[40] J. Deleume, J.-M. Cloué, E. Andrieu: J. Nucl. Mater, 2008, vol. 382, pp. 70-75.

840 [41] D.D. Krueger. In: Loria EA, editor. Superalloy 718 - metallurgy and application. TMS; 841 1989. p. 279-96.

842

[42] V. Shankar, M. Valsan, K. Bhanu Sankara Rao, S.L. Mannan: Scripta Mater, 2001, vol. 843 44, pp. 2703-2711.

844

[43] M.D. Mathew, K. Bhanu Sankara Rao, S.L. Mannan: Mater. Sci. Eng. A, 2004, vol. 372, 845 pp. 327-333.

846

[44] D. Cai, W. Zhang, P. Nie, W. Liu, M. Yao: Mater. Charact. 2007, vol. 58, pp. 220-225.

847

[45] X. Xing, X. Di, B. Wang: J. Alloys Compd., 2014, vol. 593, pp. 110-116.

848 [46] L. Ferrer, B. Pieraggi, J.F. Uginet: Superalloys 718, 612 and Various Derivatives, E. A. 849 Loria, ed., TMS, Warrendale, PA, 1991.

850 [47] M.G. Burke, M.K. Miller: Superalloys 718, 612 and Various Derivatives, E. A. Loria, 851 ed., TMS, Warrendale, PA, 1991.

852 [48] C.B. Shoemaker, A.H. Fox, D.P. Shoemaker: Acta Cryst. 1960, vol. 13, pp. 585-587. 
853 [49] C.C. Silva, H.C. Miranda, M.F. Motta, D.C.F. Ferreira, R.R. Marinho, G. Dalpiaz: 854 Mater. Sci. Forum, 2014, vol. 783-786, pp. 2816-2821.

855 [50] M. Kohler: Superalloys 718, 612 and Various Derivatives, E. A. Loria, ed., TMS, 856 Warrendale, PA, 1991.

857 [51] J. Sheng, S. Huang, J.Z. Zhou, Z.W. Wang: Eng. Fract. Mech. 2017, vol. 169, pp. 99858108.

859 [52] I. Kirman, D.H. Warrington: Metall. Trans. A., 1970, pp. 2667-2675.

860 [53] A. Kumar, V. Shankar, T. Jayakumar, K.B.S. Rao, B. Raj: In: Proc. Europ. Conf. 861 Nondestr. Test., J. Serrano, ed., Barcelona, Spain, 2002.

862

863

864

865

866

867

868

869

870 
873 Figure 20. Experimental setup used in the welding process: (a) robotic system, (b) GTAW

874

875

876

877

878

879

880

881

882

883

884 guide wire feed and torch.

Figure 21. Schematic diagram showing: (a) the location and orientation of the Charpy-V specimens taken from the weld cladding; (b) dimensions of the Charpy impact specimens.

Figure 22. (a) SEM micrographs using secondary electrons showing the Ni-fcc matrix and the secondary phases of the sample as-welded, (b) In detail, an agglomerate formed by a cuboidal precipitate of $\mathrm{NbC/TiN}$ wrapped by $\mathrm{Nb}$-rich Laves phase, (c) EDS spectrum of Laves phase, (d) EDS spectrum of $\mathrm{NbC/TiN}$ cuboidal precipitate.

Figure 23. (a) Representative microstructure of the sample aged at $650^{\circ} \mathrm{C}$ for 10 hours; (b) Detail of the Eutectic-like Laves phase and some cuboidal precipitates of NbTi carbides/nitrides.

Figure 24. (a) Representative microstructure of the sample aged at $650^{\circ} \mathrm{C}$ for 100 hours; (b) Detail decomposition of the Laves phase with significantly reduced dimensions, and where some cuboidal precipitates of carbides/nitrides can also be seen.

Figure 25. (a) Representative microstructure of the sample aged at $650{ }^{\circ} \mathrm{C}$ for 200 hours showing practically only NbTi carbides/nitrides; (b) Detail showing a small particle of Laves phase reminiscent of the incomplete decomposition.

Figure 26. (a) Grain boundary precipitation in an early stage observed in the sample aged at $650{ }^{\circ} \mathrm{C}$ for 100 hours; (b) Grain boundary precipitation like continuous film observed in the sample aged at $650{ }^{\circ} \mathrm{C}$ for 200 hours.

Figure 27. (a) Microchemical analysis of nano-sized precipitates along the grain boundary performed by EDS; (b) EDS spectrum of the particle; and (c) Spectrum of the matrix adjacent to the precipitate. 
Figure 28. Phase diagram calculated by Thermo-Calc ${ }^{\odot}$ based on the weld metal chemical composition.

Figure 29. Precipitation along the grain boundary and a very thin precipitation dispersed into the interdendritic region which may be an indicative of the $\gamma^{\prime \prime}\left(\mathrm{Ni}_{3} \mathrm{Nb}\right)$ phase.

Figure 30. Examples of SEM micrographs using secondary electrons showing the aged microstructure at $950{ }^{\circ} \mathrm{C}$ for 10 hours taken from different positions.

Figure 31. Details of TCP phases in the microstructure showing $\mathrm{Ni}_{3} \mathrm{Nb} \delta$-phase needles together with $\mathrm{Nb}$-rich Laves phases into the interdendritic region. Also a large cubic precipitate of NbTi complex carbide/nitrite was observed.

Figure 32. Chemical mapping obtained by EDS for the alloying elements: (a) SEM image, (b) $\mathrm{Mo},(\mathrm{c}) \mathrm{Nb},(\mathrm{d}) \mathrm{Ni}$, and (e) Ti.

Figure 33. Examples of SEM micrographs using secondary electrons showing the aged microstructure at $950{ }^{\circ} \mathrm{C}$ for 100 hours taken from different positions.

Figure 34. In detail, some secondary phases formed by Laves phase unsolved, $\delta$-phase $\mathrm{Ni}_{3} \mathrm{Nb}$ needle-like and some NbTi carbide/nitride cuboidal particles. Sample aged at $950{ }^{\circ} \mathrm{C}$ for $100 \mathrm{~h}$.

Figure 35. Examples of SEM micrographs using secondary electrons showing the aged microstructure at $950{ }^{\circ} \mathrm{C}$ for 200 hours taken from different positions. (a) and (b) Regions showing cubic NbTi carbides/nitrides and large NbC carbides; (c) and (d) Small cubic NbTi carbides/nitrides and a fine precipitation at the grain boundaries can be seen.

Figure 36. X-ray diffractograms from powder extraction concentrated in the secondary phases: (a) Sample aged at $650{ }^{\circ} \mathrm{C}$ for $10 \mathrm{~h}$; and (b) Sample aged at $950{ }^{\circ} \mathrm{C}$ for $10 \mathrm{~h}$.

Figure 37. Results of the effect of aging temperature and time on the absorbed energy in the Charpy-V impact test, evaluated by analysis of variance.

Figure 38. Fractography images of the conditions at $650^{\circ} \mathrm{C}$ for (a) $10 \mathrm{~h}$ and (b) $200 \mathrm{~h}$. 
921 Figure 20. Fractography images of the conditions at $950^{\circ} \mathrm{C}$ for (a) $10 \mathrm{~h}$ and (b) $200 \mathrm{~h}$.

922 Figure 21. EDS mapping of the condition aged at $950^{\circ} \mathrm{C}$ for $200 \mathrm{~h}$. (a) Fracture surface image

923 and yours respective chemical mapping of the elements (b) $\mathrm{Ti}$, (c) $\mathrm{Nb}$, (d) Mo, (e) $\mathrm{Ni}$ and (f) 924 Cr.

925 Figure 22. Results of the effect of aging temperature and time on the microhardness Vickers 926 test evaluated by analysis of variance.

927 Figure 23. Ultrasonic a) velocity and b) attenuation measurements.

928

929 
931

932 Table 1. Chemical composition in percent weight of the weld metal/coating and base metal.

933 Table 2. Results of the chemical composition analysis performed by SEM/EDS on: (a) Laves 934 phase and (b) Complex NbTi carbide/nitride.

935 Table 3. Mean weld metal chemical composition in \% wt.

936 Table 4. Impact strength of as-welded and aged condition obtained by the Charpy-V impact 937 test.

938

939 


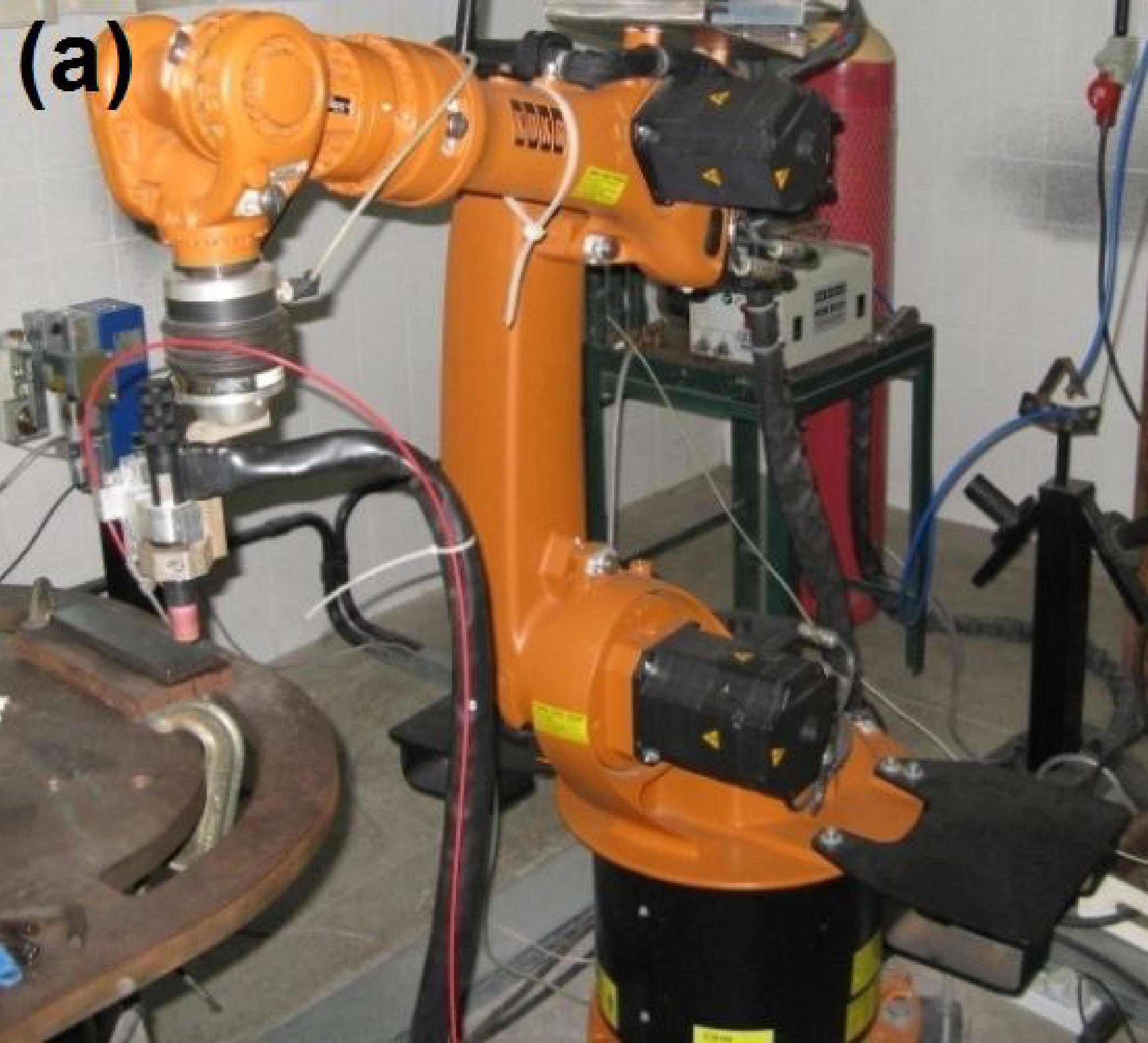




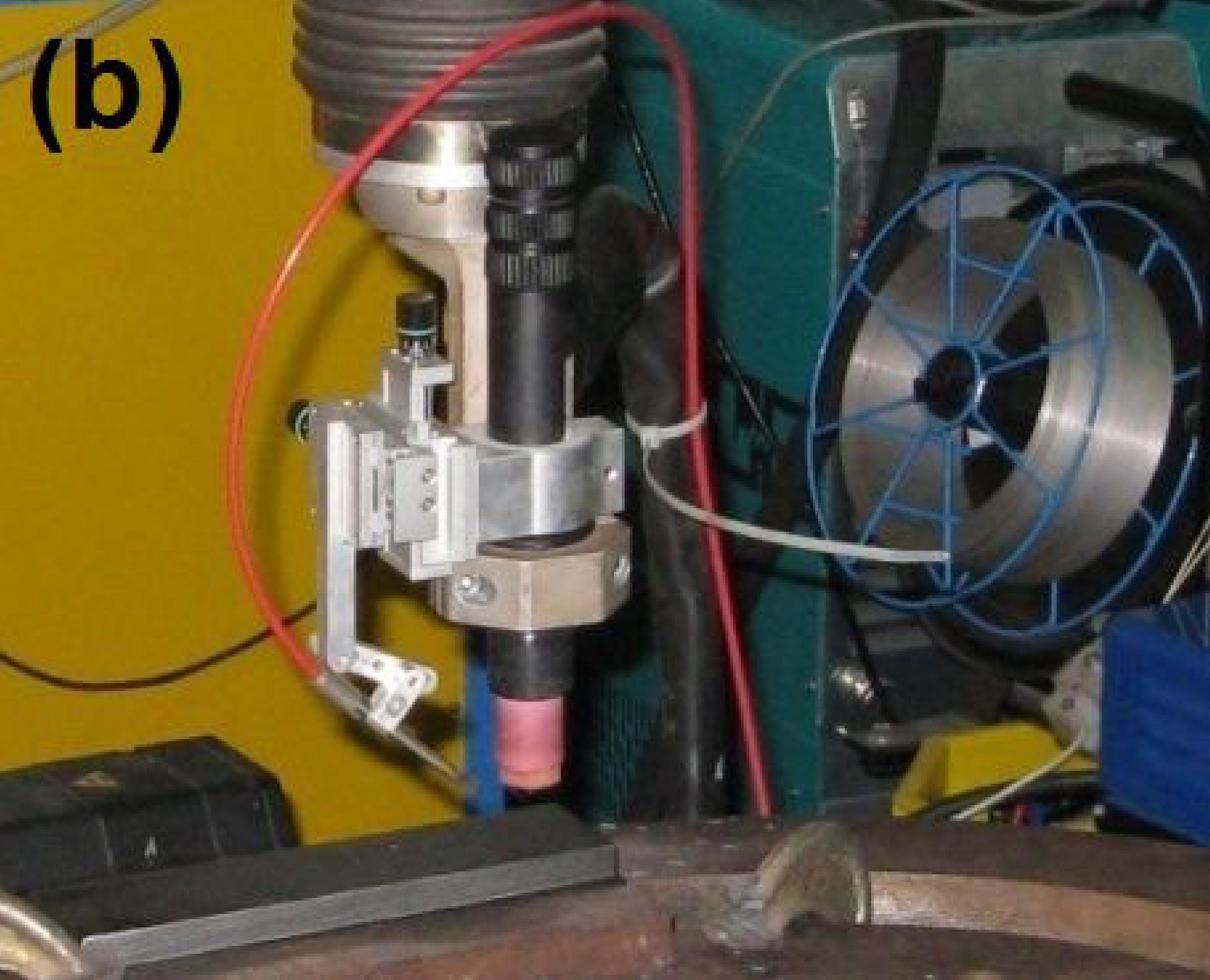


(a)

Cladding

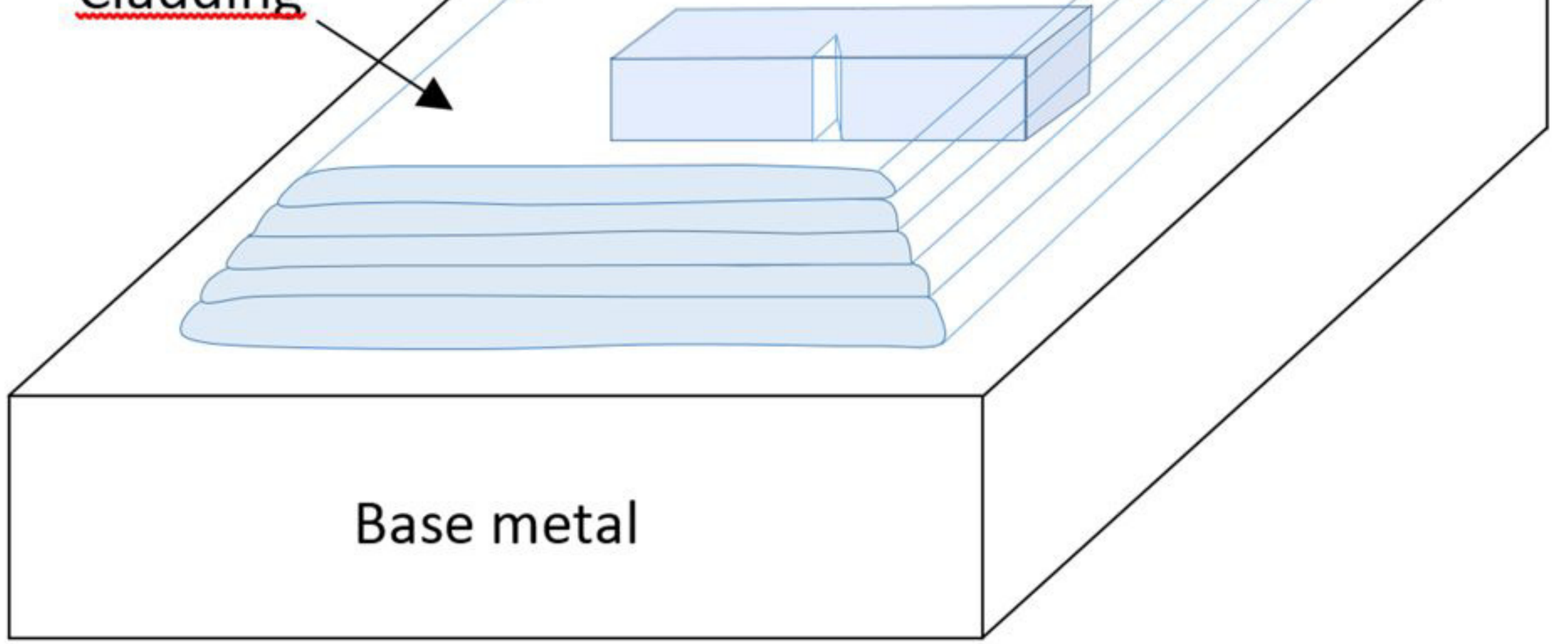


I

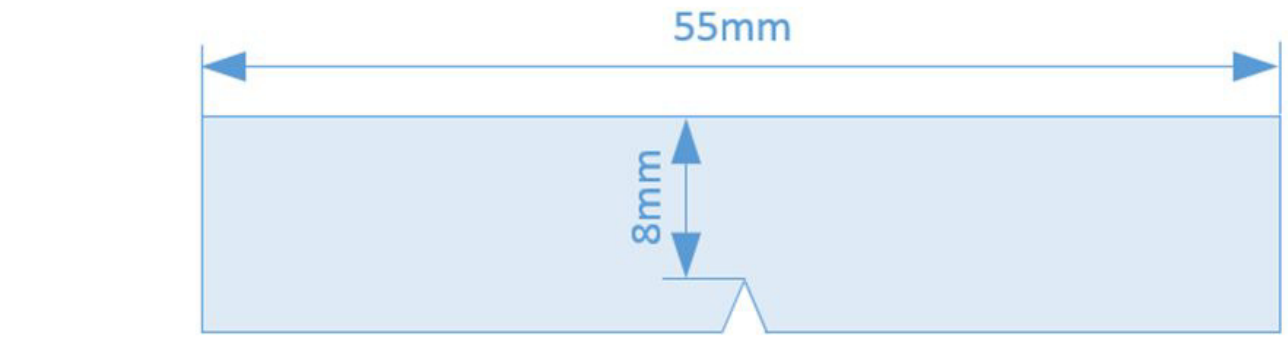
(b)
$10 \mathrm{~mm}$
$55 \mathrm{~mm}$

\section{.}

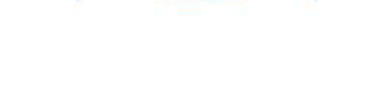


(b)

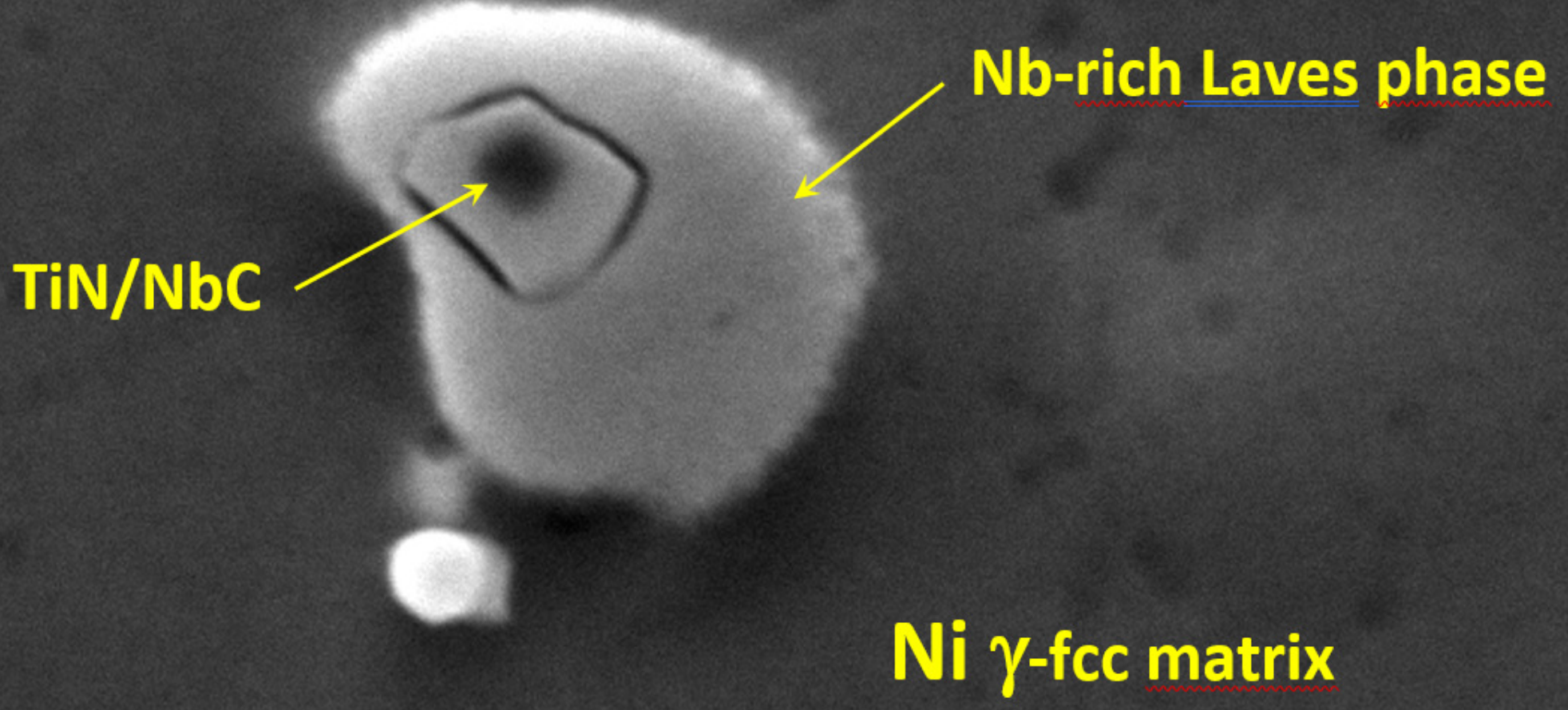

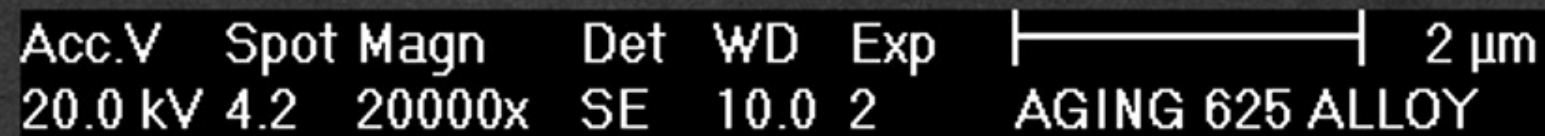




\section{(c)}

NiL

NiK

MoL

$\mathrm{Cr}$ 


\section{\&A3. \\ $\sin \frac{8}{6}=3 .$.}

8.

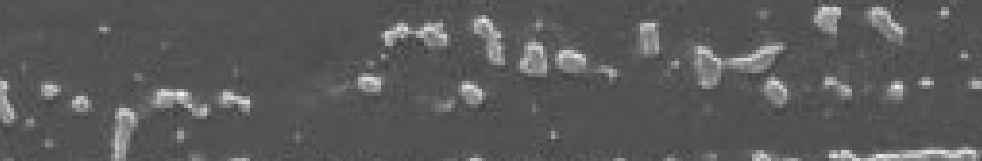

․ $\operatorname{cis}: 0^{\circ}$

$$
\begin{aligned}
& \therefore+4,7000+
\end{aligned}
$$

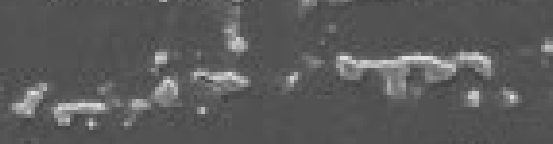

$$
\begin{aligned}
& \rightarrow \log ^{\circ}+2 \hat{s}^{2}
\end{aligned}
$$

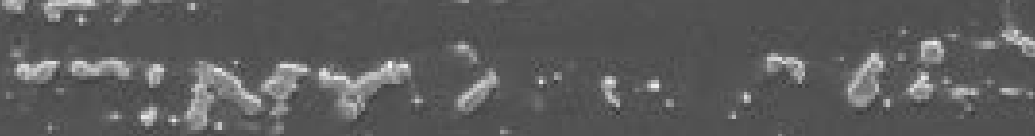

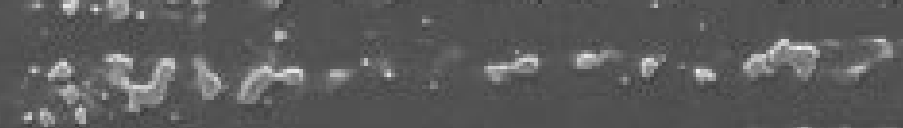

$$
\begin{aligned}
& \rightarrow \lim _{2} \text { o } 9 \text { : }
\end{aligned}
$$

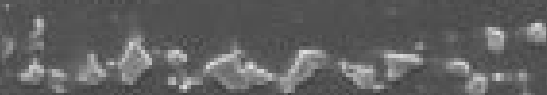

\section{$\cos ^{n} x^{n}, 2$}

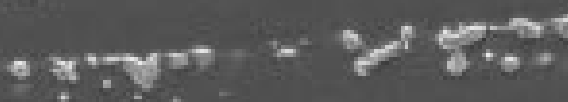

$$
\rightarrow: \infty, a+\infty, 0,0
$$

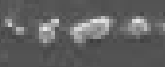

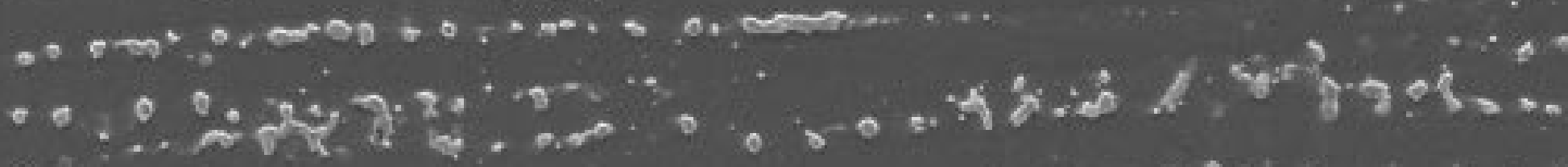

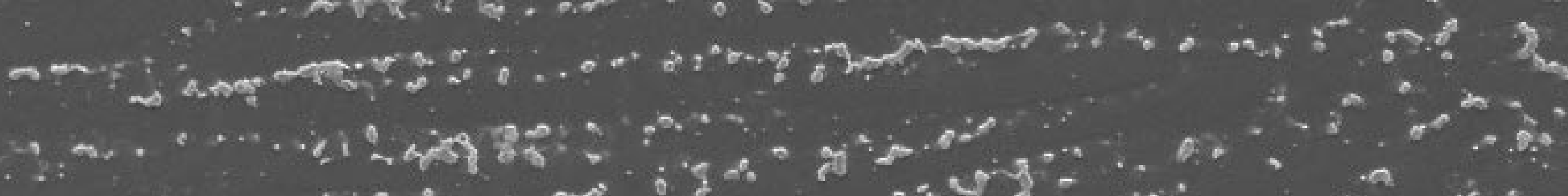

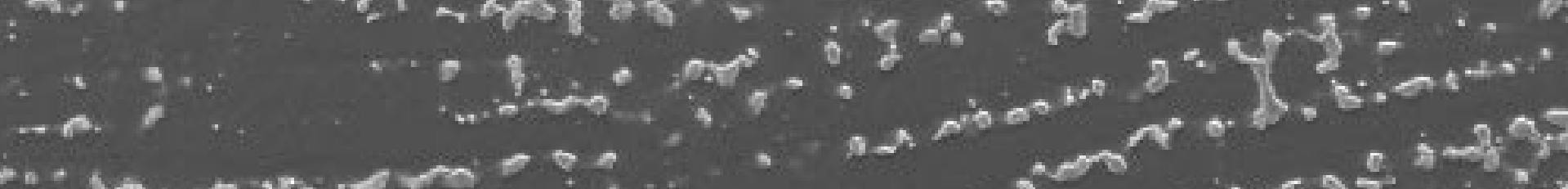

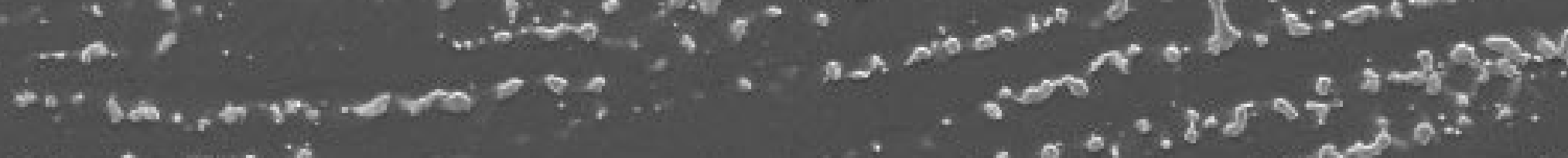
$+0,100,0 \%$ SE 10.01

\section{$100 \mu \mathrm{m}$}


(b)

Dissolution of

\section{Laves phase}

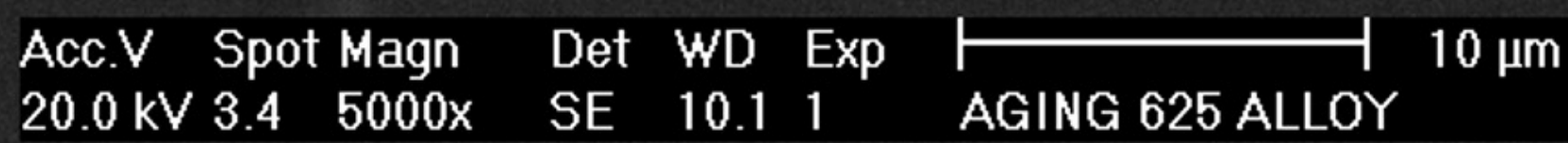




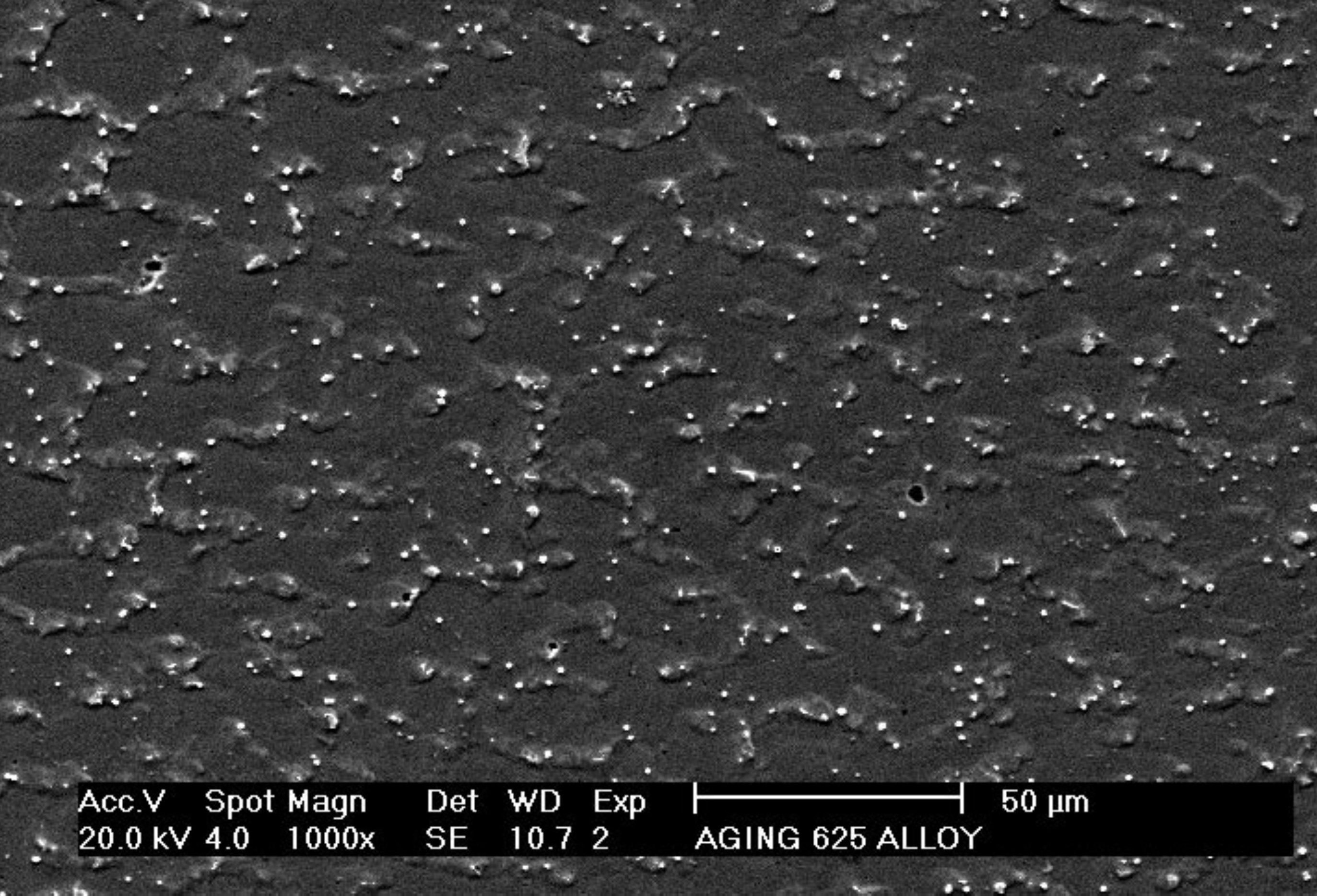




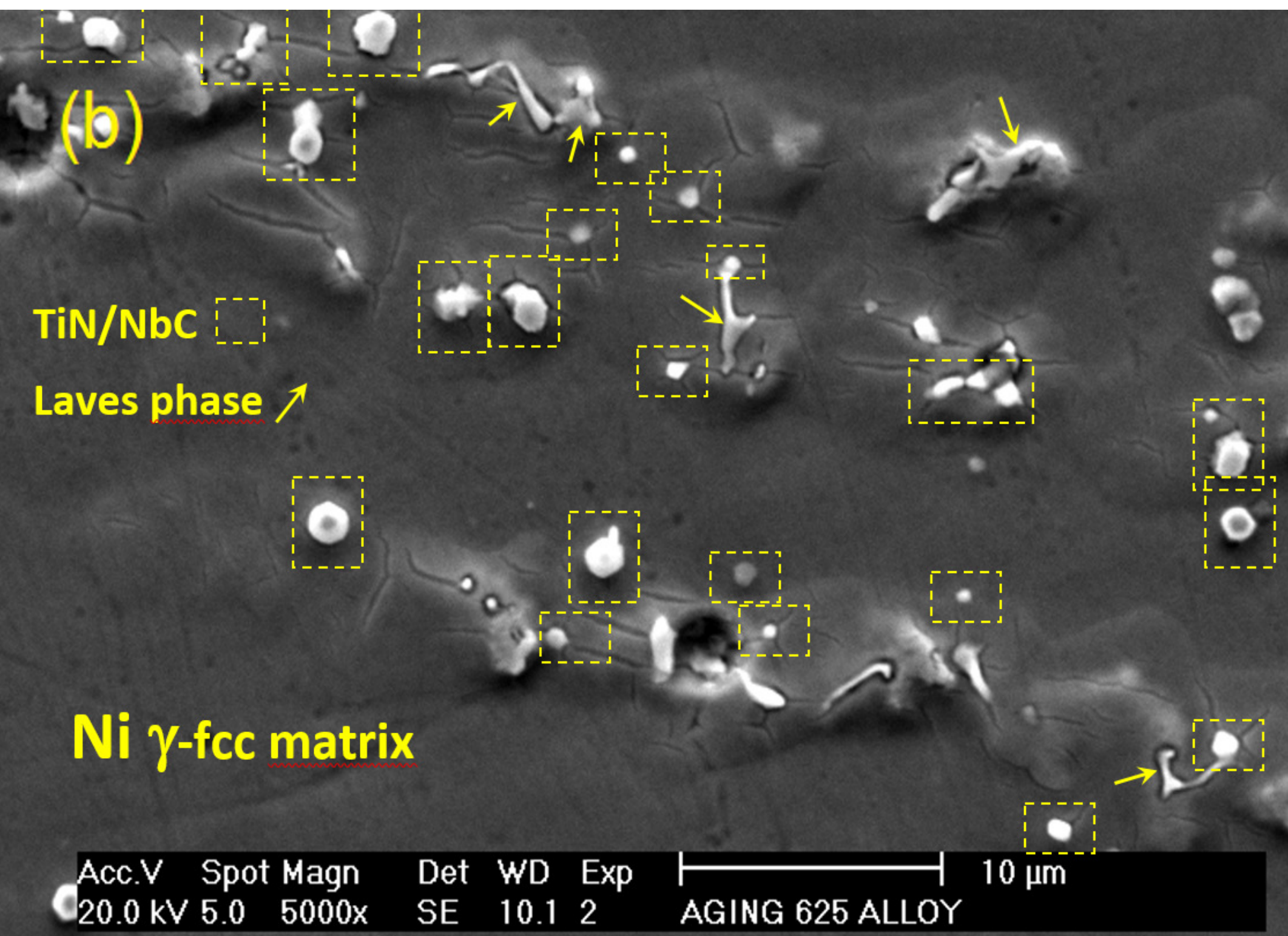




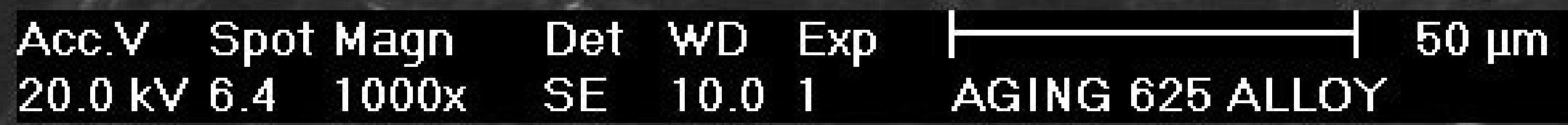




\section{(b)}

\section{NbC}

$\mathrm{NbC}$
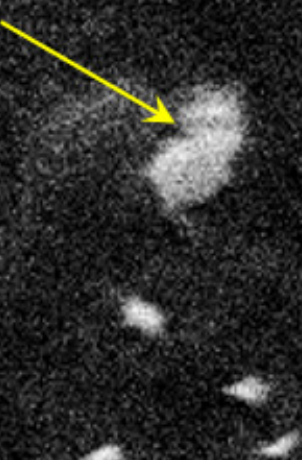

Acc.V Spot Magn $20.0 \mathrm{kV} 4.08000 \mathrm{x}$

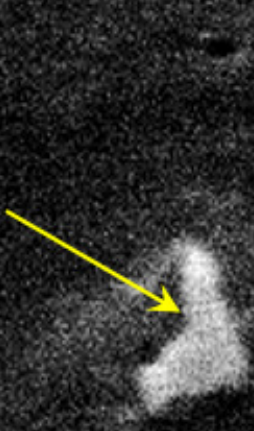
TiN/NbC

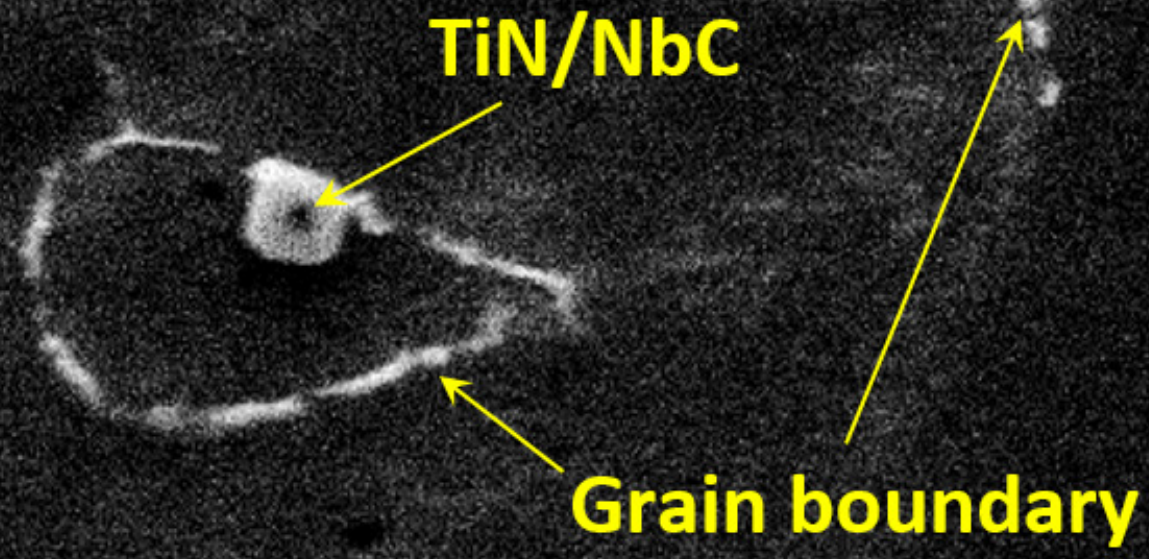
precipitation

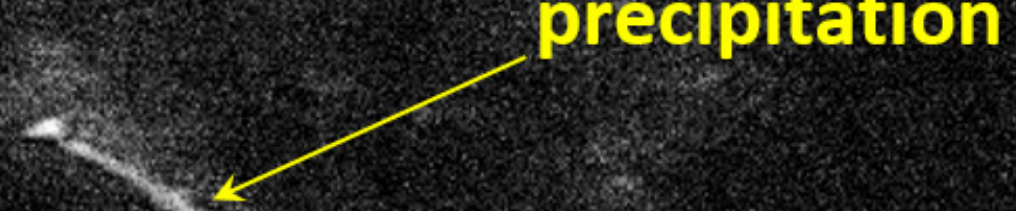




\section{(b)}
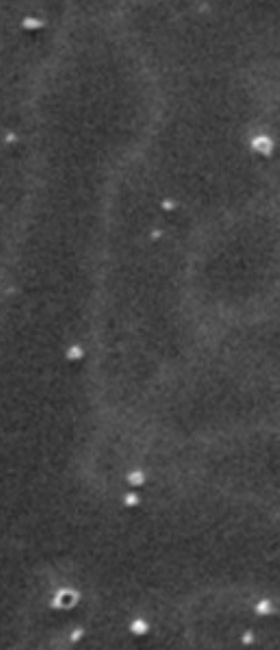

-

Acc.V Spot Magn .20 .0 kV $5.52000 x$

Det WD Exp SE 10.01

AGING 625 ALLOY

\section{Continuous} precipitation film.

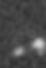

4

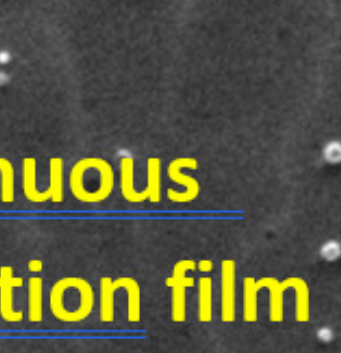




\title{
Precipitation along
}

\section{grain boundary}

\section{EDS shot on precipitate}

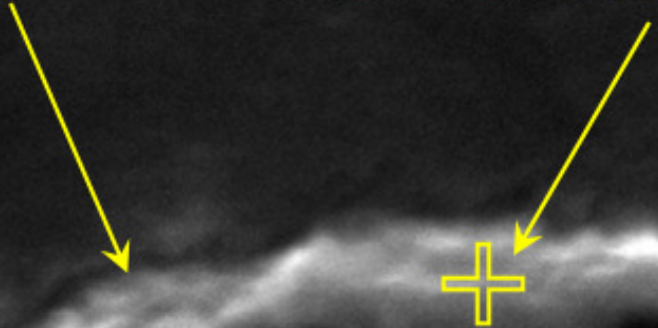

\author{
ك \\ EDS shot on matrix
}

\begin{tabular}{c|c|c|c|c|c|c|c}
\hline$\& 8$ & $5 / 29 / 2014$ & mag $⿴ 囗 十)$ & WD & det & HV & mode & $\longmapsto$ \\
\cline { 6 - 7 } & $1: 47: 20 \mathrm{PM}$ & $100000 \mathrm{x}$ & $8.3 \mathrm{~mm}$ & ETD & $20.00 \mathrm{kV}$ & $\mathrm{SE}$ & UFC - Central Analitica - Quanta FEG
\end{tabular}




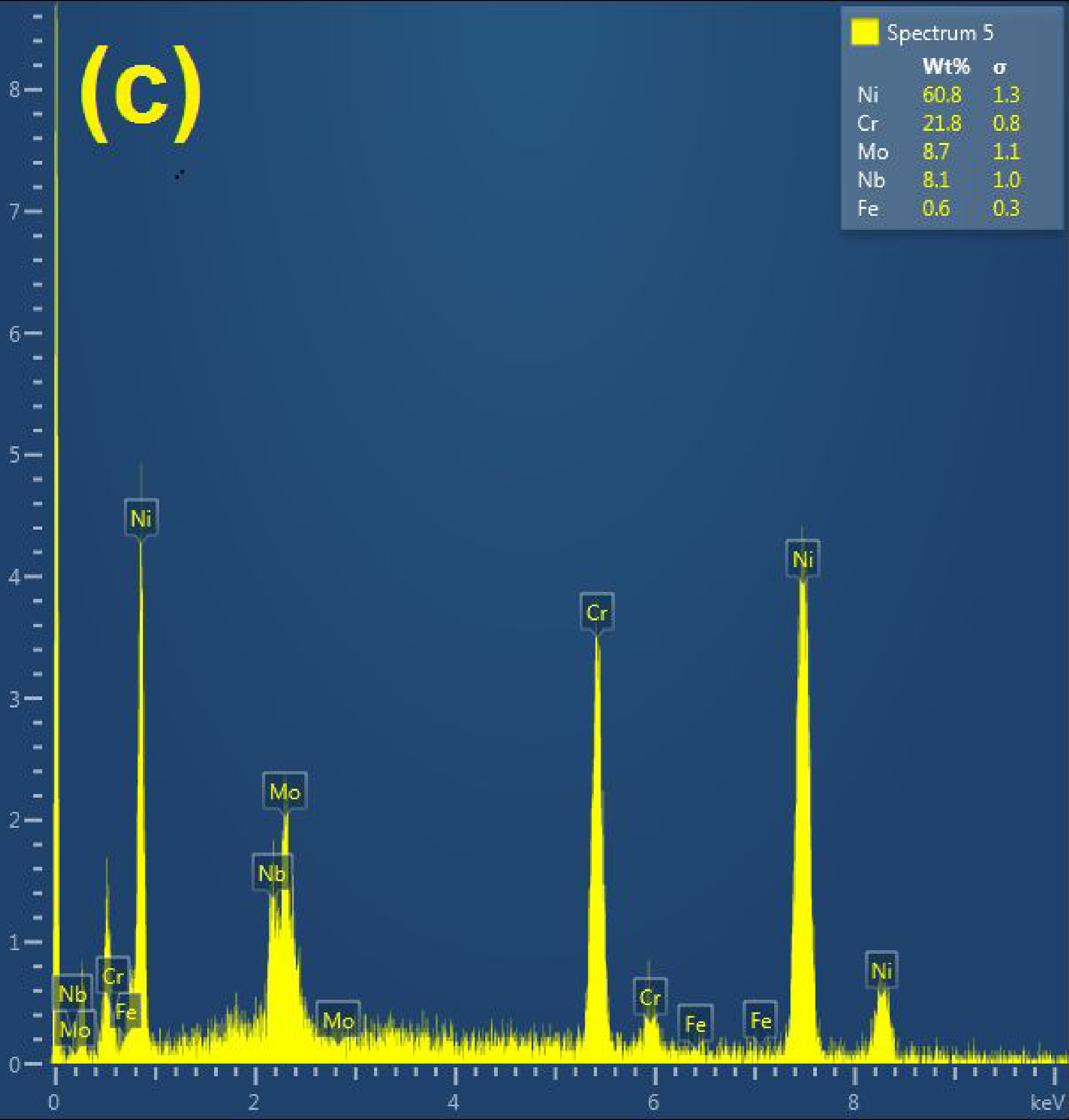




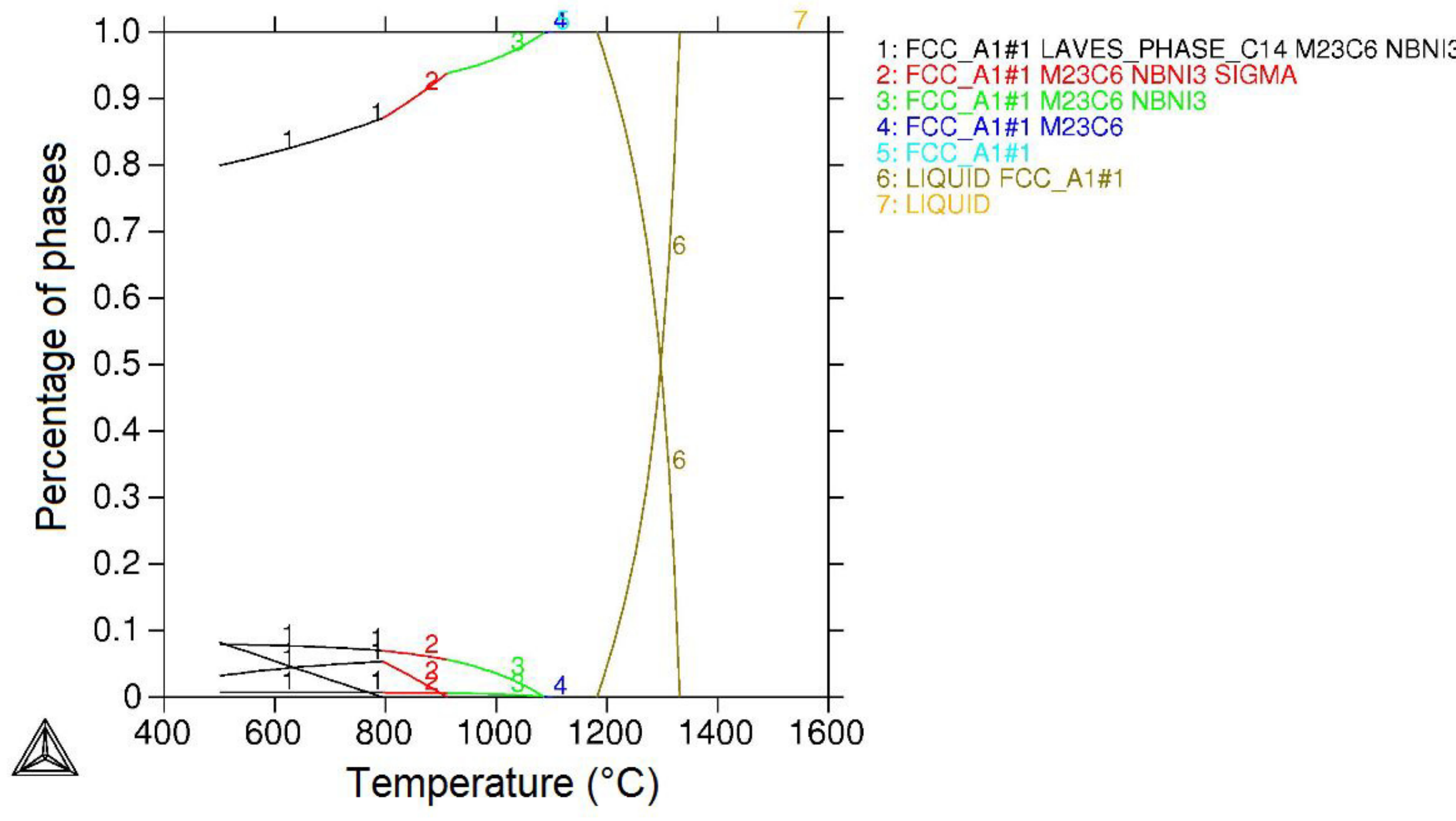




\section{(a)}

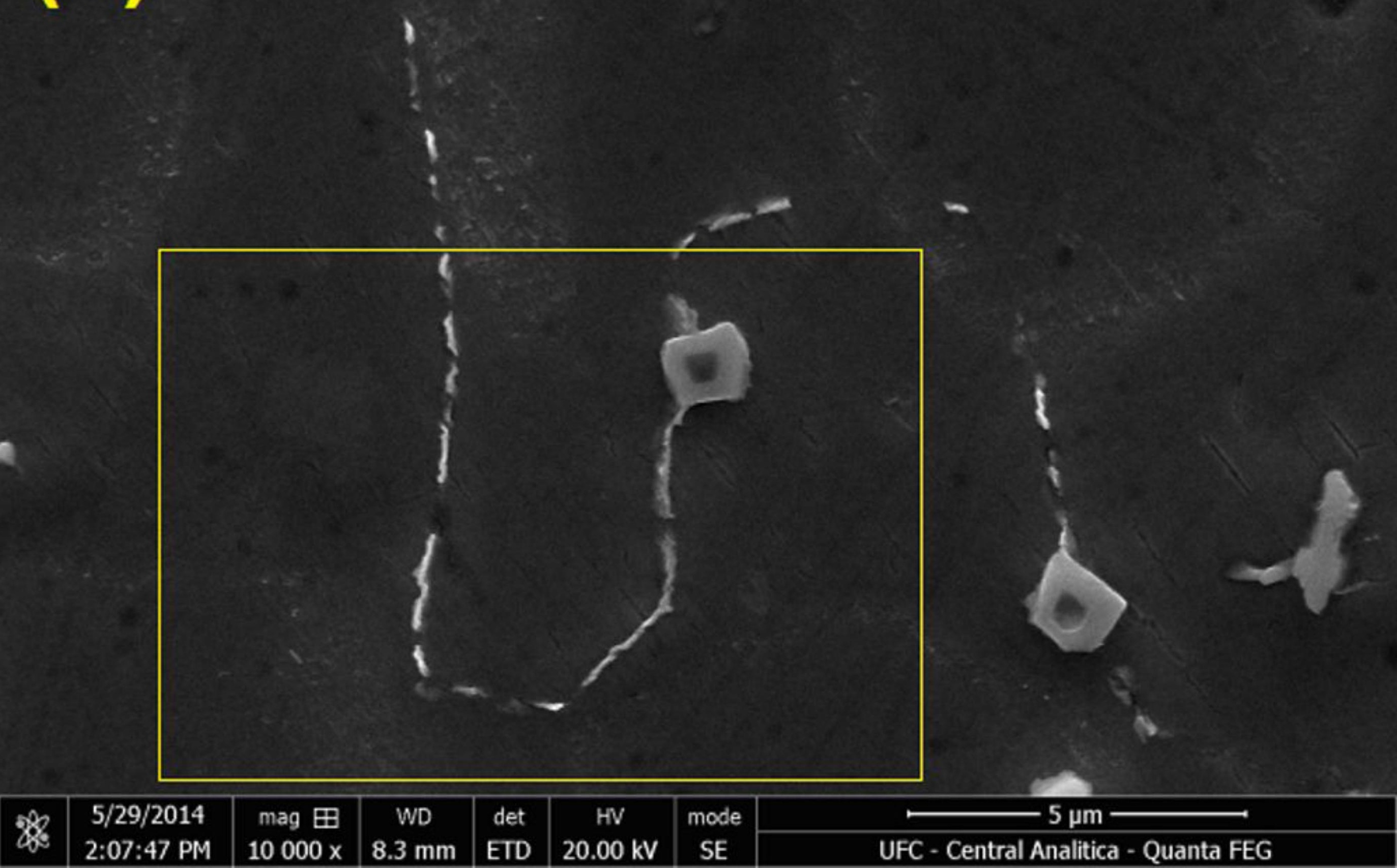




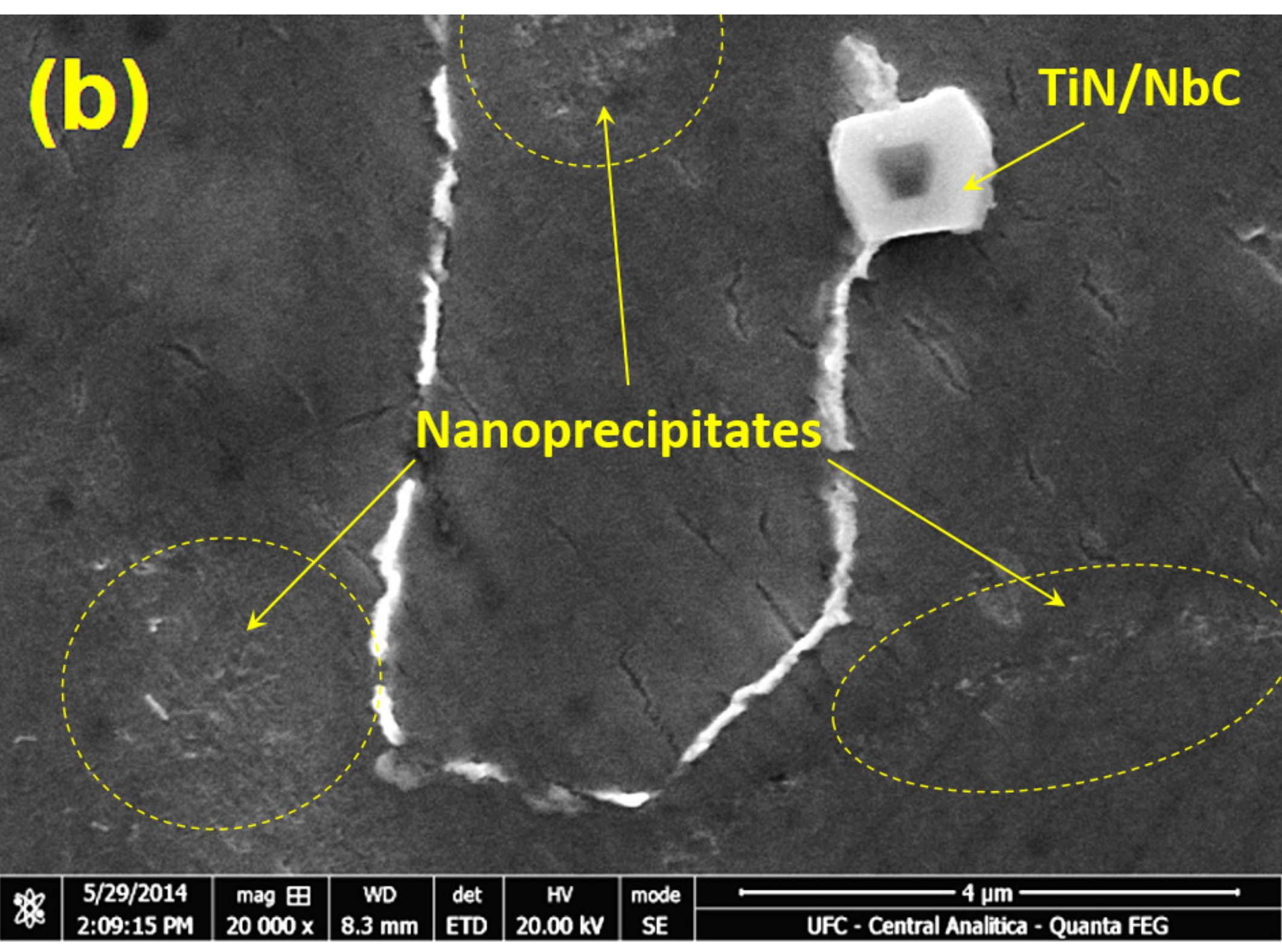


(a) $2+\infty \cdots$

2:

a.

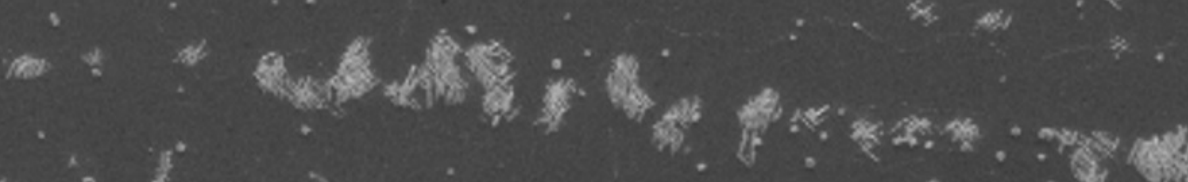

$3 . \infty-\infty x^{\infty}$

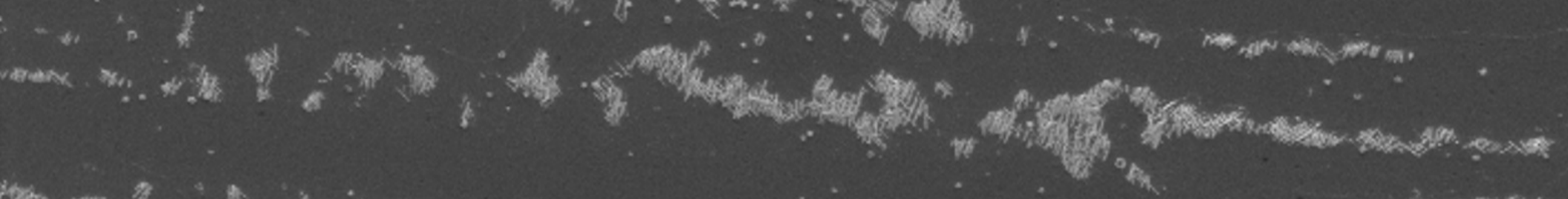

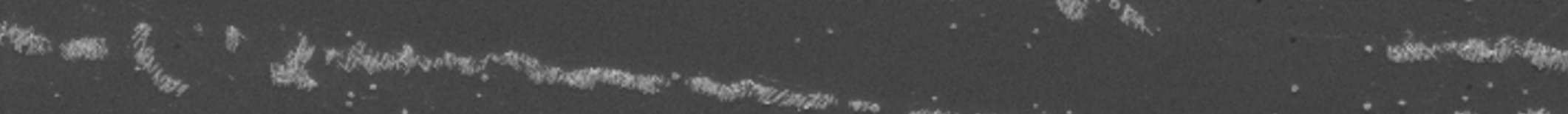



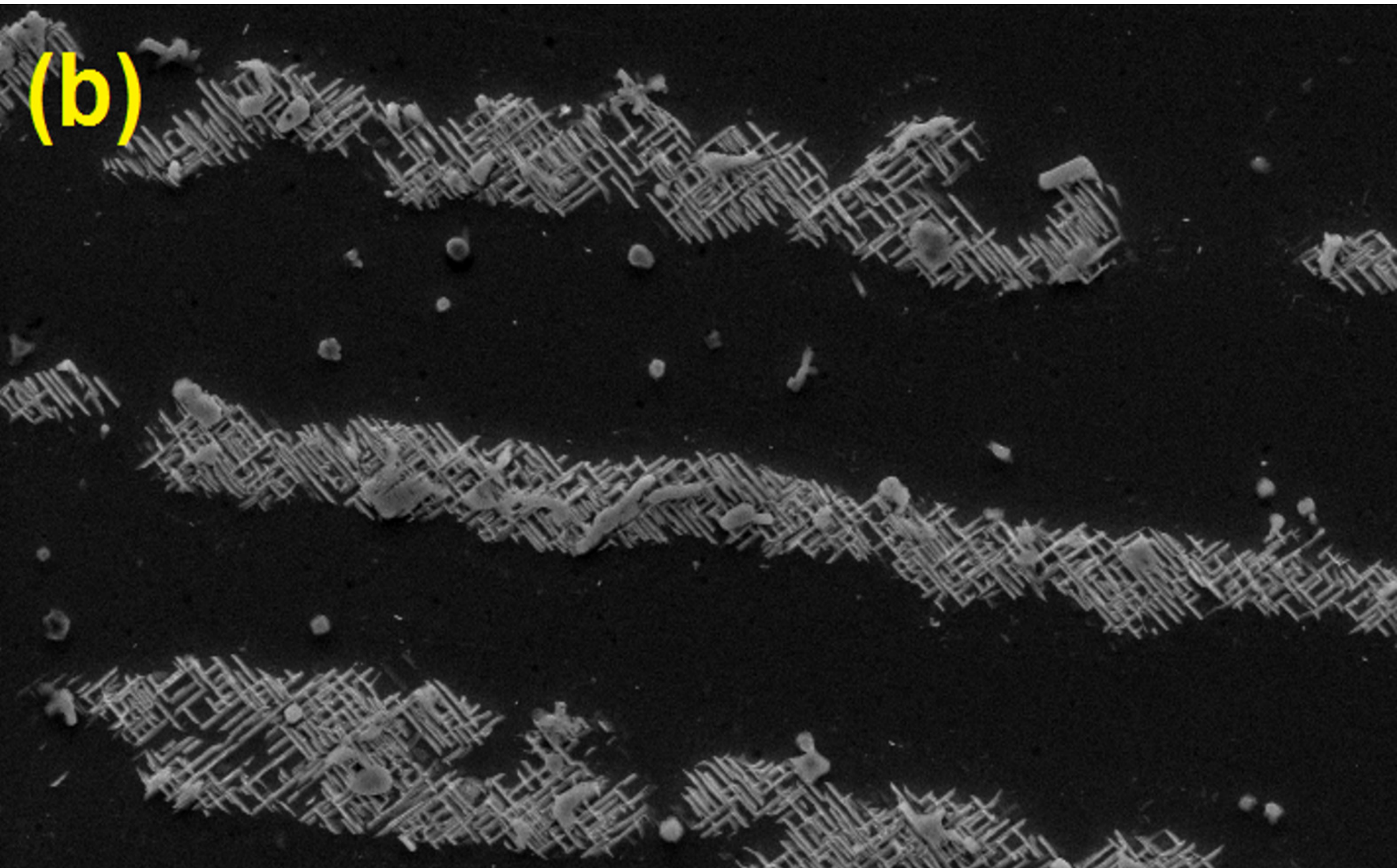

$\begin{array}{llllll}\text { Acc.V Spot Magn } & \text { Det } & \text { WD } & \text { Exp } & \\ 20.0 \mathrm{kV} & 3.5 \quad 2000 \mathrm{x} & \text { SE } 10.0 & 1\end{array}$

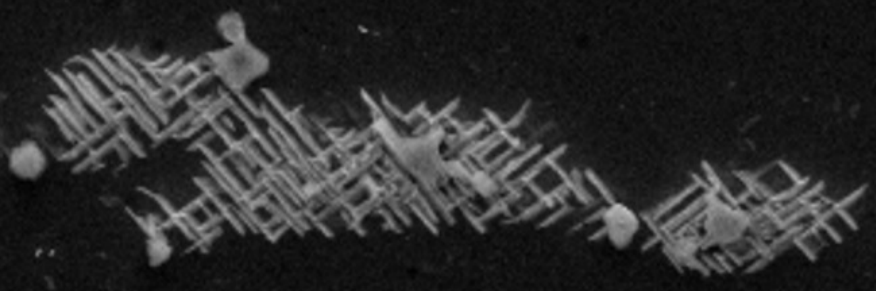

$\begin{array}{lllll}\text { Acc.V Spot Magn } & \text { Det WD Exp } & \text { Fing Superalloys } \\ 20.0 \mathrm{kV} 3.52000 \mathrm{x} & \text { SE } 10.01 & \text { Agin }\end{array}$




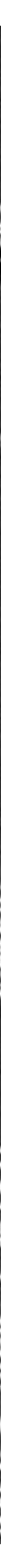




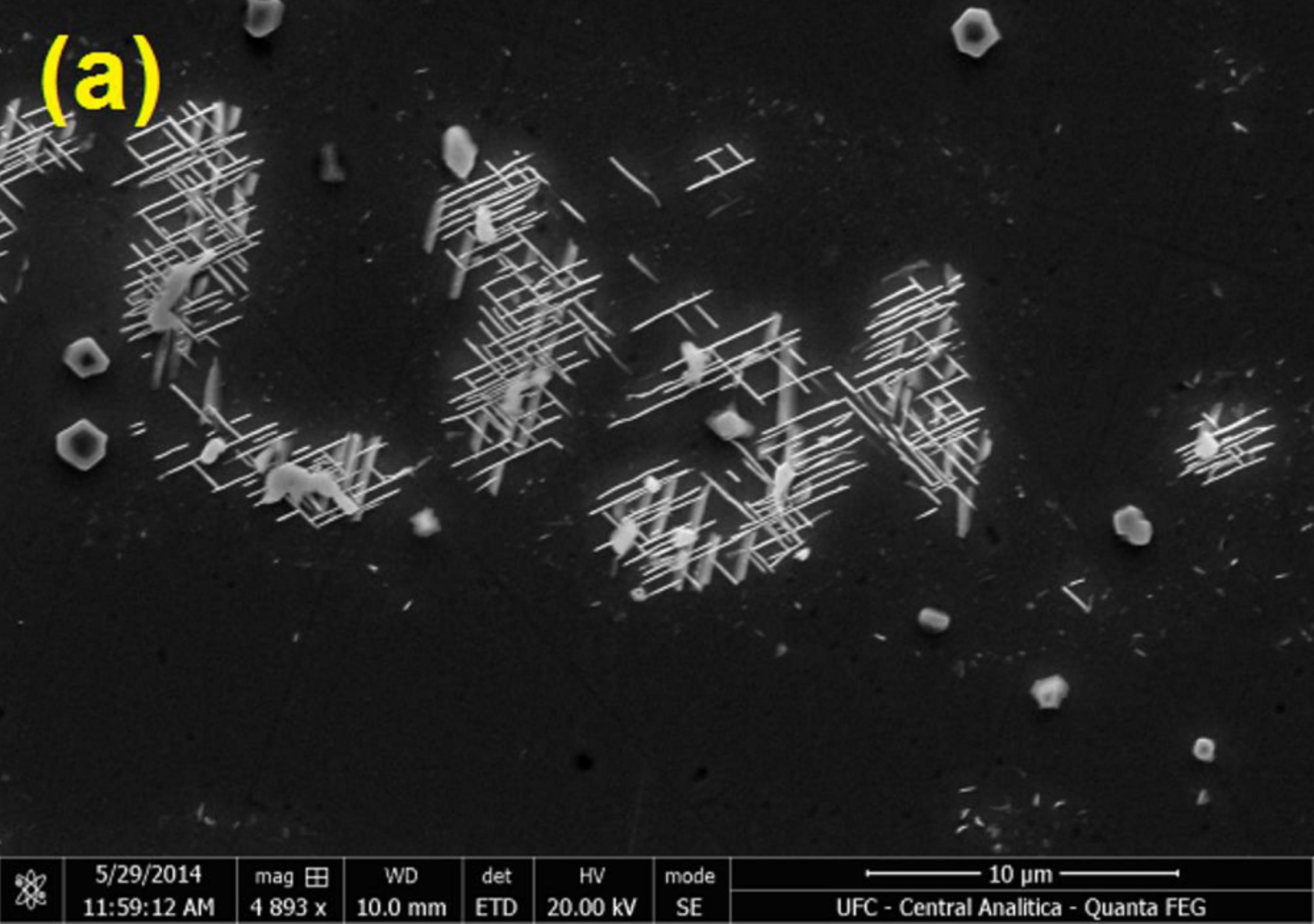




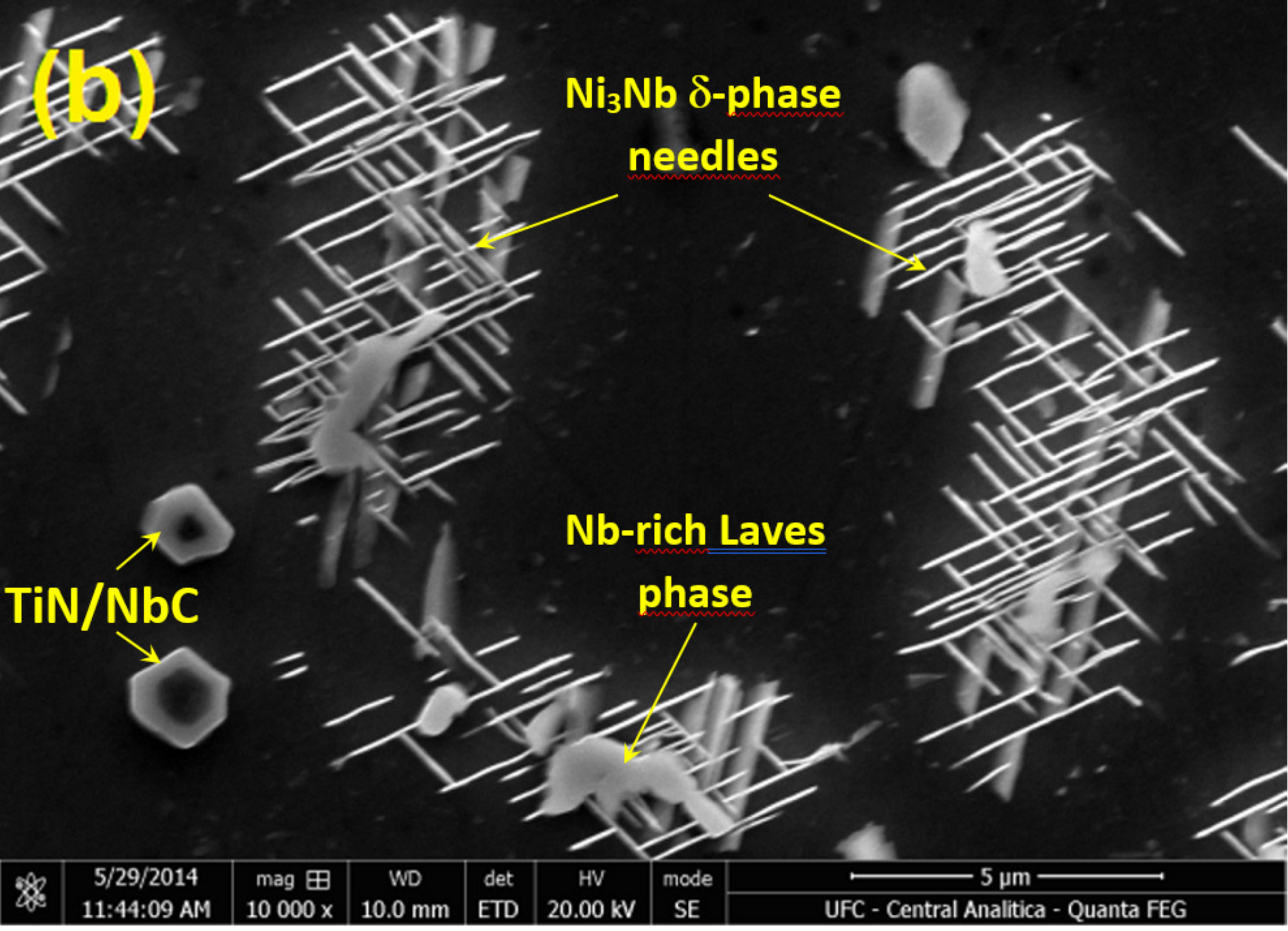


(a)

缘

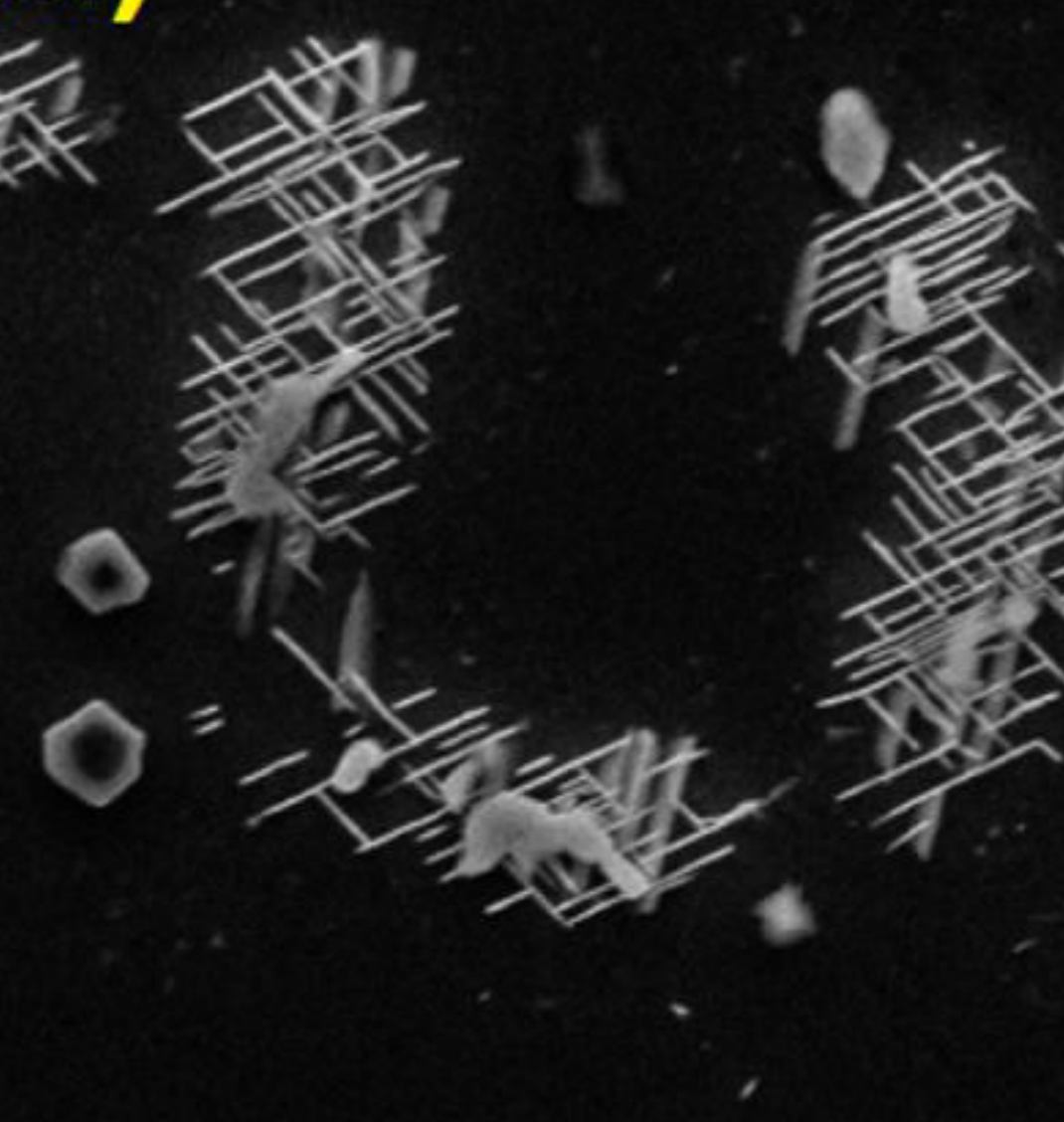

$-$

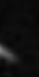
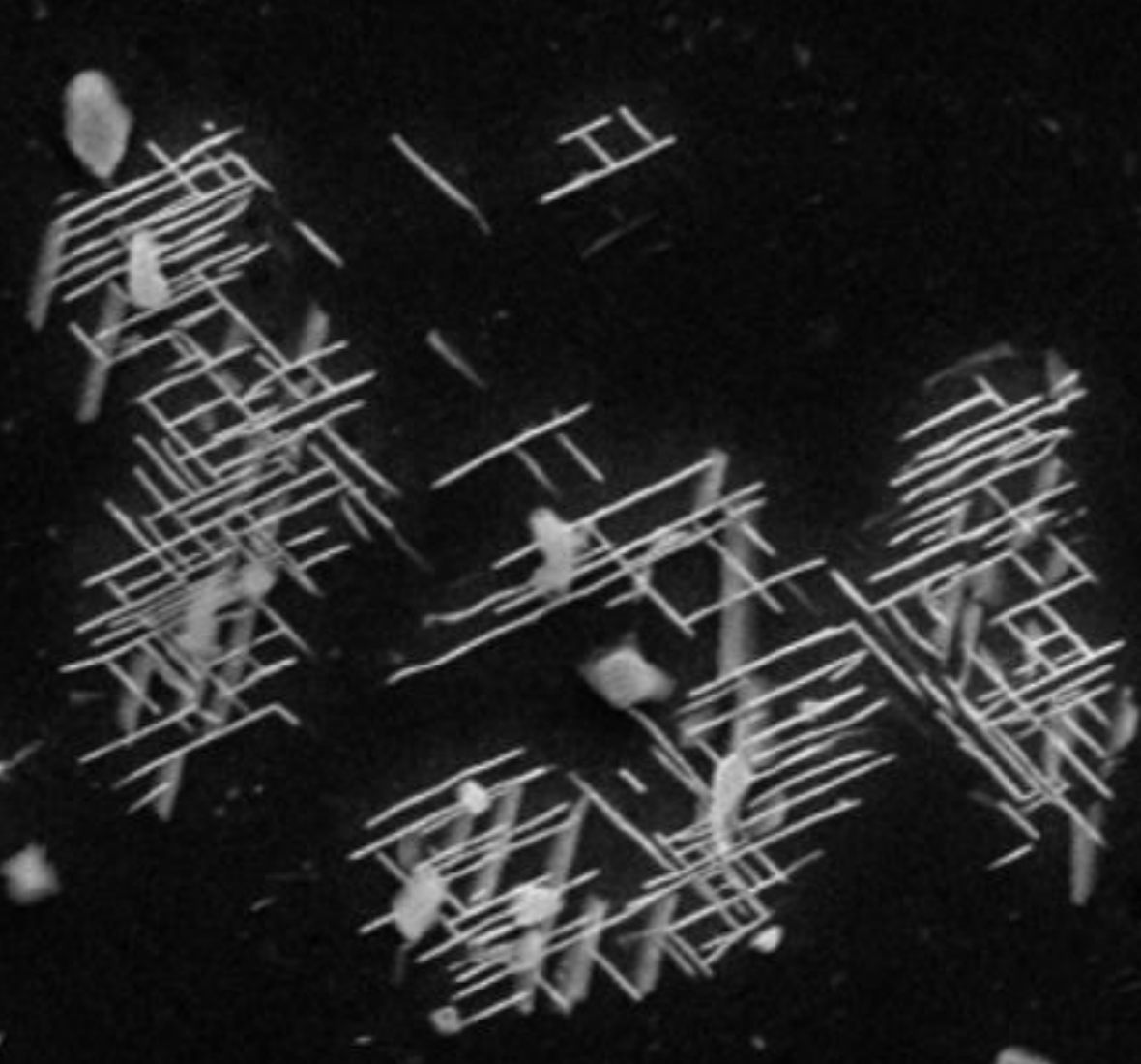

,

$-\infty$

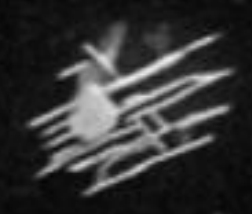

$-$ 
(b)

$10 \mu \mathrm{m}$ 
(e)
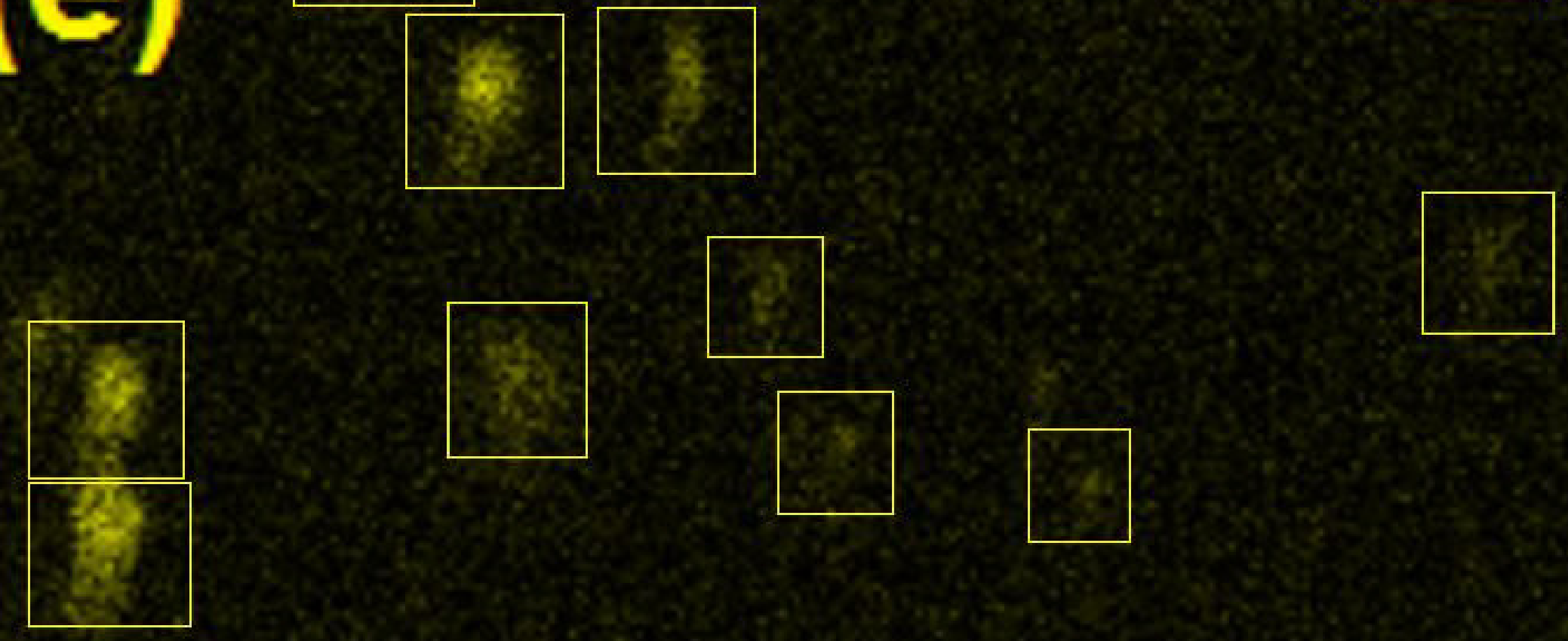

$10 \mu \mathrm{m}$
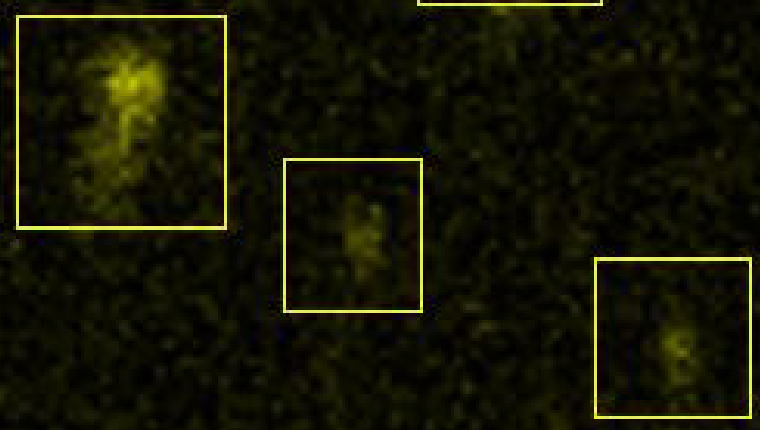


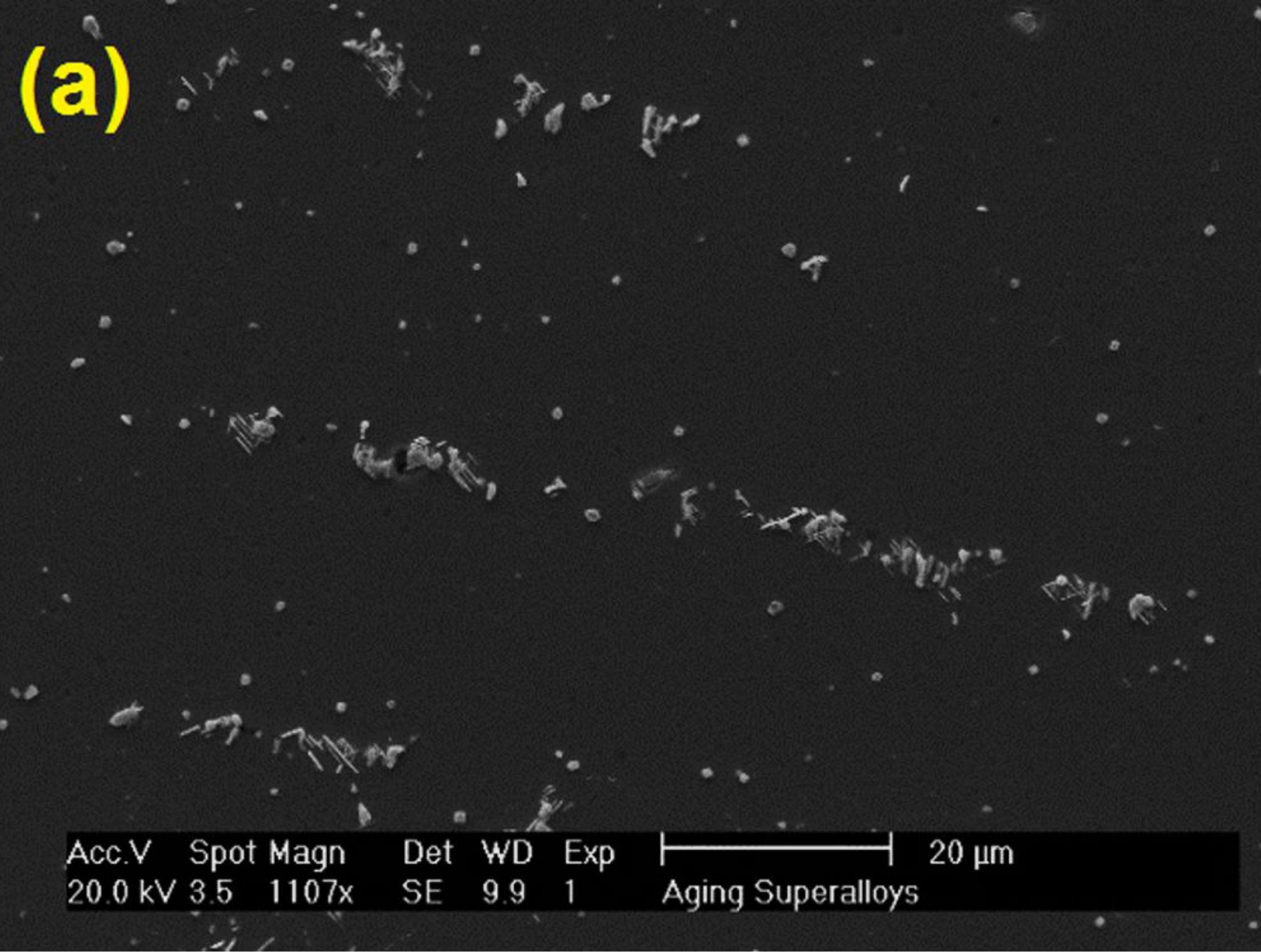




\section{(b)}
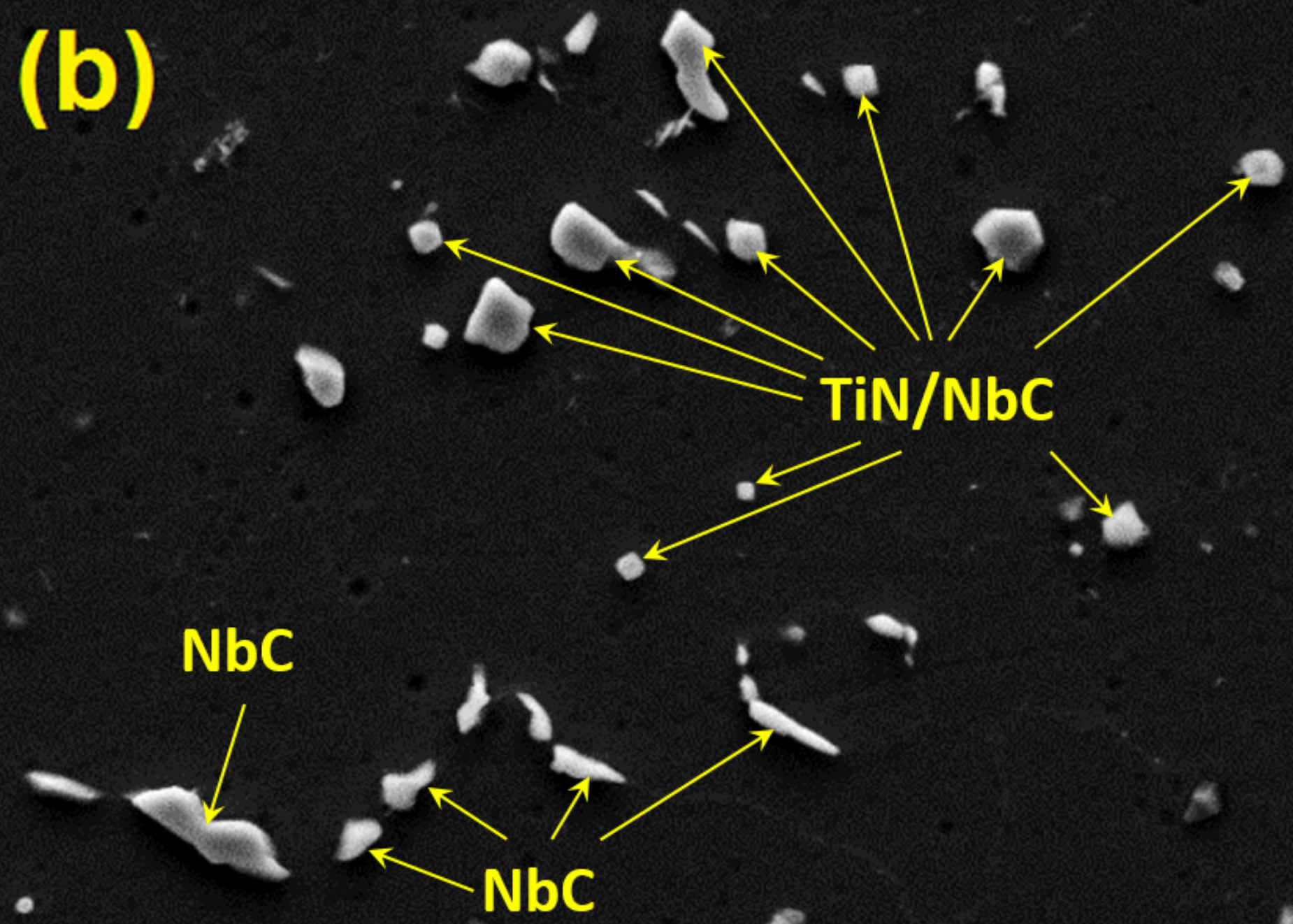

0

Acc.V Spot Magn Det WD Exp $20.0 \mathrm{kV} 4.0 \quad 5000 \mathrm{x}$ SE $10.01 \quad 625$ alloy aged at $9500 \mathrm{C}$ 
(a)

\section{$\mathrm{Ni}_{3} \mathrm{Nb} \delta$-phase}
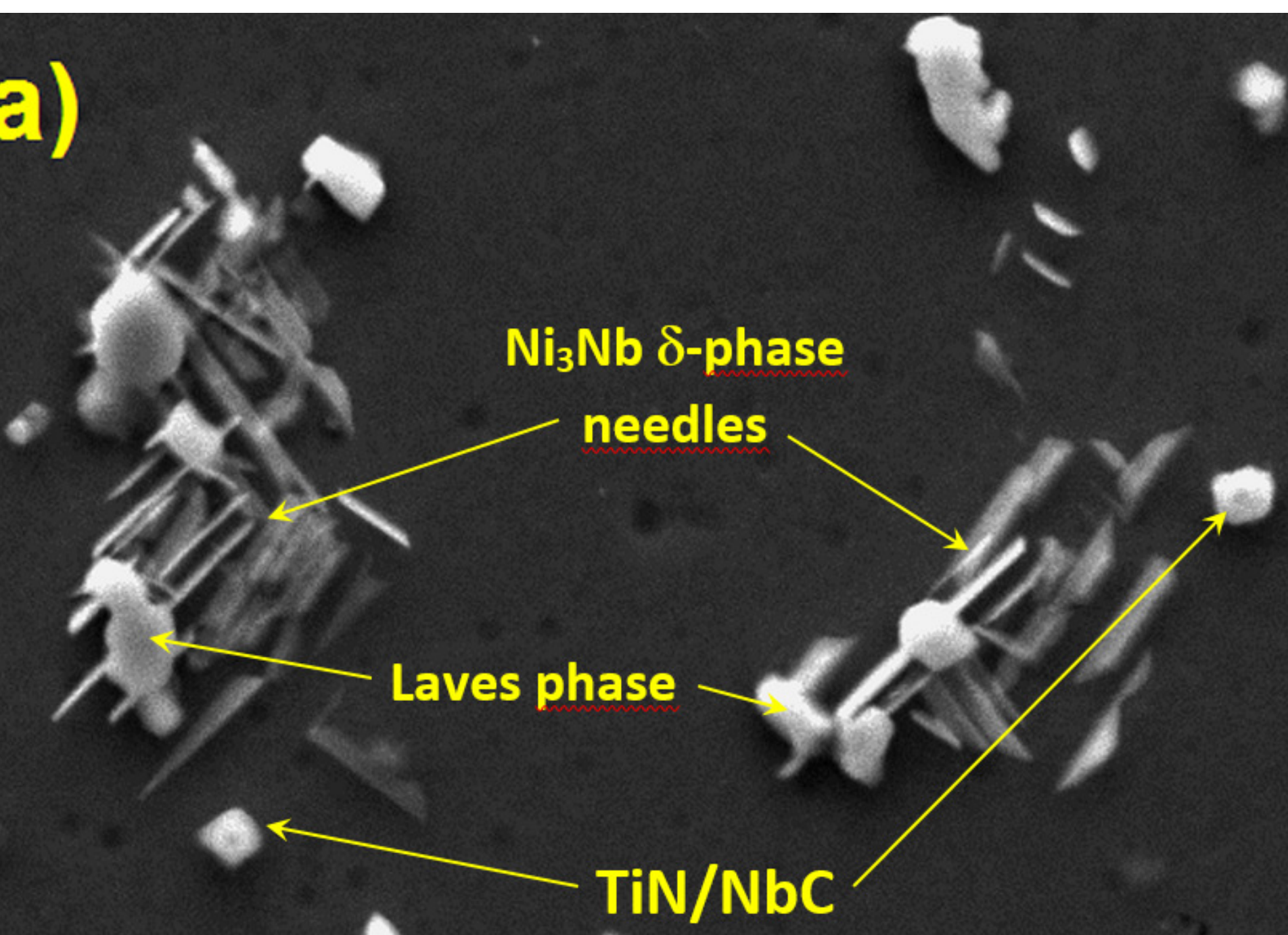

Acc.V Spot Magn Det WD Exp $20.0 \mathrm{kV} 4.0 \quad 10000 \mathrm{x}$ SE 10.01

$\longmapsto 5 \mu \mathrm{m}$ 625 alloy aged at $9500 \mathrm{C}$ 


\section{(b)}

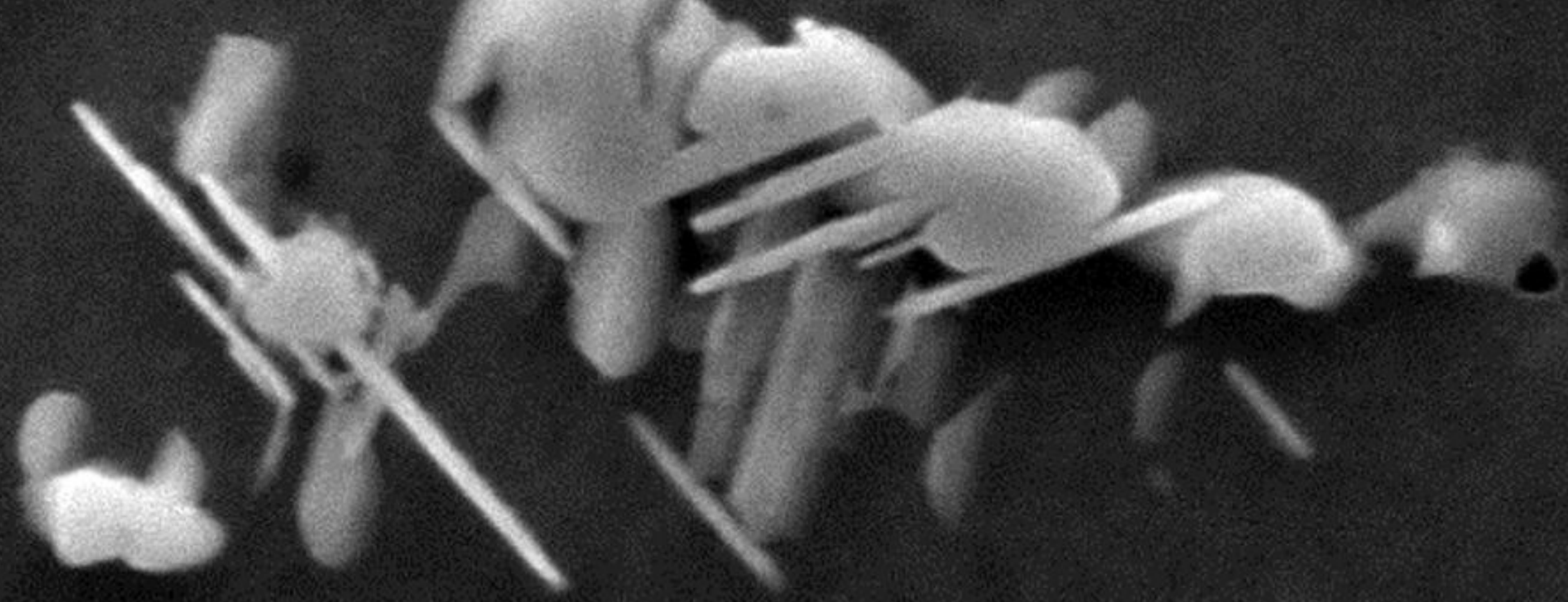

\section{Acc.V Spot Magn Det WD Exp $\longmapsto 2 \mu \mathrm{m}$ 20.0 kV $3.1 \quad 10000 x \quad$ SE $\quad 9.91 \quad 1 \quad$ Aging Superalloys}



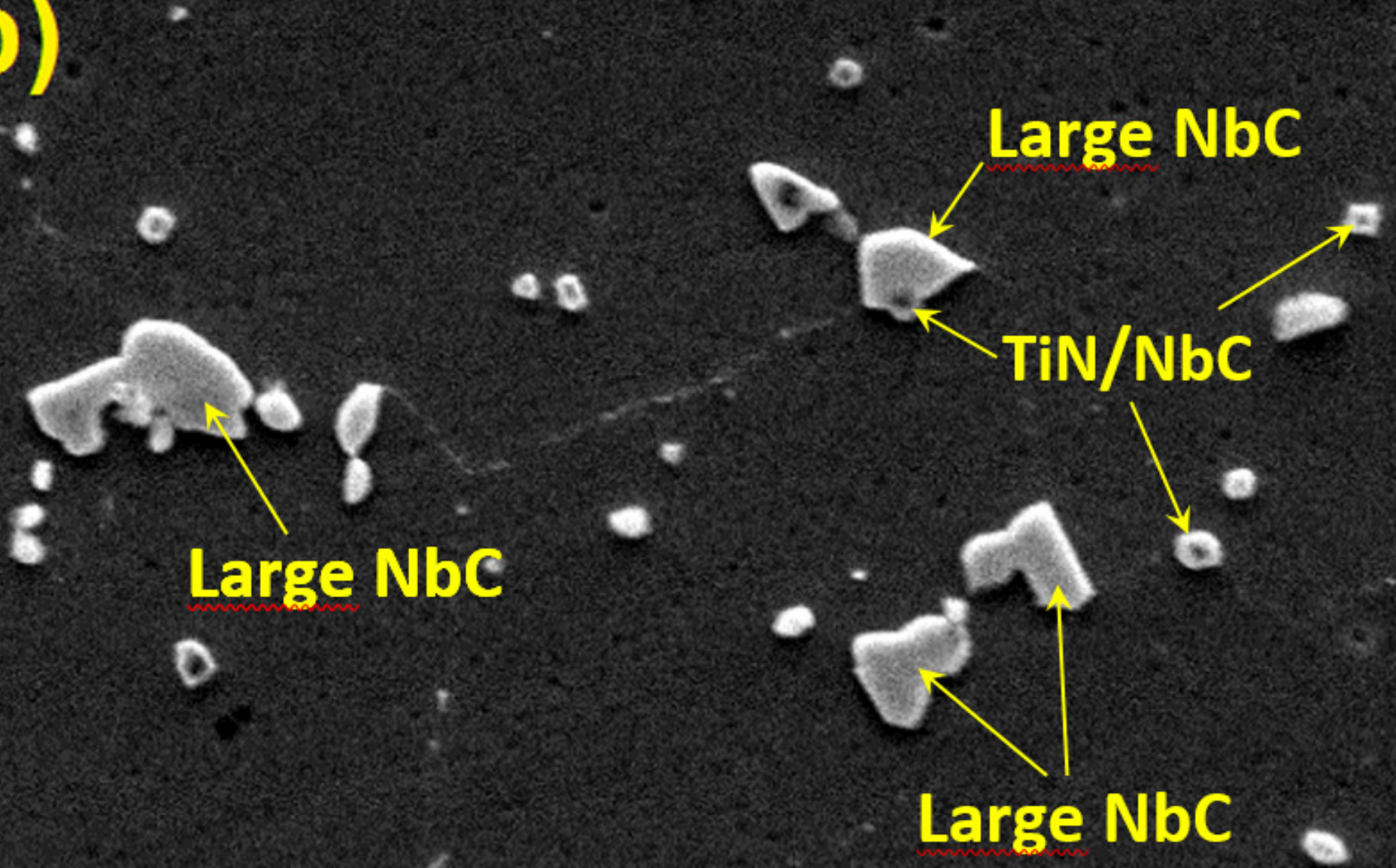

o

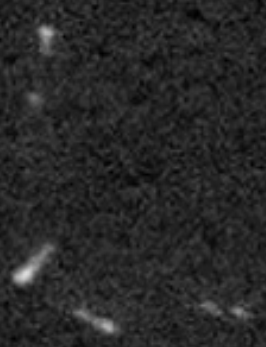

Acc.V Spot Magn Det WD Exp $20.0 \mathrm{kV} 4.6 \quad 4000 \mathrm{x}$ SE $10.11 \quad$ Aging Superalloys 


\section{$10 \mu \mathrm{m}$}




\section{(d)}
Acc.V Spot Magn
Det WD Exp
$20.0 \mathrm{kV} 4.94000 \mathrm{x}$
SE
9.71
$10 \mu \mathrm{m}$
Aging Superalloys 


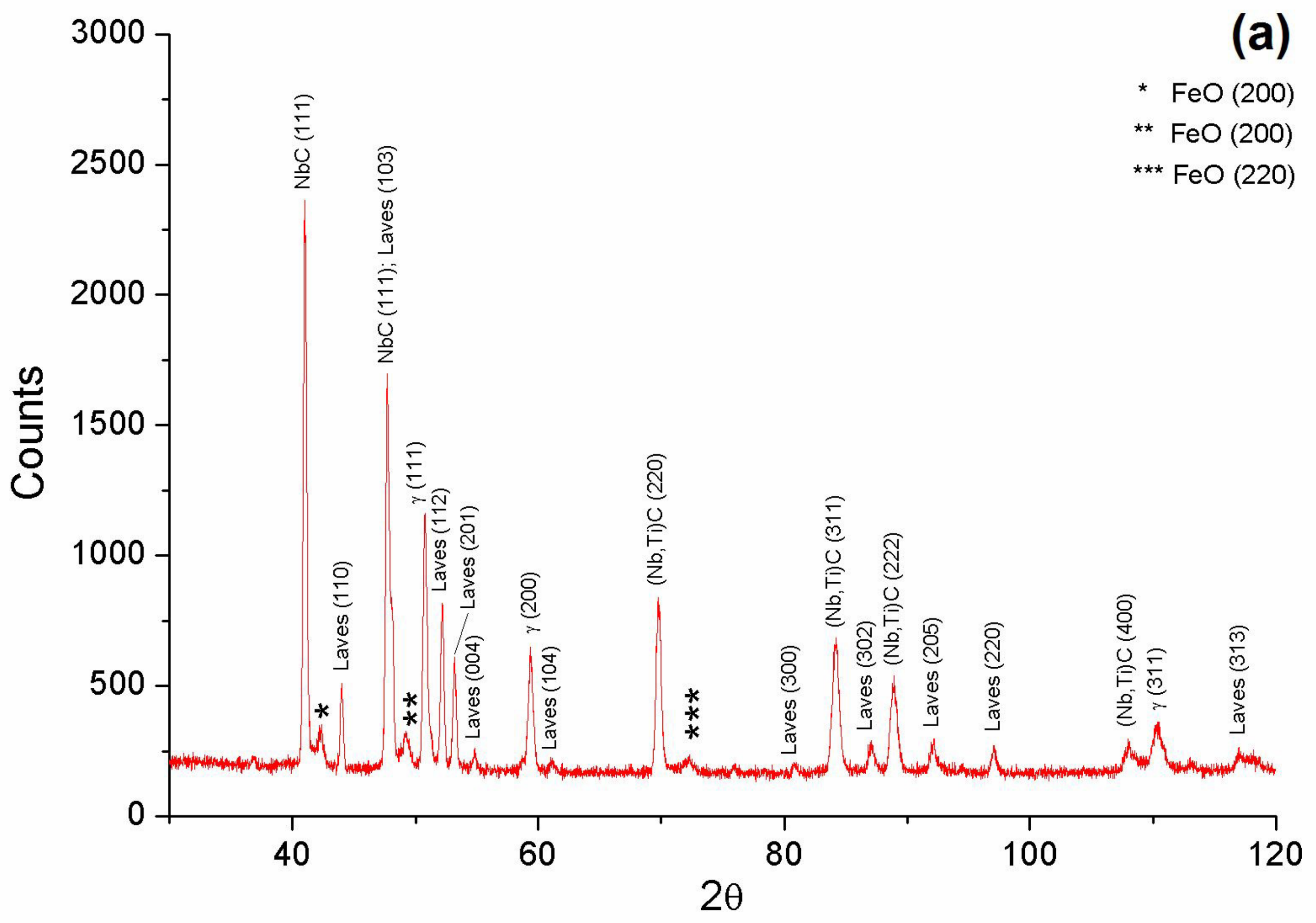




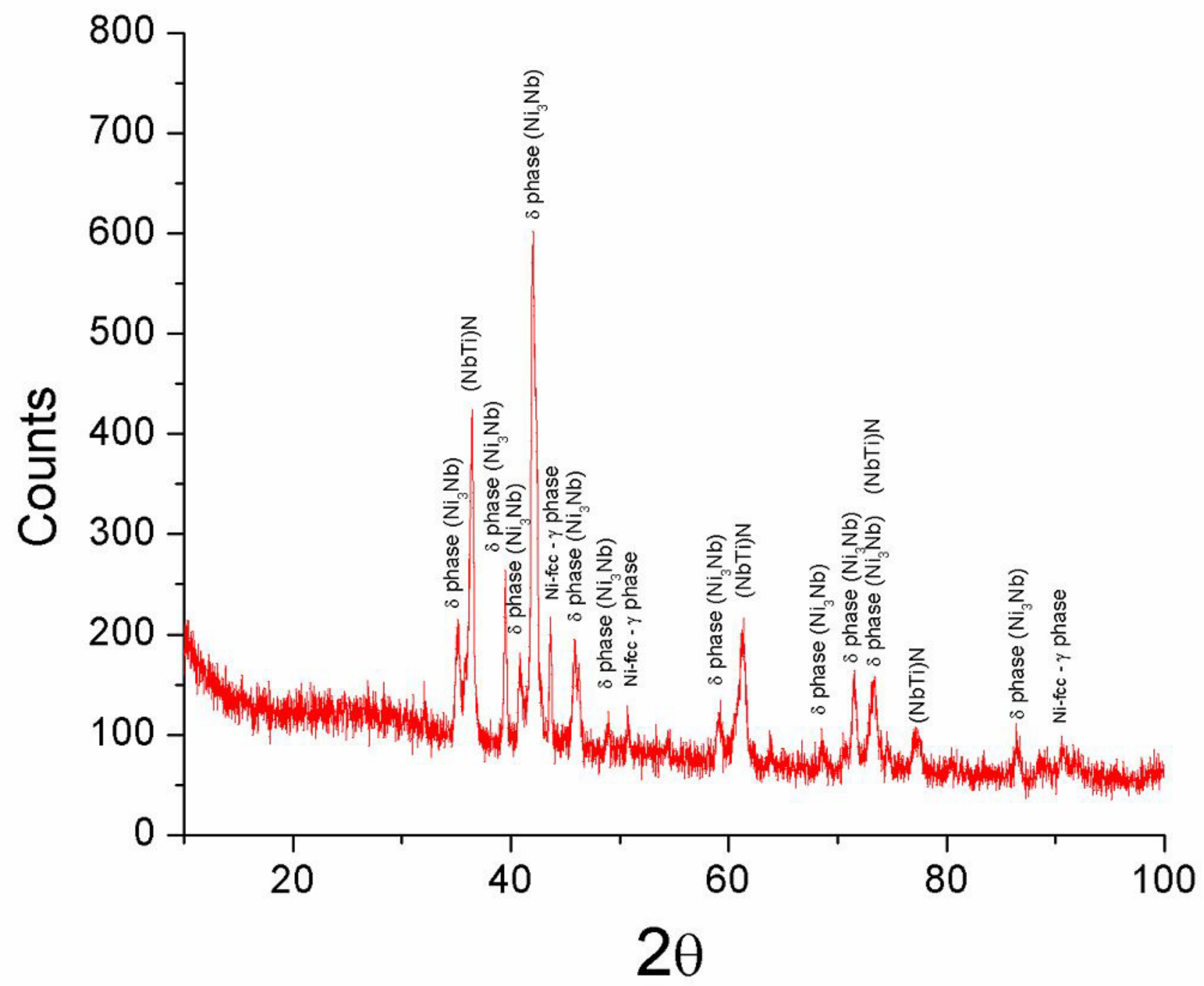

(b) 
Effect of aging on absorved energy in Charpy- $\mathrm{V}$ impact test

Current effect: $F(3,16)=17,787, p=, 00002$

Effective hypothesis decomposition

Vertical bars denote 0,95 confidence intervals

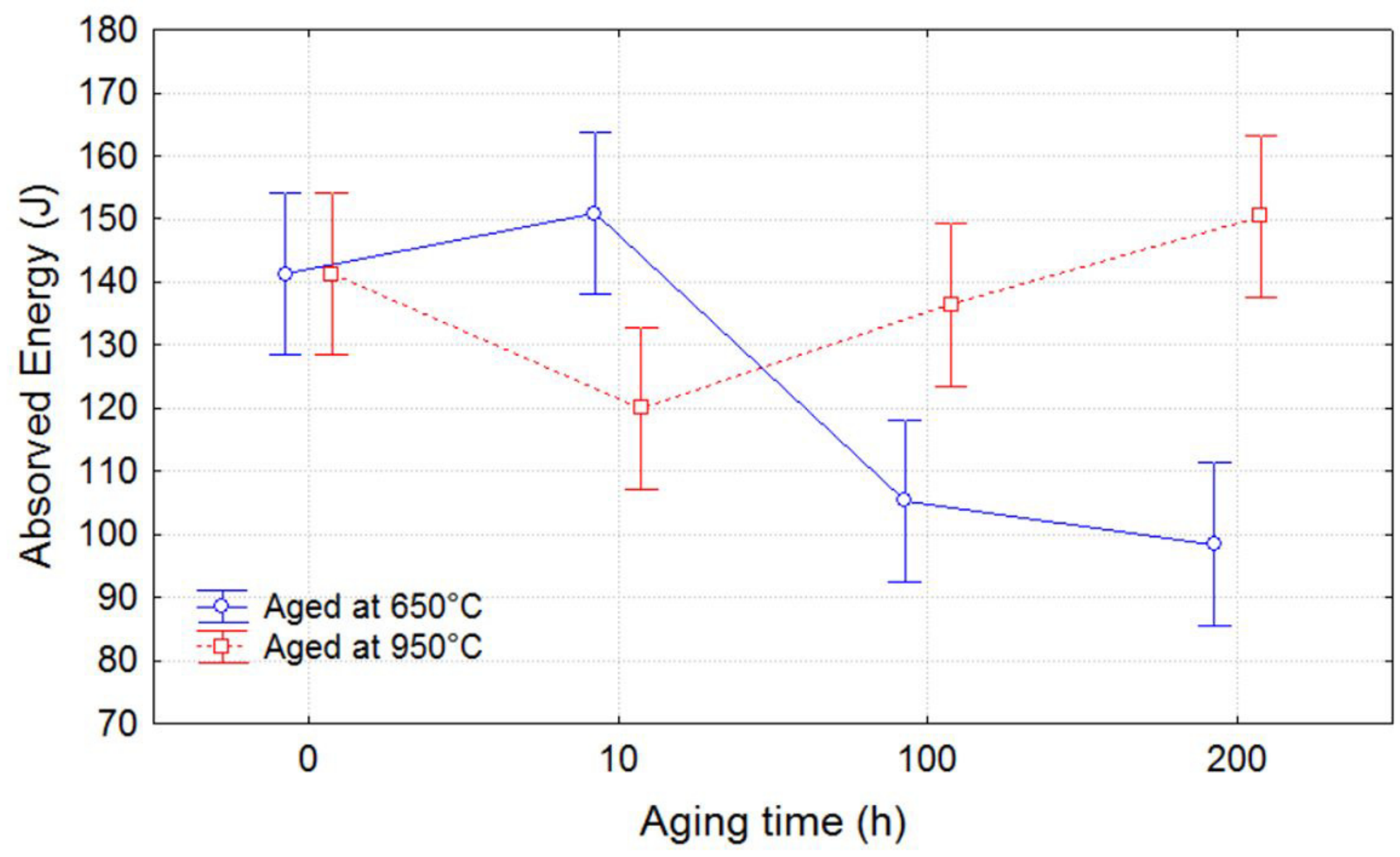


a) $650^{\circ} \mathrm{C}-10 \mathrm{~h}$

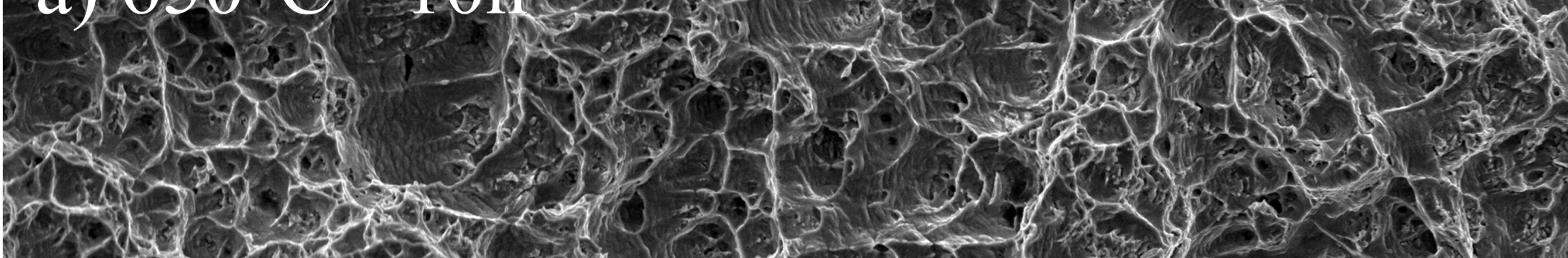
bor 015

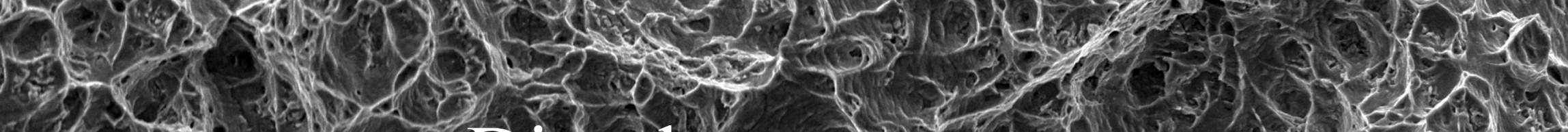
- 2. Dimples 6 os 73 .

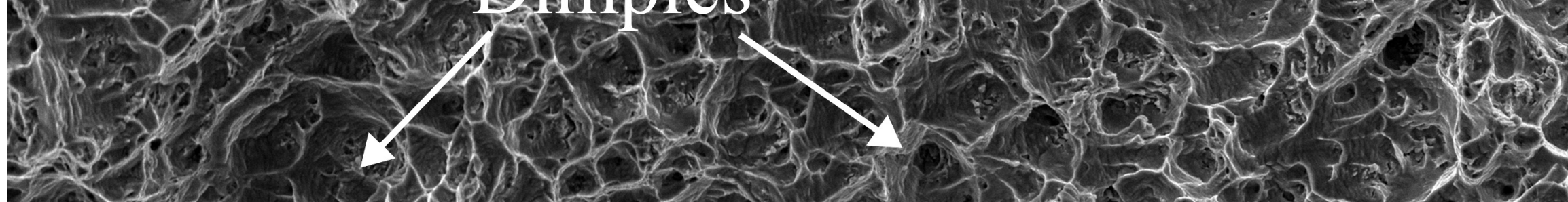

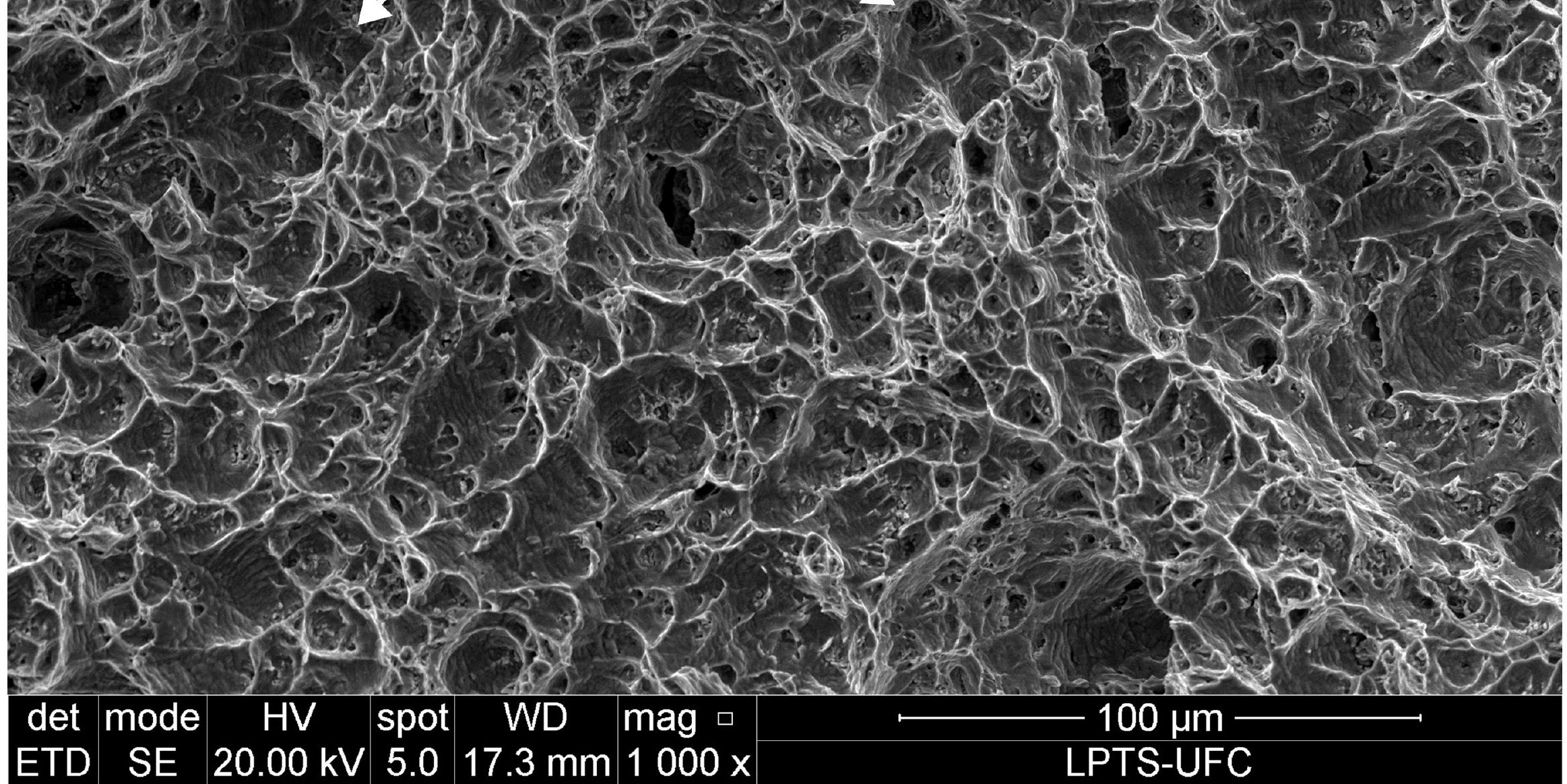


b) $650^{\circ} \mathrm{C}-200 \mathrm{~h},(\mathrm{cos})$

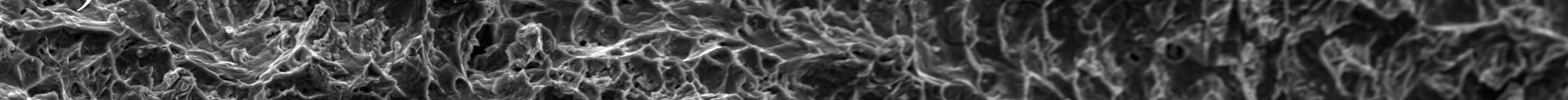
2.t.

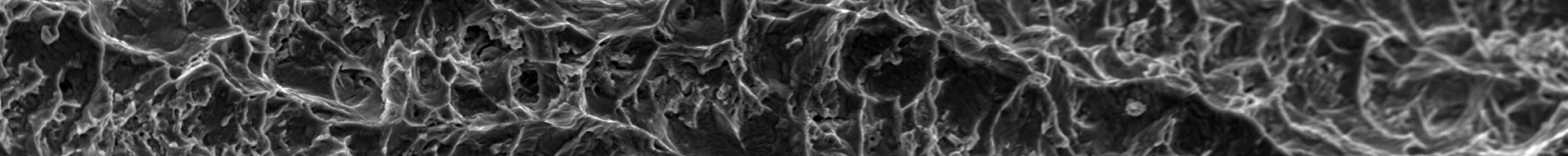
Bendinticregion-

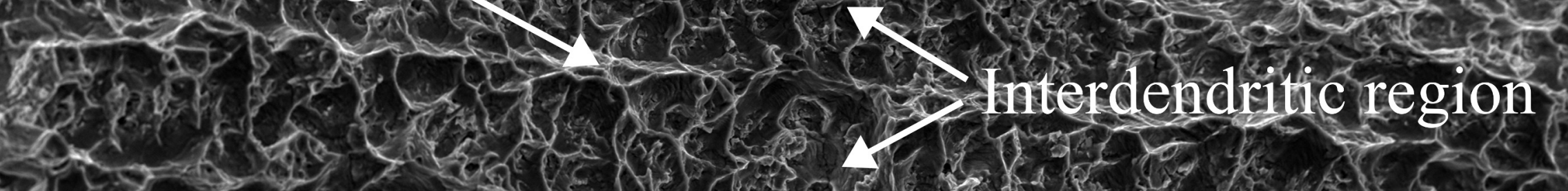
sy

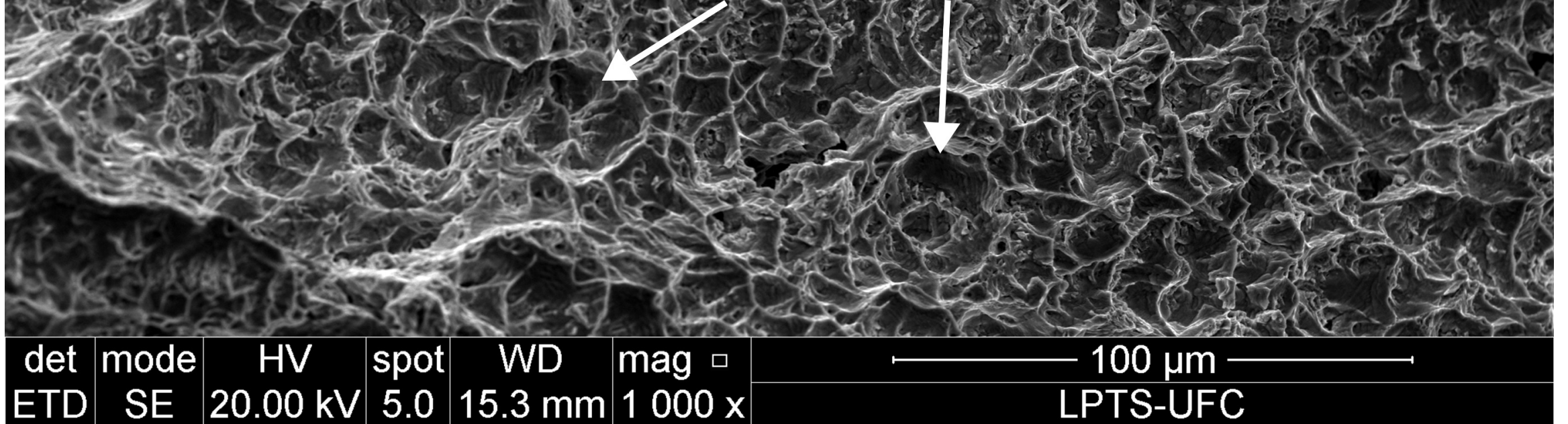


a) $950^{\circ} \mathrm{C}-10 \mathrm{~h}$ $2-1=1 /$

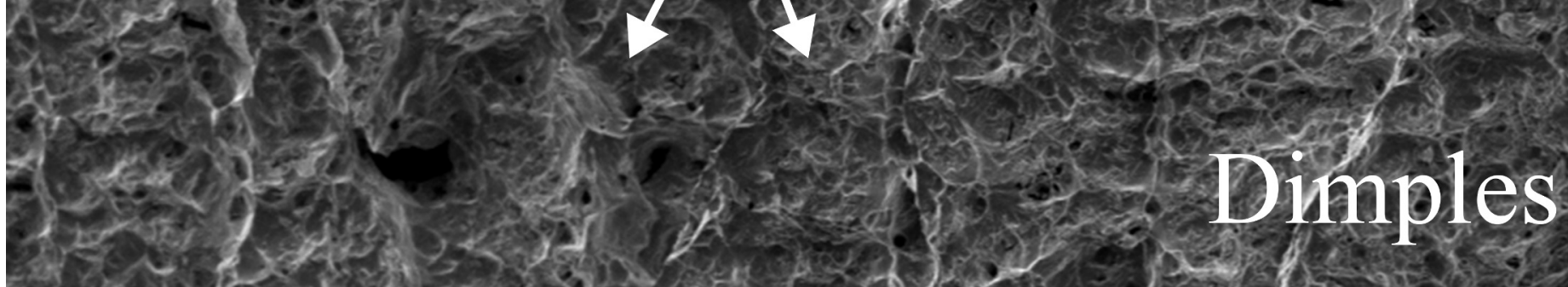

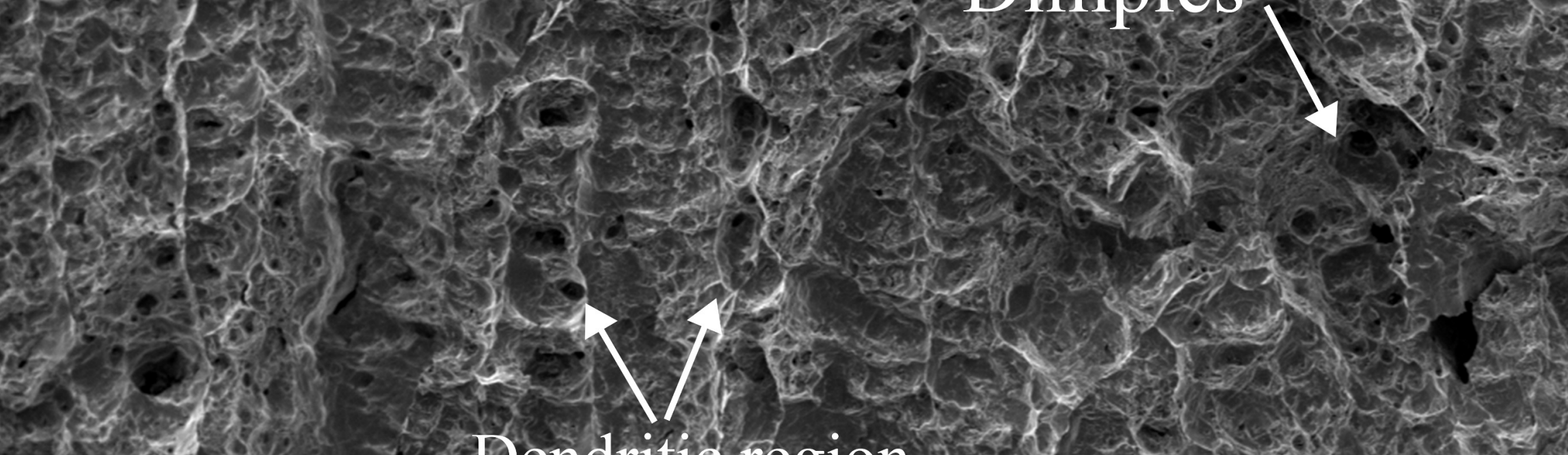

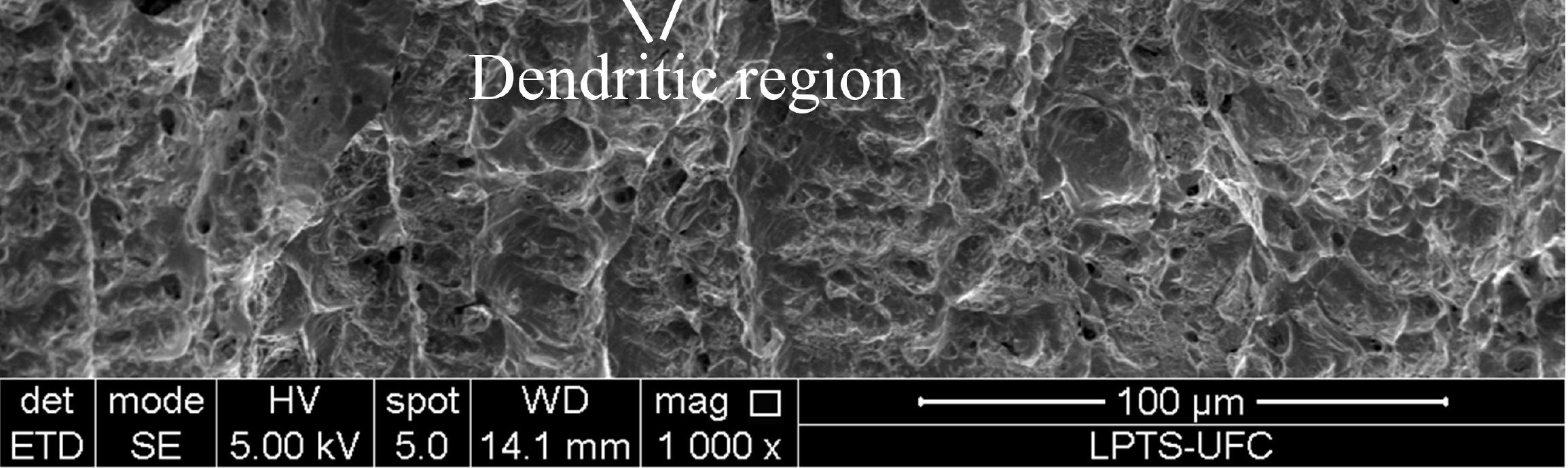



b) $950^{\circ} \mathrm{C}-200 \mathrm{~h}$. (2) Dimples

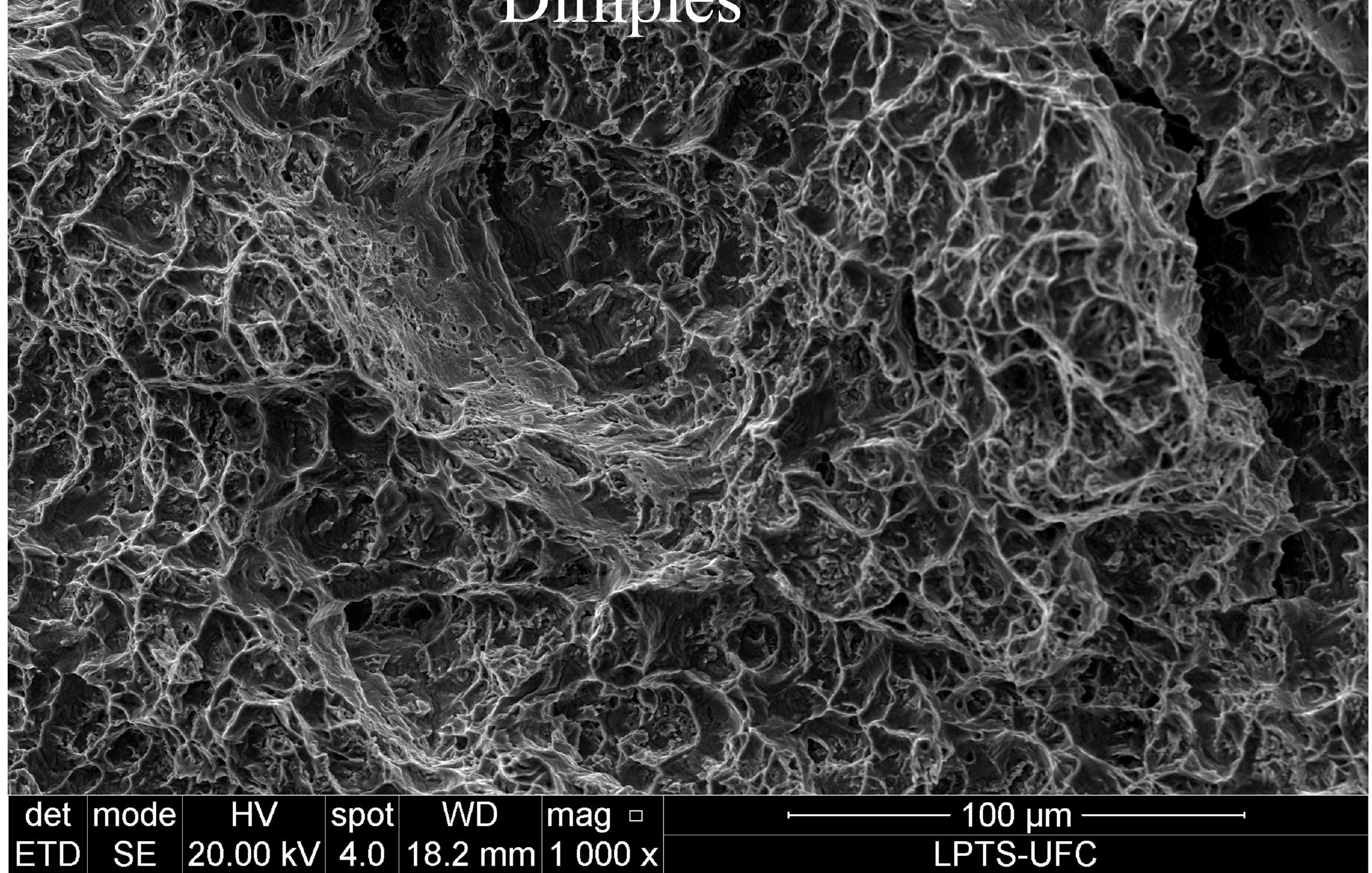




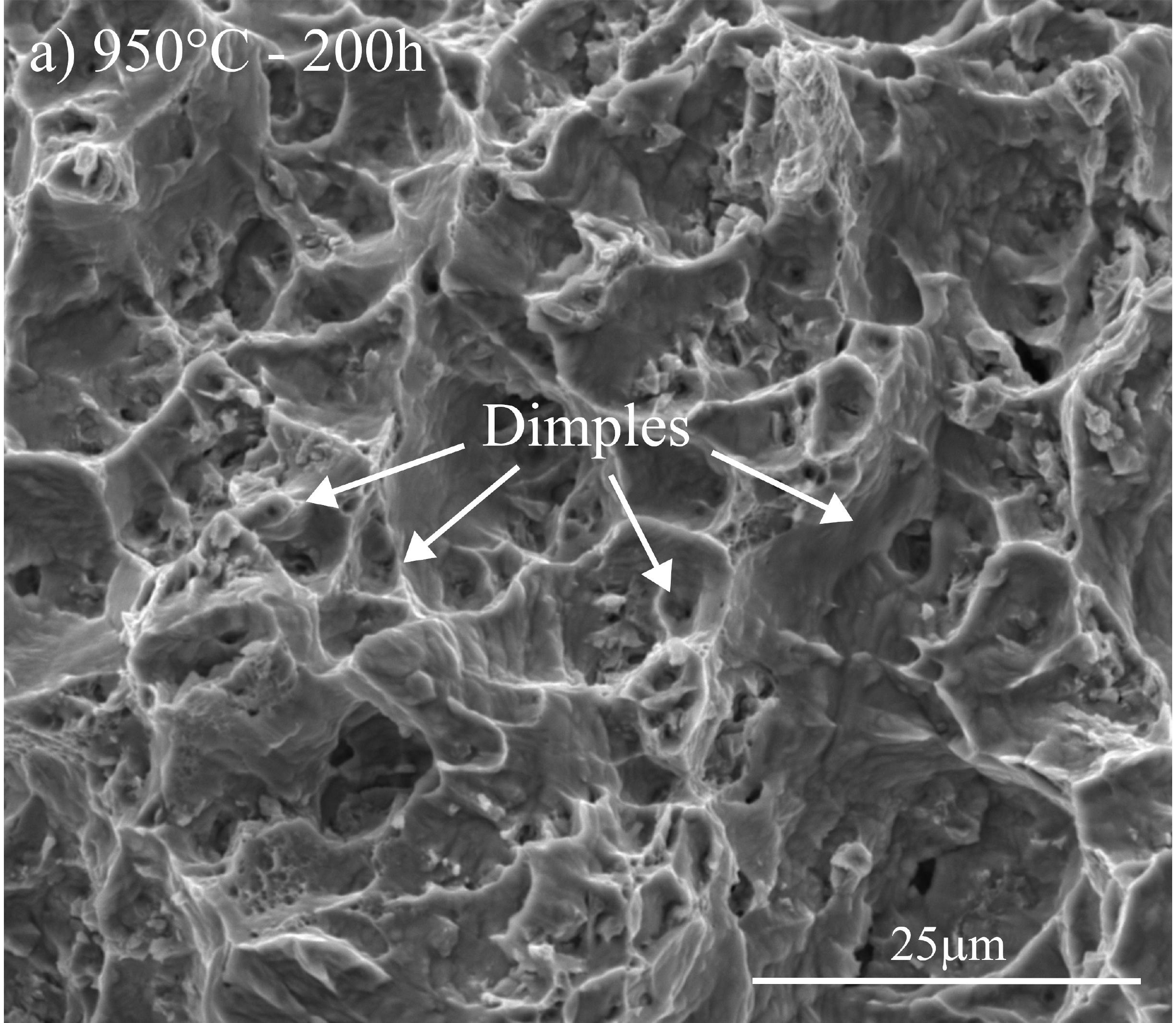


b) $\mathrm{Tr}$

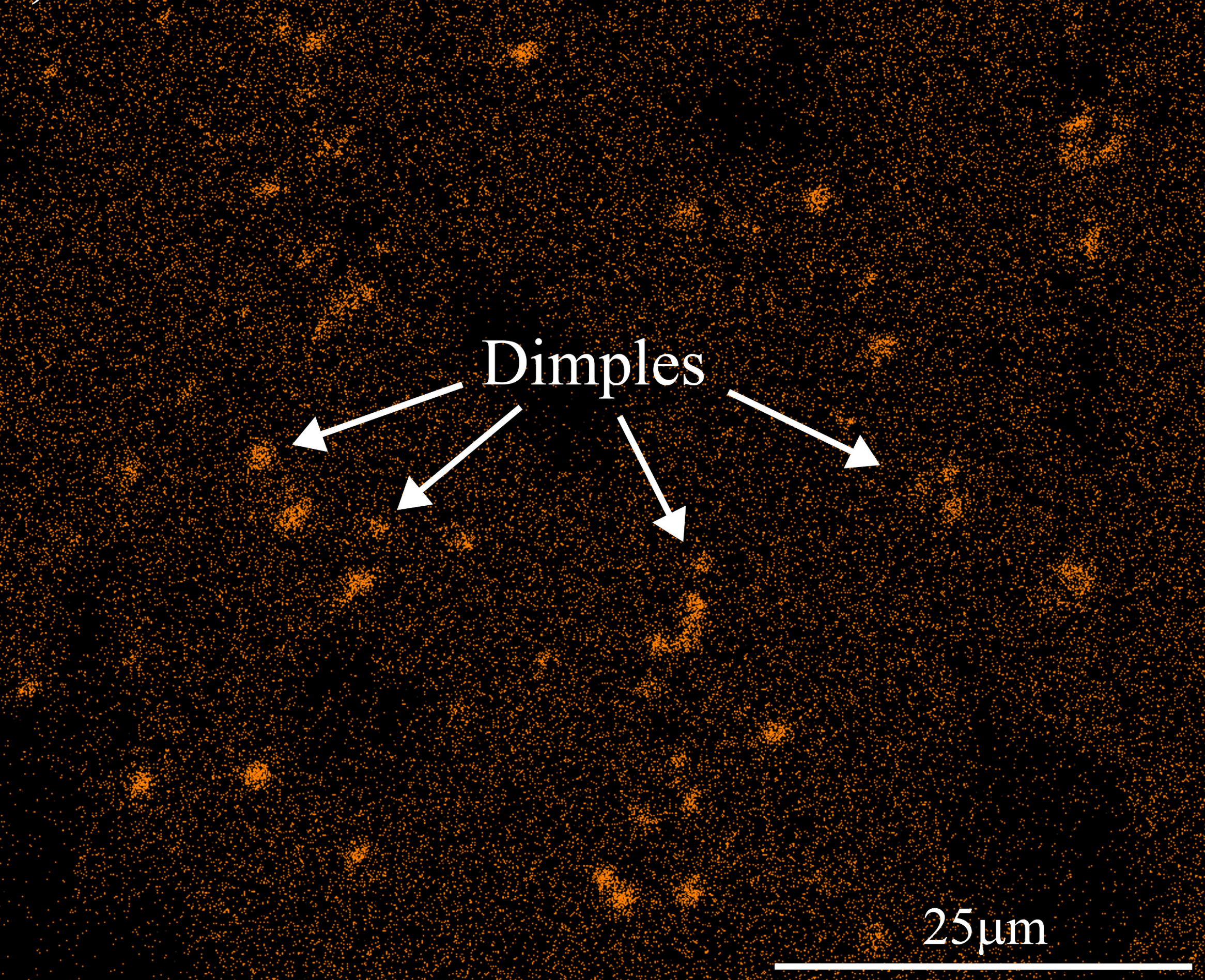


c) $\mathrm{Nb}$

ㄱ.

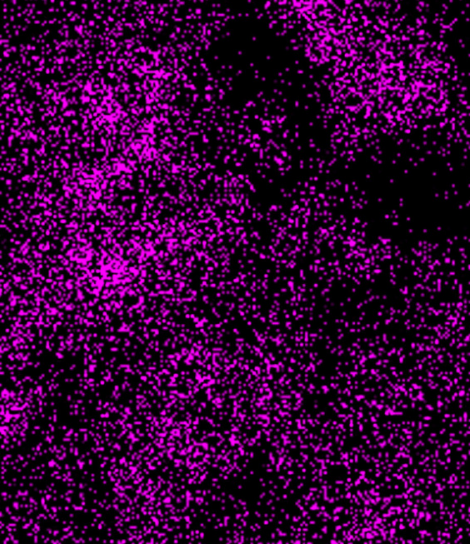
\%

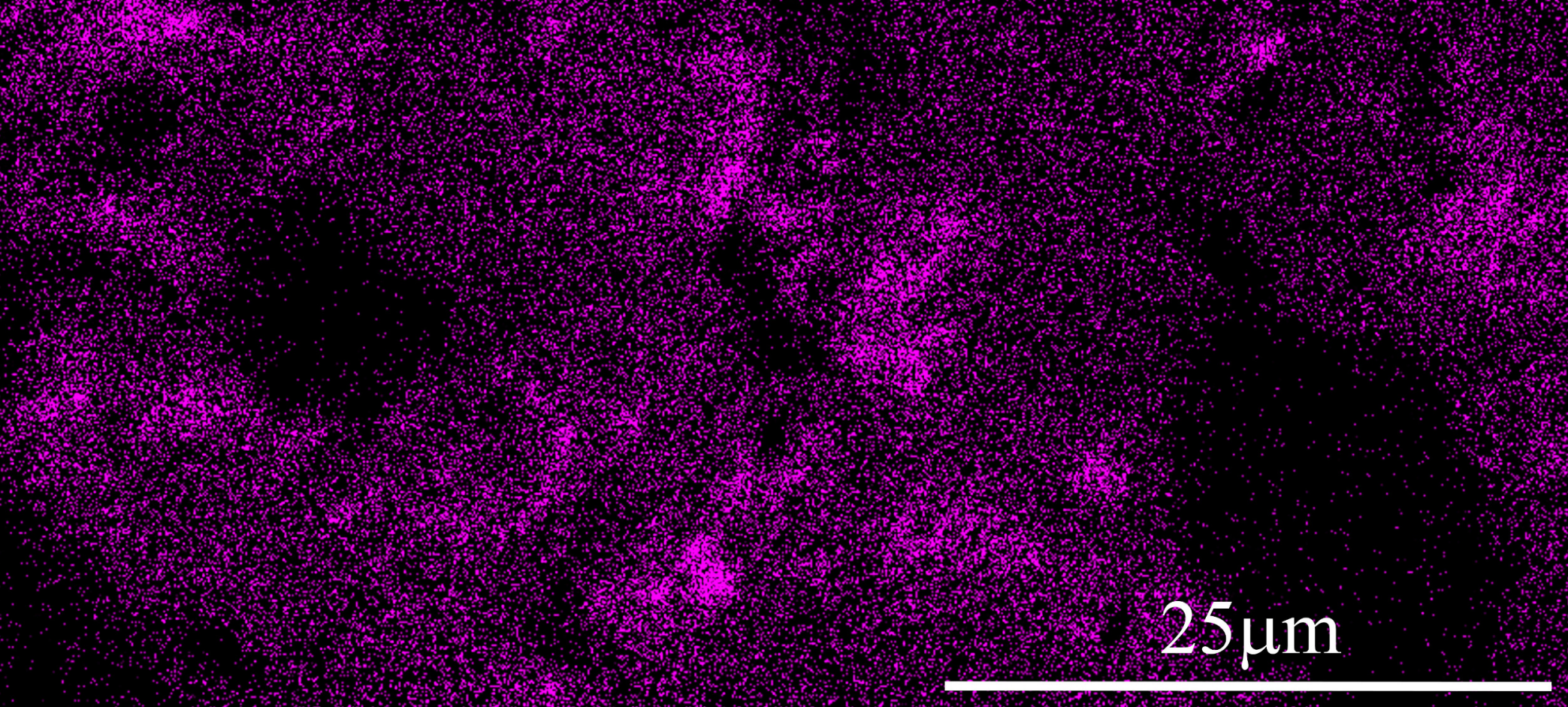

$25 \mu \mathrm{m}$ 


\section{d) Mo}

-

3.

3

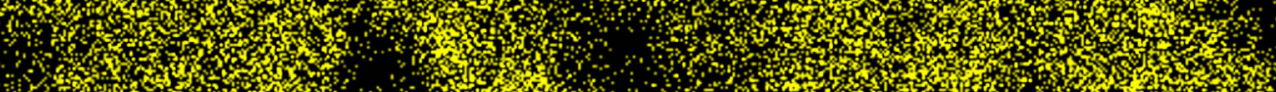

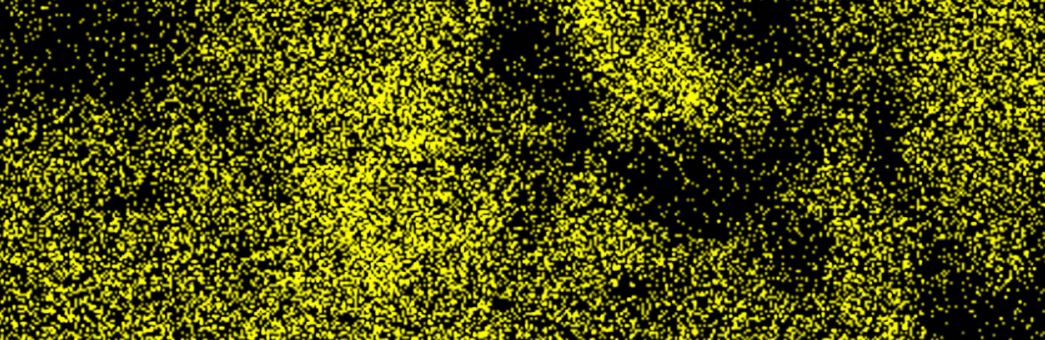

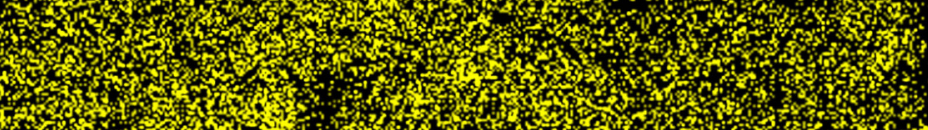

M

7.

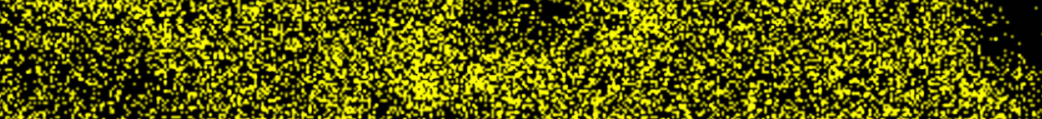

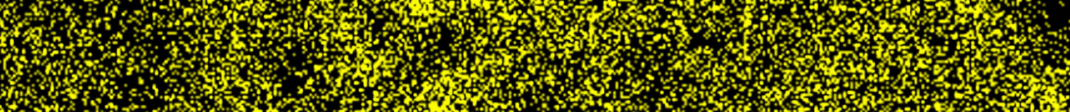




\section{e) Ni}

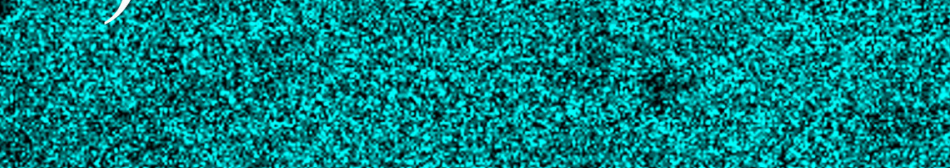

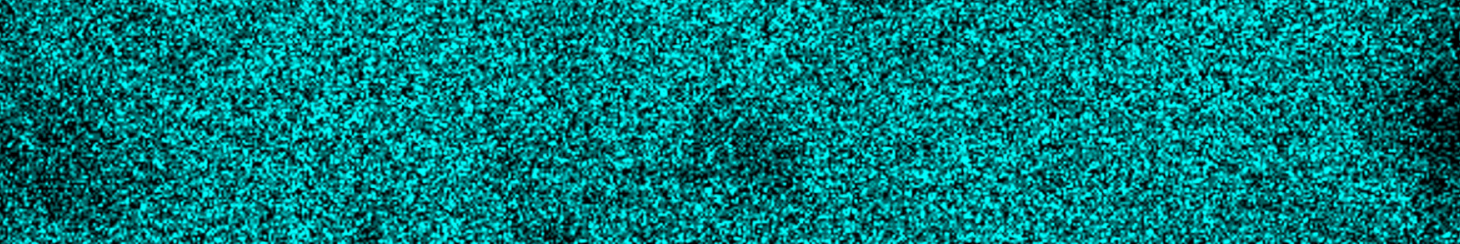

T. T.7.7.

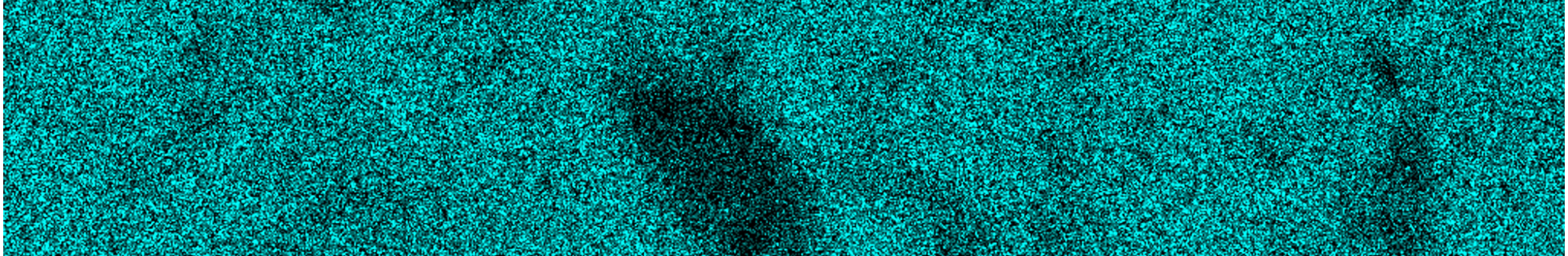
T.7. 1.7. -

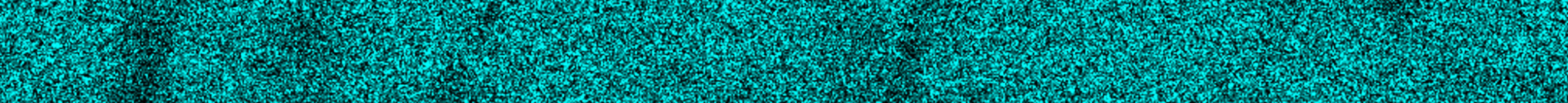
1.7.

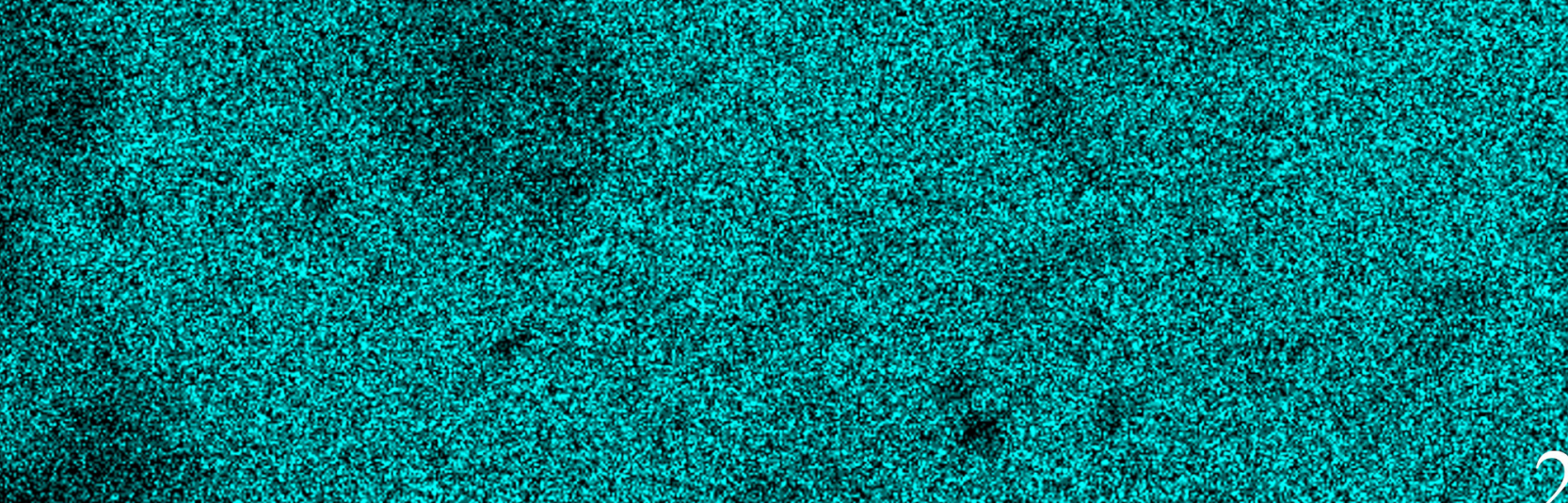

(1) (2. 
1) $\mathrm{Cr}$

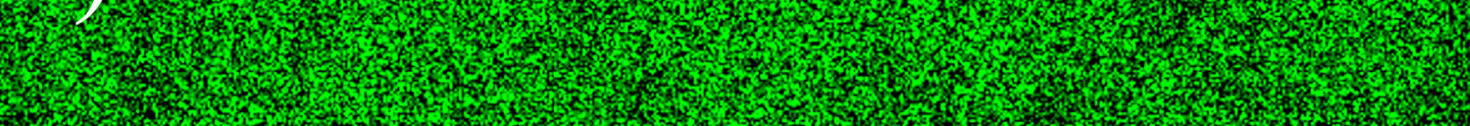

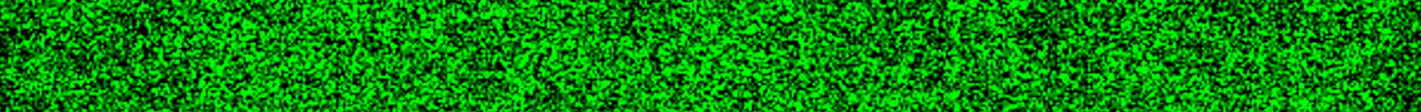

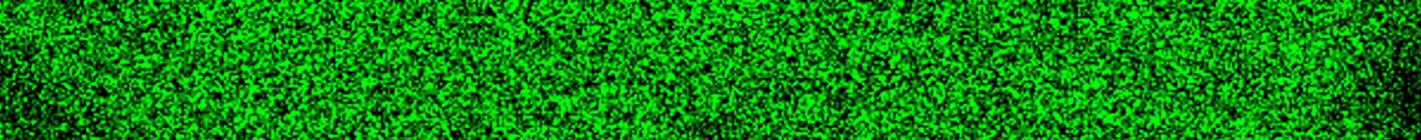

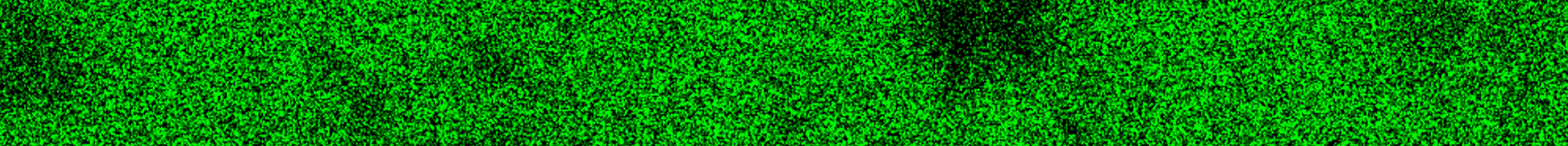

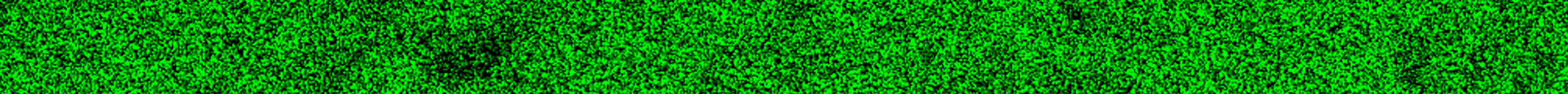

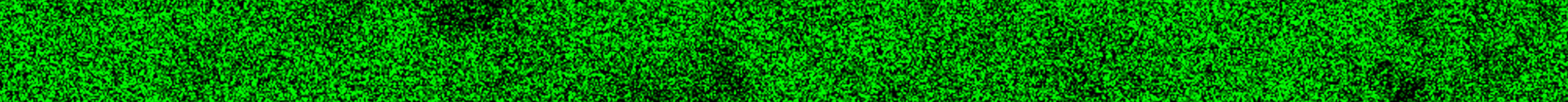

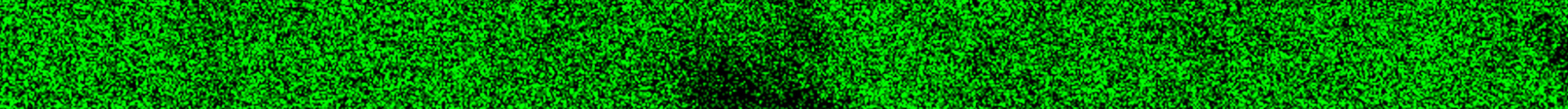

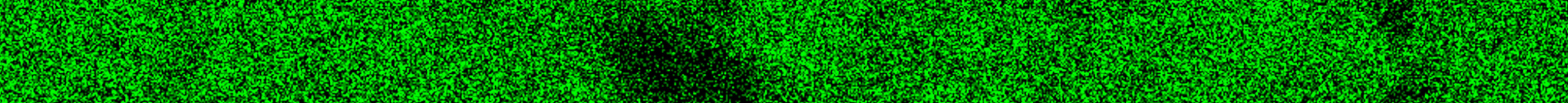
T.7.

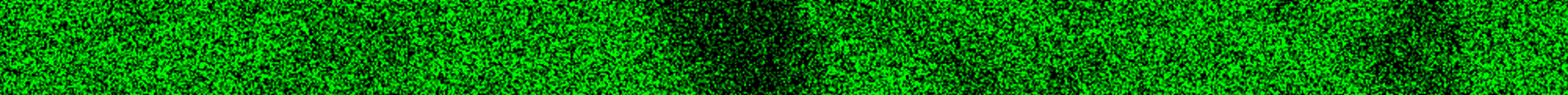

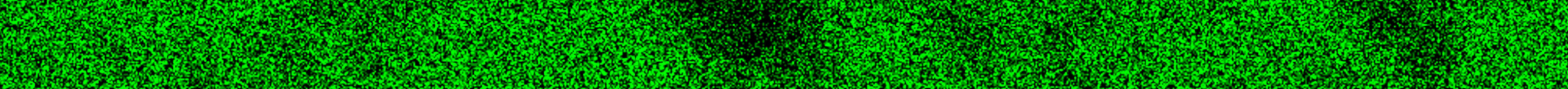

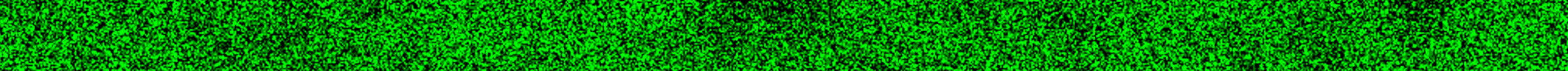
7. T.1.7.

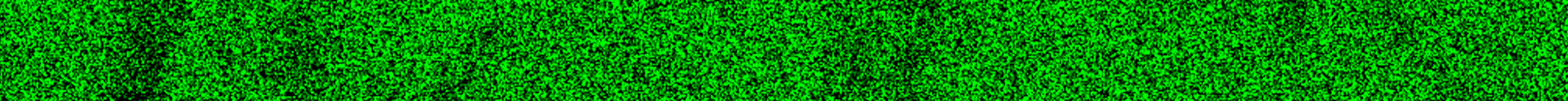

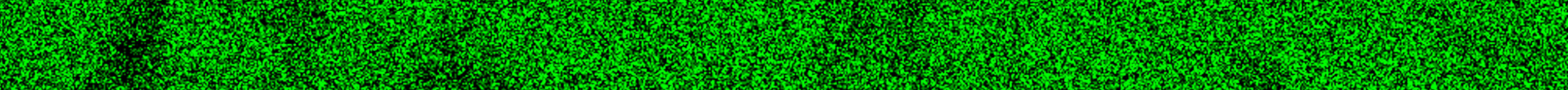
1.7.

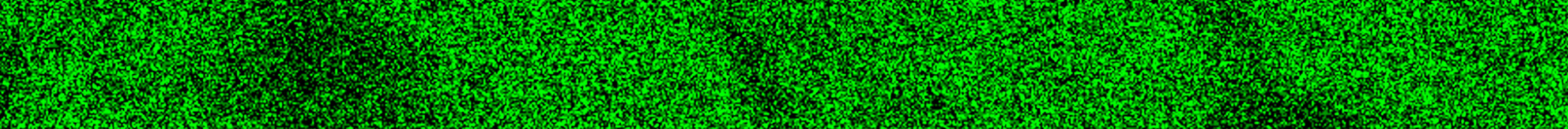

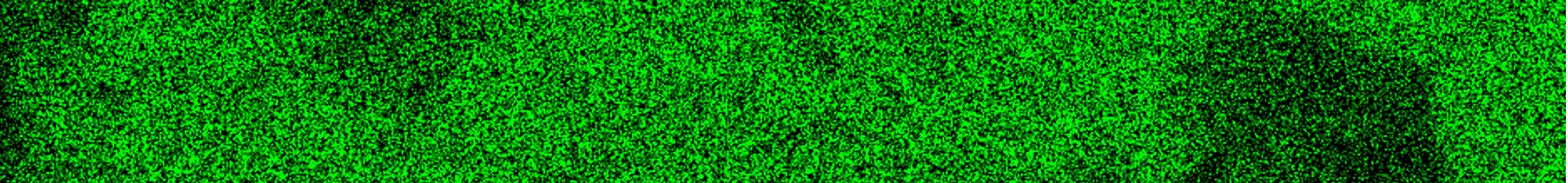

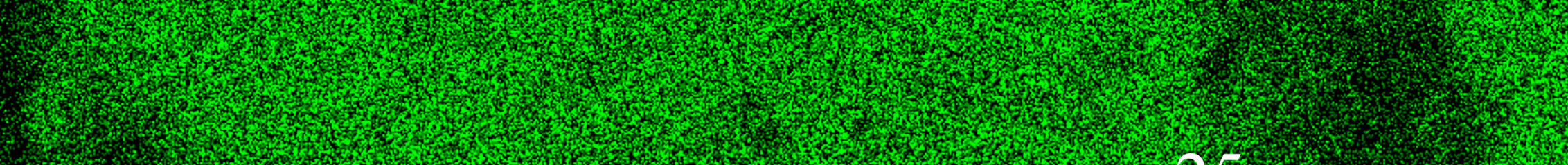

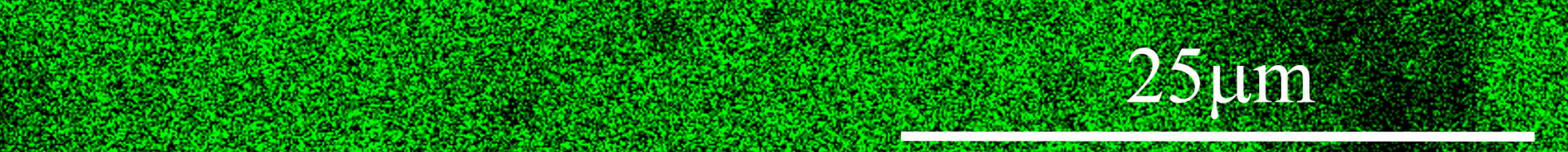




\section{Effect of Aging on Microhardness Behavior}

Wilks lambda $=, 01355, F(6,30)=37,954, p=, 00000$

Effective hypothesis decomposition

Vertical bars denote 0,95 confidence intervals

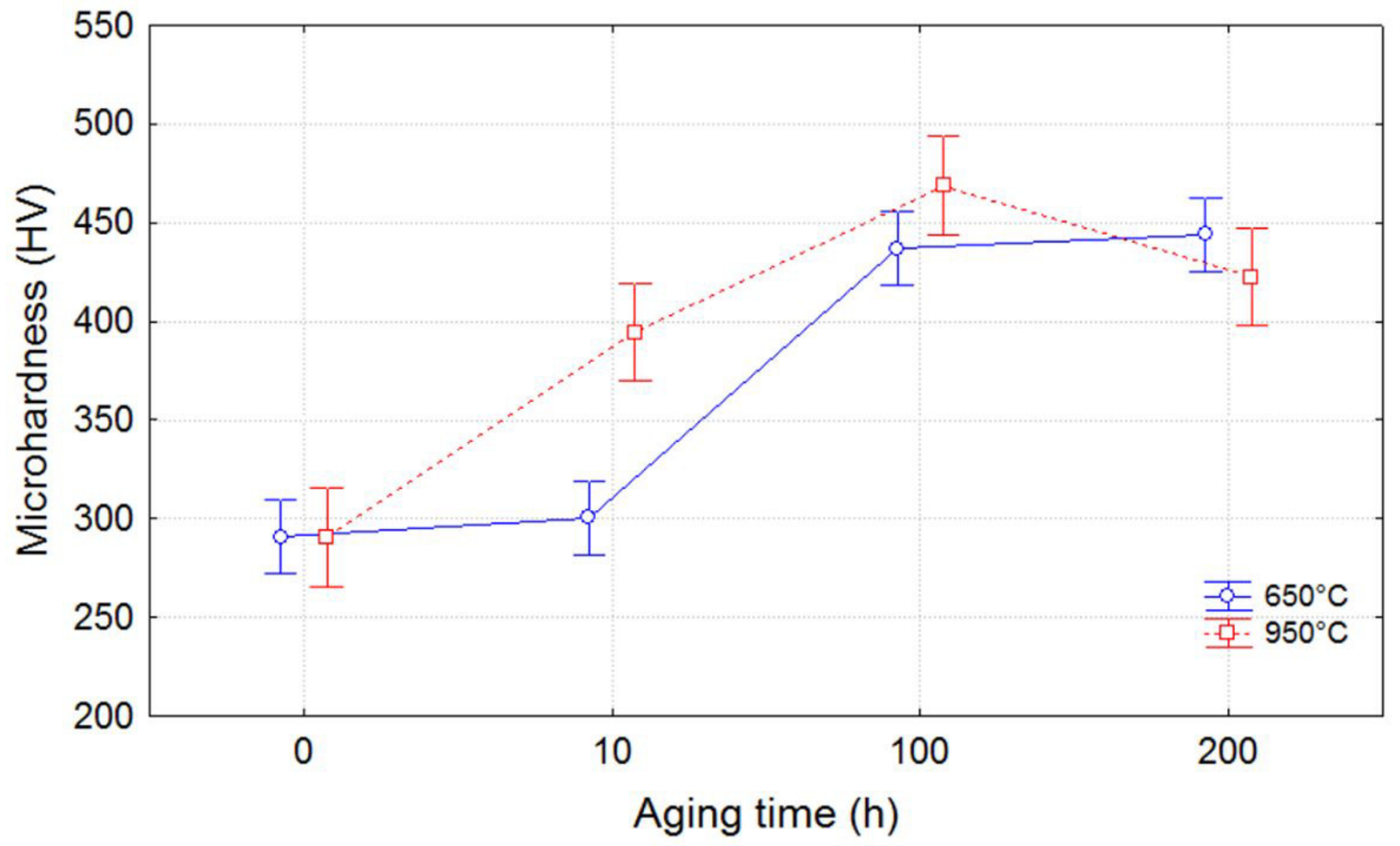


(a)

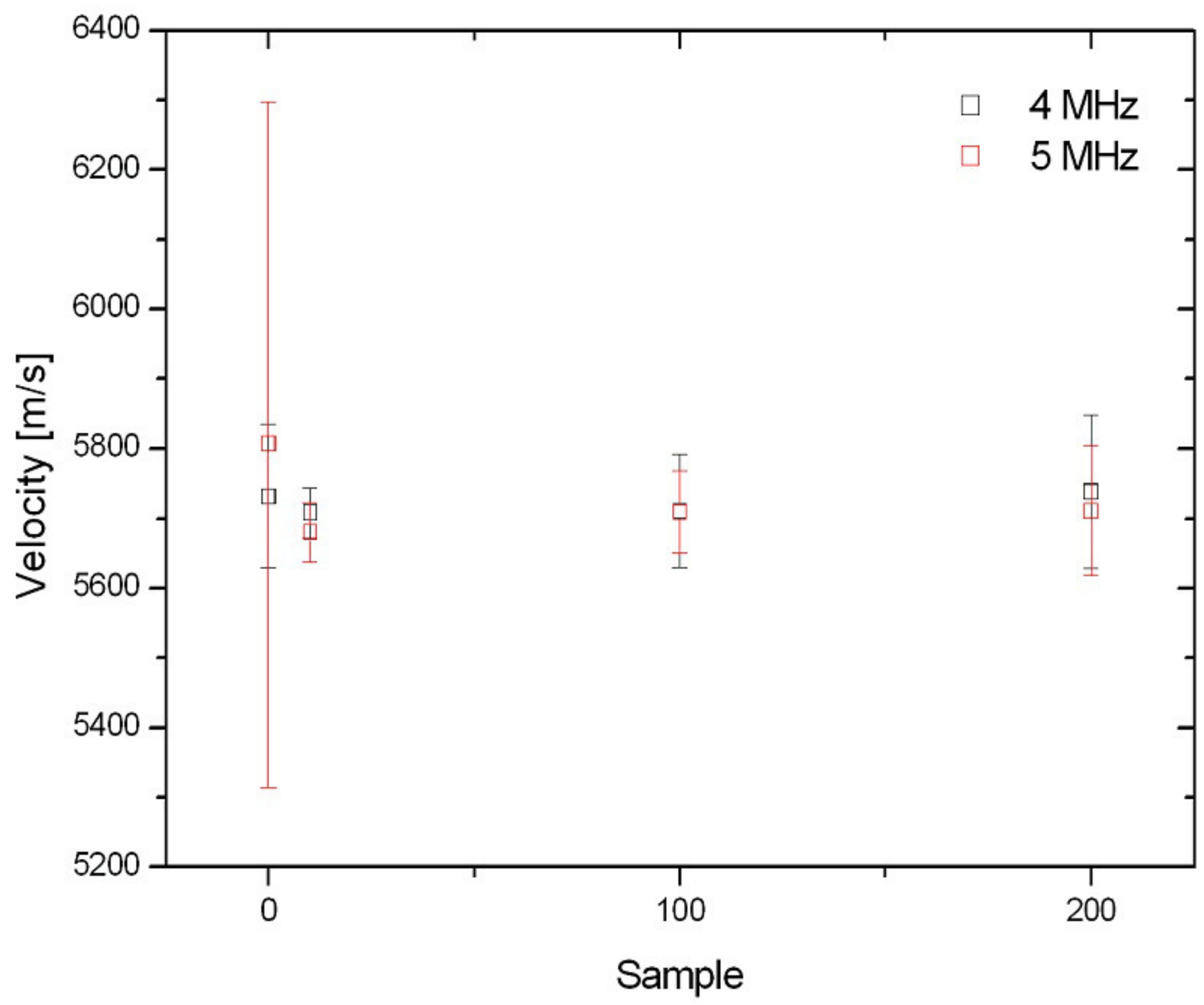


(b)

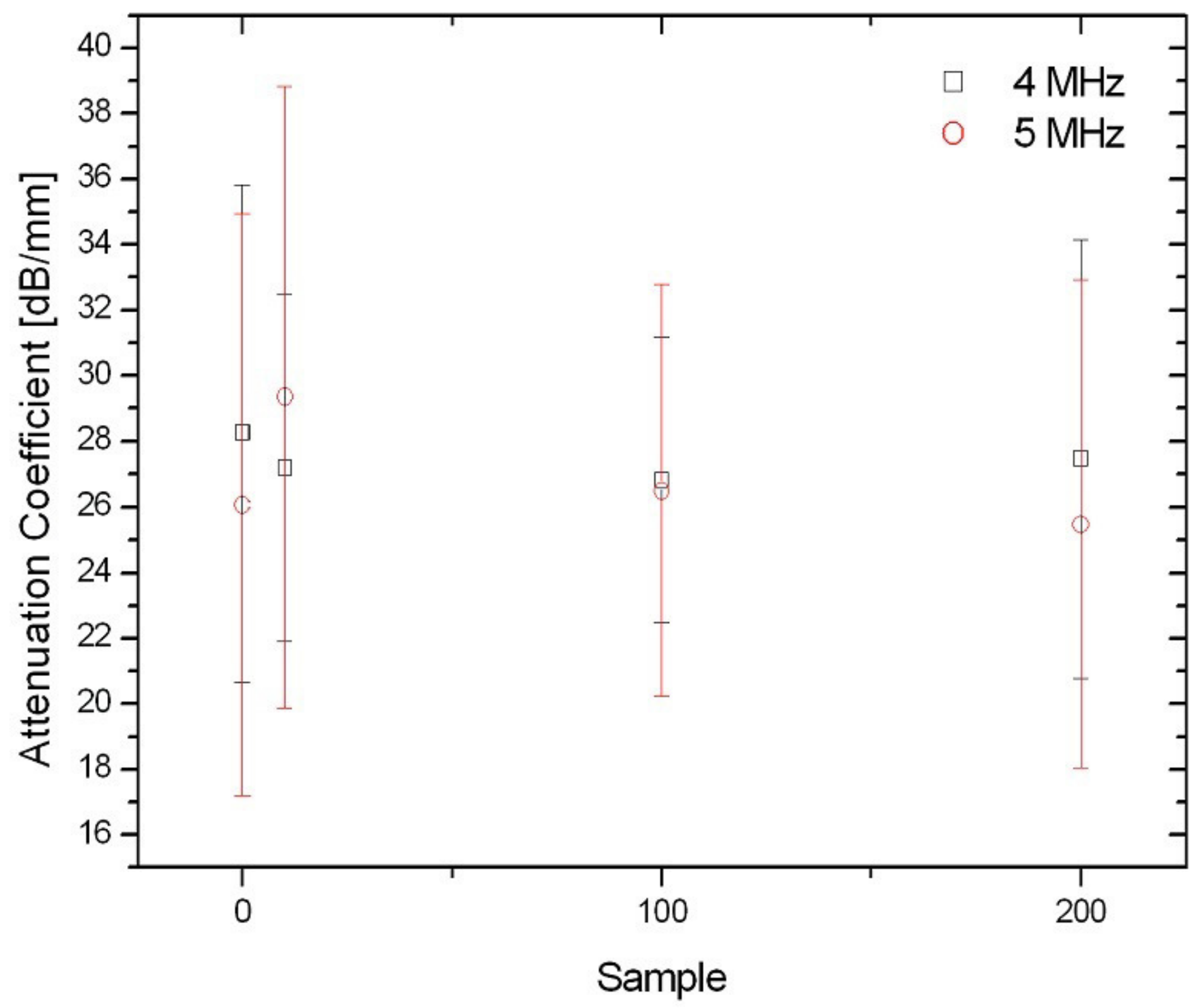


Table 1. Chemical composition in percent weight of the weld metal/coating and base metal.

\begin{tabular}{ccccccccc}
\hline \multirow{2}{*}{$\begin{array}{c}\text { AWS ERNiCrMo-3 } \\
\text { (INCONEL 625 alloy }\end{array}$} & $\mathrm{Ni}$ & $\mathrm{C}$ & $\mathrm{Cr}$ & $\mathrm{Mo}$ & $\mathrm{W}$ & $\mathrm{Fe}$ & $\mathrm{Al}$ & $\mathrm{Ti}$ \\
\cline { 2 - 9 } - Weld metal) & $\mathrm{Nb}$ & 0.011 & 22.2 & 9.13 & - & 0.19 & 0.09 & 0.23 \\
\cline { 2 - 9 } & $\mathrm{Nb}$ & $\mathrm{Mn}$ & $\mathrm{Si}$ & $\mathrm{Cu}$ & $\mathrm{Co}$ & $\mathrm{V}$ & $\mathrm{P}$ & $\mathrm{S}$ \\
\hline ASTM A36 steel & $\mathrm{Ni}$ & $\mathrm{C}$ & $\mathrm{Cr}$ & $\mathrm{Mo}$ & $\mathrm{Fe}$ & $\mathrm{Al}$ & $\mathrm{Mn}$ & $\mathrm{Si}$ \\
\cline { 2 - 9 } (Base metal) & 0.01 & 0.15 & 0.02 & 0.01 & Balance & 0.02 & 0.95 & 0.2 \\
\hline
\end{tabular}

Table 2. Results of the chemical composition analysis performed by SEM/EDS on: (a) Laves phase and (b) Complex NbTi carbide/nitride.

\begin{tabular}{llll}
\hline \multicolumn{2}{c}{ a) } & Laves phase & \multicolumn{2}{c}{ b) } & NbTi carbide/nitride \\
\hline Element & wt. $\%$ & Element & wt. \% \\
& & & \\
\hline NbK & 18.29 & NK & 6.37 \\
\hline MoL & 21.18 & NbL & 25.23 \\
\hline CrK & 17.27 & MoL & 8.39 \\
\hline NiK & 43.26 & TiK & 15.60 \\
\hline- & - & CrK & 13.88 \\
\hline- & - & NiK & 30.52 \\
\hline
\end{tabular}

Table 3. Mean weld metal chemical composition in $\%$ wt.

\begin{tabular}{cccccccc}
\hline $\mathrm{C}$ & $\mathrm{Cr}$ & $\mathrm{Mo}$ & $\mathrm{Nb}$ & $\mathrm{Fe}$ & $\mathrm{Ti}$ & $\mathrm{Si}$ & $\mathrm{Ni}$ \\
\hline 0.1 & 21.51 & 7.455 & 3.285 & 2.31 & 0.665 & 0.145 & Balance \\
\hline
\end{tabular}


Table 4. Impact strength of as-welded and aged condition obtained by the Charpy-V impact test.

\begin{tabular}{ll}
\hline Sample & Impact strength $(\mathrm{J})$ \\
\hline As-welded (0h) & $141.3 \pm 14.3$ \\
\hline $650^{\circ} \mathrm{C} / 10 \mathrm{~h}$ & $150.9 \pm 6.8$ \\
\hline $650^{\circ} \mathrm{C} / 100 \mathrm{~h}$ & $105.3 \pm 3.3$ \\
\hline $650^{\circ} \mathrm{C} / 200 \mathrm{~h}$ & $98.4 \pm 1.2$ \\
\hline $950^{\circ} \mathrm{C} / 10 \mathrm{~h}$ & $120.0 \pm 3.7$ \\
\hline $950^{\circ} \mathrm{C} / 100 \mathrm{~h}$ & $136.4 \pm 6.9$ \\
\hline $950^{\circ} \mathrm{C} / 200 \mathrm{~h}$ & $150.4 \pm 5.5$ \\
\hline
\end{tabular}

